\title{
DIGITALCOMMONS
}

@WAYNESTATE —

Wayne State University

Wayne State University Dissertations

$1-1-2012$

\section{Motion(less) pictures: the cinema of stasis}

Justin Remeselnik

Wayne State University,

Follow this and additional works at: http://digitalcommons.wayne.edu/oa_dissertations

Part of the Esthetics Commons, Film and Media Studies Commons, and the Theory and Criticism Commons

\section{Recommended Citation}

Remeselnik, Justin, "Motion(less) pictures: the cinema of stasis" (2012). Wayne State University Dissertations. Paper 472.

This Open Access Dissertation is brought to you for free and open access by DigitalCommons@WayneState. It has been accepted for inclusion in Wayne State University Dissertations by an authorized administrator of DigitalCommons@WayneState. 


\title{
MOTION(LESS) PICTURES: THE CINEMA OF STASIS
}

\author{
by \\ JUSTIN REMESELNIK \\ DISSERTATION \\ Submitted to the Graduate School \\ of Wayne State University, \\ Detroit, Michigan \\ in partial fulfillment of the requirements \\ for the degree of \\ DOCTOR OF PHILOSOPHY
}

2012

MAJOR: ENGLISH

Approved by

Advisor Date


(C) COPYRIGHT BY

\section{JUSTIN REMESELNIK}

2012

All Rights Reserved 


\section{ACKNOWLEDGEMENTS}

I would like to begin by thanking Kirsten Thompson, who has always gone far beyond the call of duty to help me improve as a writer and researcher (even providing me with detailed feedback on papers I wrote outside of her classes). It was Kirsten who first proposed that I write a dissertation about static films after reading an early draft of a seminar paper I wrote on the subject. Her encouraging remarks persuaded me that I had stumbled on a project worth pursuing. This dissertation simply would not exist without her tireless guidance and support.

I would also like to thank the other members of my committee. I first took a class with Steve Shaviro when I was in the Masters program at Wayne State, and it was this course-with its challenging theoretical texts and bizarre yet utterly compelling films-that inspired me to pursue a PhD in Film and Media Studies. (This is also where I received my first exposure to the films of Andy Warhol.) I am also incredibly thankful to have Scott Richmond on my committee, not only because he has a near-encyclopedic knowledge of avant-garde cinema, but also because of the remarkable amount of time and energy that he has been willing to devote to helping me become a better thinker. Scott has always believed in me and my project, and for that, I cannot thank him enough. Finally, reading Roy Grundmann's book Andy Warhol's Blow Job was something of an epiphany for me, as it helped me to realize how much mileage a smart scholar could get out of a single simple static film. I am honored to have such a perceptive thinker and researcher on my committee.

I would like to thank my father for exposing me to a broad variety of art, music, literature, and cinema from a young age (and for arguing with me for hours on end about deep philosophical topics). I would also like to thank my mother for forcing me to read a book every week as soon as I was able to, and for always offering her unconditional love and 
encouragement. I am forever indebted to Nana and Grandpa, who have supported me throughout the past four years in more ways than I can count. Finally, my deepest gratitude goes to my wife, Katrina, who has been a daily source of love, kindness, encouragement, and wisdom. Words cannot express how fortunate I am to have her in my life. 


\section{TABLE OF CONTENTS}

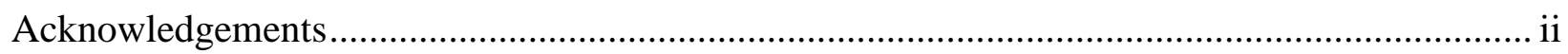

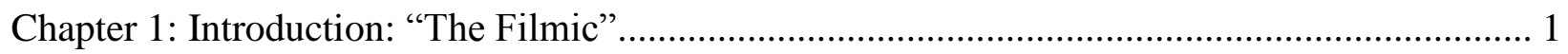

Chapter 2: "Serious Immobilities: Andy Warhol, Erik Satie, and the Furniture Film”............... 33

Chapter 3: "Stasis in Fluxus: Disappearing Music for Face and Protracted Cinema"............... 64

Chapter 4: "Structuring Time: Michael Snow’s So Is This and the Textual Film”.................... 89

Chapter 5: “Colored Blindness: Derek Jarman’s Blue and the Monochrome Film”................. 119

Conclusion: "Static Cinema in the $21^{\text {st }}$ Century" ............................................................... 148

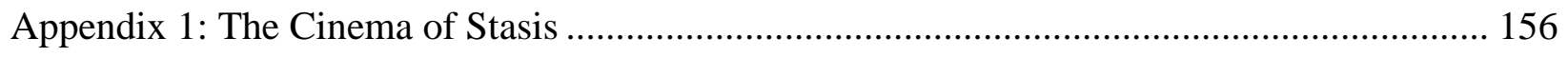

Appendix 2: Films Relevant to Understanding the Cinema of Stasis................................... 162

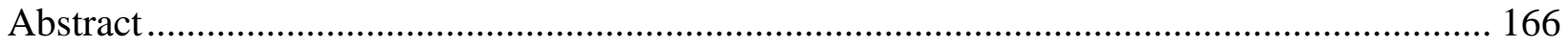

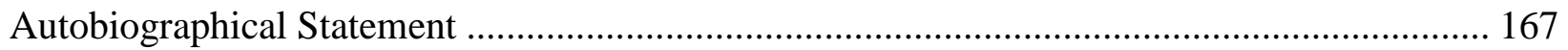




\section{CHAPTER 1: INTRODUCTION}

\section{THE FILMIC}

"[T]he more we consume moving images, the more the single still image rises above the rest, substituting itself for our reality." - Gisèle Freund ${ }^{1}$

"There is nothing in the structural logic of the cinema filmstrip that precludes sequestering any single image. A still photograph is simply an isolated frame taken out of the infinite cinema." Hollis Frampton ${ }^{2}$

Larry Gottheim's film Fog Line (1970) begins with a still shot of a landscape covered in dense fog. All that can be seen through the fog are the outlines of a few trees intersected by four high-tension wires. The setting is subtly beautiful, and the complete lack of sound creates a space for meditation. Minutes pass. Apart from some slight shaking, the camera does not move, nor do any elements within the mise-en-scène. The trees and telephone wires become easier to make out as the fog lifts, although the fog's retreat is so gradual, its movement is not perceived by the viewer. After 11 minutes of the same motionless shot, the film abruptly ends (see Figure 1).

During my first viewing, I found Fog Line simultaneously boring and absorbing. I was bored because, on a superficial level, nothing happened. Yet I was fascinated because I had never encountered a film like this before. It was so still, so uneventful, I felt like I was staring at a photograph or a painting for several minutes rather than watching a movie.

\footnotetext{
${ }^{1}$ Quoted in Raymond Bellour, "Concerning "The Photographic"” (trans. Chris Darke), in Still Moving: Between Cinema and Photography, eds. Karen Beckman and Jean Ma (Durham: Duke University Press, 2008 ), 270.

${ }^{2}$ Hollis Frampton, On the Camera Arts and Consecutive Matters: The Writings of Hollis Frampton, ed. Bruce Jenkins (Cambridge: MIT Press, 2009), 134.
} 


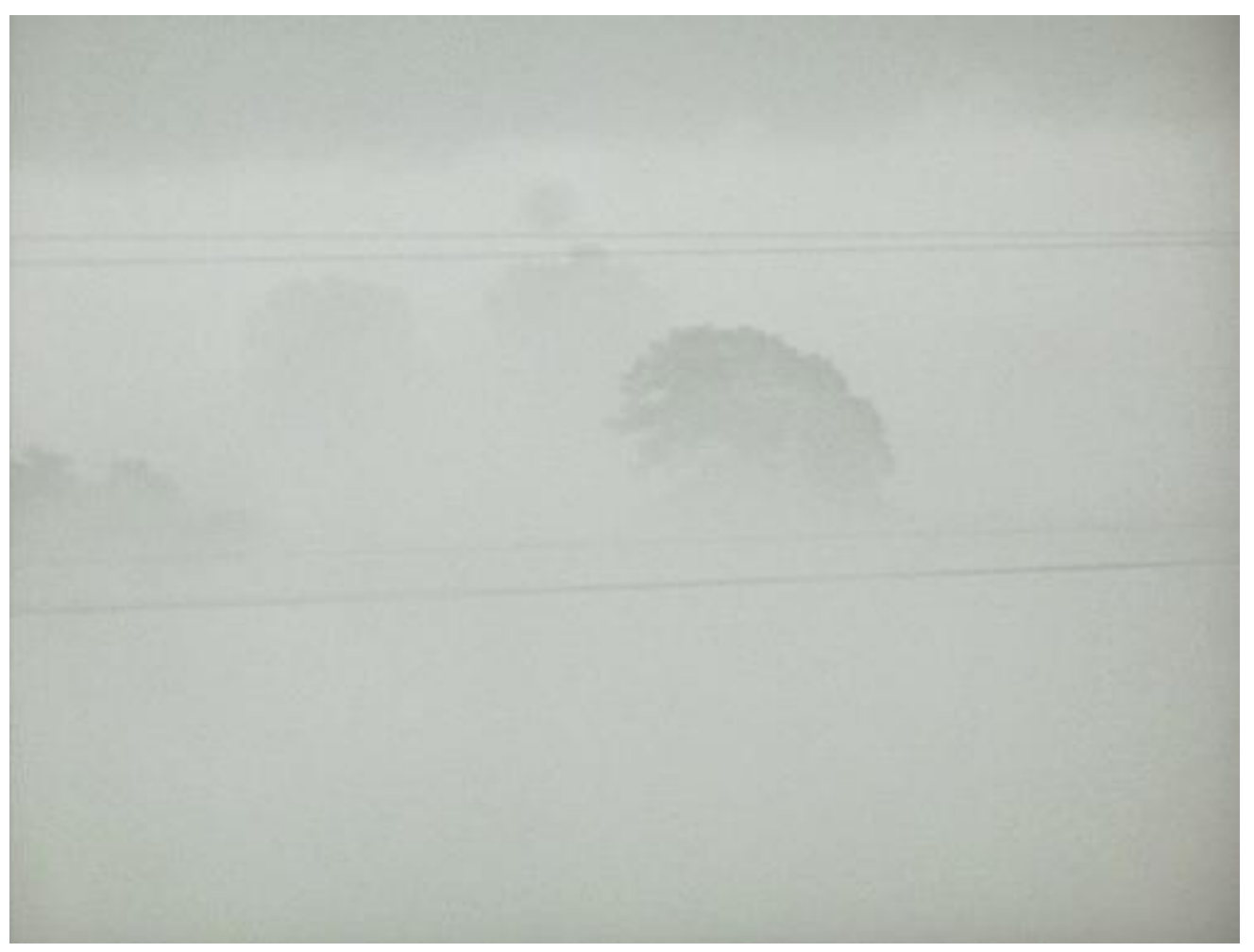

Figure 1: Larry Gottheim, Fog Line (1970)

When I watched Fog Line a second time, I realized that there was actually more movement than I had initially registered. At one point, several minutes into the film, barely visible grainy shadows (in actuality, horses) slowly wander from one side of the landscape to the other. (Gottheim had intentionally selected this location for his film because of the horses that regularly moved through it.) At another point, a small, almost indiscernible bird quickly flies above the wires. Like most viewers, I had missed these developments in my first careful viewing; it was as if the prolonged inertia had tricked my mind into thinking I was looking at a still. I was unable to easily detect the minimal motion within the shot since, after the first few minutes of stasis, I was no longer expecting movement of any kind. Scott MacDonald describes the spectatorial experience engendered by Fog Line cogently: "For a few moments at the beginning of the film, viewers cannot be sure that the image they're looking at is a motion 
picture. Indeed, it is only once the fog has thinned enough for an identification of the image to be possible that we can recognize that something other than the movie projector - the fog itself - is moving."3

While Fog Line is a remarkable and unique cinematic experience, it is not without predecessors, nor is it without successors. In fact, it places itself in a rich and variegated tradition which I will call the cinema of stasis. Static films ${ }^{4}$ offer radical challenges to conventional conceptions of cinema, since they are ostensibly motion pictures without motion. In most films, an impression of movement is provided either by the motion of the camera or the motion of elements within the mise-en-scène-usually both. In contrast, static films generally feature no camera movement, as well as little or no movement within the frame. Instead, these films foreground stasis and consequently blur the lines between traditional visual art and motion pictures. $^{5}$

It should be noted that the term movement is polysemous and is sometimes used in a broader sense than what I have in mind here. For example, Gilles Deleuze suggests that movement can be achieved in film, not only through the motion of the camera or elements in the frame, but also through montage, which he claims "allows the achievement of a pure mobility extracted from the movements of characters." ${ }^{\circ}$ As the Oxford English Dictionary indicates, movement can refer to "a change in place or position," and by this definition any cinematic montage (even a montage of still shots) would constitute movement. However, movement can

\footnotetext{
${ }^{3}$ Scott MacDonald, The Garden in the Machine: A Field Guide to Independent Films about Place (Berkeley: University of California Press, 2001), 9.

${ }^{4}$ My use of the term static film should not be confused with Dadaist Raoul Hausmann's, who uses the appellation to refer to photomontage. See Raoul Hausmann, "Photomontage," in Photography in the Modern Era: European Documents and Critical Writings, 1913-1940, ed. Christopher Phillips (New York: Metropolitan Museum of Art and Aperture, 1989), 179.

${ }^{5}$ For lack of a better term, I will use the term traditional visual art to refer to sketches, paintings, photographs, sculptures, and other historically "static" visual arts.

${ }^{6}$ Gilles Deleuze, Cinema 1: The Movement-Image, trans. Hugh Tomlinson and Barbara Habberjam (Minneapolis: University of Minnesota Press, 1986), 25.
} 
also designate "the action or process of moving,", and it is this more specific definition that I have in mind. In other words, a film that engages in montage can still be considered a static film for my purposes, so long as the elements within the frame are static (as in, say, Chris Marker's La jetée [The Jetty] [1962]). For while the spectator's point of view is shifting "in place or position," no "action or process of moving" is directly observed; in cases like these, the movement itself takes place off-camera. ${ }^{8}$

While individual static films have been the subject of scholarly attention, the cinema of stasis as a modality has not yet been adequately theorized. I want to remedy this by analyzing several subsets of static cinema - the furniture film, the protracted film, the textual film, and the monochrome film - drawing attention to the diversity and multivalence of cinematic stasis. I also want to attempt to answer several questions that are intrinsically posed by static films: Why take a medium uniquely positioned to create the illusion of movement and instead use it to create a quasi-photographic stasis? What forms of spectatorship are appropriate in approaching these works? And finally, what are the implications of these experiments for the ontology of film?

Of course, stasis has always played an important role in cinema's ontology. Even in films that appear to offer constant movement, the ostensible motion is an illusion insofar as it is created by a series of still frames in quick succession. ${ }^{9}$ But beyond this, even the appearance of

7 OED Online. November 2010. Oxford University Press. http://www.oed.com/view/Entry/ 123031?redirectedFrom=movement.

${ }^{8}$ Of course, Deleuze uses the French term mouvement; however, a similar polysemy inheres in this word as well. I should briefly note that one could also conceptualize the constantly changing sound track of a film as a kind of auditory movement. While this dissertation will primarily explore stillness as a visual phenomenon, I will examine the relationship between visual and aural stasis in Chapter 3.

${ }^{9}$ In the days of early cinema, it was widely believed that this illusion was the result of persistence of vision, a phenomenon produced by afterimages that would briefly persist on the retina and thus provide a false sense of continuity. While many film scholars and lecturers continue to parrot this view, Joseph and Barbara Anderson (among others) have exposed the numerous holes in this etiology, claiming that soon "only the creationists among us will cling to the myth of persistence of vision as an actual explanation of how movies come to be." Instead, the Andersons present empirical research suggesting that the perception of cinematic movement can only be understood through the study of "short-range apparent motion." See Joseph Anderson and Barbara Anderson, "The Myth of Persistence of Vision Revisited," Journal of Film and Video 45, no. 1 (1993): 3-12. See also their essay "Motion 
stasis on the screen is one that would have been familiar to cinema's early spectators. As Tom Gunning has pointed out, in the Lumière brothers' early exhibitions, "the films were initially presented as frozen unmoving images, projections of still photographs." ${ }^{10}$ After a few moments of stasis, the projector would be put in motion and the "photograph" would become animated, much to the delight of the audience. For the Lumières, stasis served as a kind of counterpoint to the startling movement that would soon come. The prolonged dominance of the still created the expectation of a slide show before subverting this expectation and showcasing the new technology of the motion picture. But if some early audiences were tricked into expecting stasis, only to be surprised by movement, later audiences would come to expect movement from a film, only to be surprised by those rare exceptions to the rule: films that returned to the primordial stasis out of which motion pictures evolved.

The very existence of terms like movie, moving picture, and motion picture reveals just how central the impression of movement has been in conventional conceptions of cinema. ${ }^{11}$ Indeed, many film theorists have problematically made movement the sine qua non of cinema. For example, in his 1934 essay "Motion," Rudolf Arnheim claimed that "film is required by aesthetic law to use and interpret motion."12 This presupposition was prevalent among many early filmmakers, even within the avant-garde (from which the cinema of stasis would eventually arise)_-Germaine Dulac asserted, "Le cinéma est l'art du mouvement et de la lumière,"13 and

\footnotetext{
Perception in Motion Pictures," in The Cinematic Apparatus, ed. Teresa de Lauretis and Stephen Heath (London: Macmillan, 1980), 76-95.

${ }^{10}$ Tom Gunning, "An Aesthetic of Astonishment: Early Film and the (In)credulous Spectator," in Film Theory and Criticism, $6^{\text {th }}$ ed., eds. Leo Braudy and Marshall Cohen (New York: Oxford University Press, 2004), 866.

${ }^{11}$ This is not the case in all languages, however. As experimental filmmaker Takahiko Iimura has pointed out, in the Japanese word for film (eiga), "the emphasis is [...] on the state of reflection rather than motion." See Esperanza Collado, "Takahiko Iimura in Interview," Experimental Conversations 5 (2009-2010), http://www. experimentalconversations.com/articles/484/takahiko-iimura-in-interview/.

${ }_{12}^{12}$ Rudolf Arnheim, "Motion," in Film as Art (Berkeley: University of California Press, 1957), 181.

${ }^{13}$ Quoted in Tom Gunning, "Moving Away from the Index: Cinema and the Impression of Reality," differences: A Journal of Feminist Cultural Studies 18, no. 1 (2007): 38.
} 
Slavko Vorkapich called movement "the fundamental principle of the cinema art: [cinema's] language must be, first of all, a language of motions. ${ }^{, 14}$ However, other avant-gardists, like Douglass Crockwell, were more cautious in their theorizations, problematizing the assumed centrality of movement to cinematic practice. For Crockwell, "Visually the motion picture is sequential art...Motion is but one of the incidental byproducts." ${ }^{15}$ Along similar lines, Peter Kubelka has declared, "Cinema is not movement. Cinema is a projection of stills-which means images which do not move - in a very quick rhythm."16 These theorizations serve as useful reminders that even in traditional motion pictures, stasis is always deeply embedded in the ontology of film. As Laura Mulvey points out, “[C]inema's stillness [is] a projected film's bestkept secret," albeit one that can now be exposed during home viewing through the use of the pause button. ${ }^{17}$

Such wildly divergent theorizations suggest an aporia at the heart of cinema's ontology. On the one hand, many film theorists have insisted that the motion perceived in cinema is illusory, an optical trick or, in the memorable formulation of Surrealist Jean Goudal, "a conscious hallucination." For Goudal, "The persistence of images on the retina, which is the physiological basis of cinema, claims to present movement to us with the actual continuity of the real; but in fact we know very well that it's an illusion, a sensory device which does not

\footnotetext{
${ }^{14}$ Quoted in William C. Wees, Light Moving in Time: Studies in the Visual Aesthetics of Avant-Garde Film (Berkeley: University of California Press, 1992), 12.

${ }^{15}$ Quoted in Tom Gunning, "Machines That Give Birth to Images: Douglass Crockwell," in Lovers of Cinema: The First American Film Avant-Garde, 1919-1945, ed. Jan-Christopher Horak (Wisconsin: University of Wisconsin Press, 1998), 343. Crockwell specifically had the Mutoscope in mind, which permitted the viewer to control the movement (or stasis) of the stills. However, his unorthodox definition of cinema remains useful, particularly since modern technologies (DVDs, computers, etc.) again give the viewer a certain amount of control over cinematic movement (with the ability to pause, as well as rewind and fast-forward at varying speeds).

${ }^{16}$ Peter Kubelka, interview by Jonas Mekas, in Structural Film Anthology, ed. Peter Gidal (London: British Film Institute, 1978), 103. (The interview was originally published in the Spring 1967 issue of Film Culture.)

${ }^{17}$ Laura Mulvey, Death $24 x$ a Second: Stillness and the Moving Image (London: Reaktion Books, 2006), 22.
} 
completely fool us."18 On the other hand, Christian Metz asserts, "In the cinema the impression of reality is also the reality of the impression, the real presence of motion." ${ }^{\prime 19}$ Or in the words of Gunning, "I think there is little question that phenomenologically we see movement on the screen, not a 'portrayal' of movement.",20

Ultimately, the apparent disagreement may be primarily a semantic one. Asking whether cinematic movement is "real" is a bit like asking whether dreams are real. The answer is, yes and no. On the one hand, the experience itself is certainly real, and it can have tangible physiological effects on the dreamer (or spectator), including fear, excitement, arousal, etc. On the other hand, a chair in a dream is ontologically of a different order than a chair in real life, just as the movement in the Lumière brothers' The Arrival of a Train at La Ciotat Station (L'arrivée d'un train en gare de La Ciotat) (1895) is ontologically distinct from the arrival of an actual train. (Even the earliest cinematic spectators were aware of this distinction, urban legends notwithstanding.) Cinematic movement, unlike movement in the "real" world, is divisible into discrete units, traditionally 24 static frames per second. (The fact that actual motion is indivisible has been noted by many philosophers, most notably Henri Bergson in Creative Evolution. ${ }^{21}$ ) But this does not make the phenomenal perception of movement in motion pictures any less real. Philosopher J.L. Austin's interrogation of the word real in Sense and Sensibilia is pertinent here: "When it isn't a real duck but a hallucination, it may still be a real hallucination — as opposed, for

\footnotetext{
18 Jean Goudal, "Surrealism and Cinema," in The Shadow and Its Shadow: Surrealist Writings on the Cinema, $3{ }^{\text {rd }}$ ed., trans. and ed. Paul Hammond (San Francisco: City Light Books, 2000), 88-89.

${ }^{19}$ Christian Metz, Film Language: A Semiotics of the Cinema, trans. Michael Taylor (Chicago: University of Chicago Press, 1974), 9.

${ }^{20}$ Gunning, "Moving Away from the Index," 44.

${ }^{21}$ Henri Bergson, Creative Evolution, trans. Arthur Mitchell (Breinigsville, PA: Nabu Press, 2010).
} 
instance, to a passing quirk of a vivid imagination." ${ }^{22}$ So if the perception of a duck moving in a film is (as Goudal would have it) hallucinatory, the hallucination itself remains real. ${ }^{23}$

But whether we conceptualize cinematic movement as real or illusory, the question remains: How do we theorize films that forgo even the impression of movement, films in which stasis predominates? Can a motion picture exist without motion? In his essay "Fire and Ice," Peter Wollen convincingly argues that "movement is not a necessary feature of film" (he references Chris Marker's La jetée, a work made up almost entirely of photographic stills, to validate this claim). ${ }^{24}$ Tom Gunning also discusses the possibility of static films: "I think we can certainly conceive of films that exclude motion, made entirely of still images. Interestingly, many films that use still images seem to do so to comment on movement. Clearly, the dialectical relation between stillness and movement provides one of the richest uses of motion in film. But I think it would be an essentialist mistake to assume a film could not avoid cinematic motion, even if the examples of such are very rare and possibly debatable." ${ }^{25}$ (Unfortunately, Gunning does not elaborate on what examples he has in mind.) The "dialectical relation between stillness and movement" has certainly been a critical element in cinematic praxis, stretching at least as far back as Edweard Muybridge's invention of the zoopraxiscope in 1879, and the significance of this dialectic has been theorized perceptively, not only by Gunning himself, but by other film scholars as well. For example, Laura Mulvey has explored the pivotal role of stillness in Roberto Rossellini's Journey to Italy (Viaggio in Italia) (1953) and Alfred Hitchcock's Psycho (1960), ${ }^{26}$ while Raymond Bellour has analyzed the use of the freeze frame in films like Dziga Vertov's

\footnotetext{
${ }^{22}$ J.L. Austin, Sense and Sensibilia (London: Oxford University Press, 1962), 69.

${ }^{23}$ Deleuze makes much the same point in his first Cinema book through a series of rhetorical questions: "[I]s not the reproduction of the illusion in a certain sense also its correction? Can we conclude that the result is artificial because the means are artificial?" See Deleuze, Cinema 1, 2. For a more extensive analysis of the "reality" of cinematic movement, see Robert Sinnerbrink, New Philosophies of Film: Thinking Images (London: Continuum, 2011), 28-44.

${ }^{24}$ Peter Wollen, "Fire and Ice," in The Cinematic, 112.

${ }^{25}$ Gunning, "Moving Away from the Index," 50.

${ }^{26}$ Mulvey, 85-122.
} 
Man with a Movie Camera (1929) and François Truffaut's The 400 Blows (Les quatre cents coups) (1959). ${ }^{27}$ While I find these analyses useful, such scholarship generally focuses on momentary intrusions of stasis in films that are teeming with movement. However, I am more interested in interrogating films in which there is little to no movement, films in which stasisnot motion - is the default setting.

Paul Schrader is one of the only writers who has directly acknowledged the existence of the cinema of stasis (what he calls "stasis films"). In his well known 1972 book, Transcendental Style in Film, Schrader discusses works like Michael Snow's Wavelength (1967), Bruce Baillie's Still Life (1966), and Stan Brakhage's Song 27, My Mountain (1968), films which feature only minimal movement. Schrader also gives attention to the early films of Andy Warhol, such as Sleep (1963), Eat (1963), and Empire (1964). (I would classify all of the above as part of the cinema of stasis.) While I am thankful that Schrader draws attention to this modality, his analysis of static films is necessarily cursory, since his overriding concern is with "transcendental" films, works which progress from a state of movement to a state of stasis in order to evoke a sense of the spiritual (e.g. the films of Yasujirō Ozu and Robert Bresson). As Schrader himself correctly notes, "stasis films" are not merely "an extension of transcendental style," but "a different breed of film altogether.",28

A more thorough theorization of stasis in cinema has been provided by the philosopher Noël Carroll. In his critique of Gregory Currie's Image and Mind: Film, Philosophy and Cognitive Science, Carroll argues that films can exist without offering the impression of

\footnotetext{
${ }^{27}$ Bellour, "Concerning 'The Photographic,"” 253-276.

${ }^{28}$ Paul Schrader, Transcendental Style in Film: Ozu, Bresson, Dreyer (Berkeley: University of California Press, 1972), 168. In contrast to the films Schrader focuses on (which shift from movement to stasis), Elena del Rio explores how the films of Rainer Werner Fassbinder often feature tableaux vivant which suddenly erupt into violent mobility. See Elena del Rio, Deleuze and the Cinemas of Performance: Powers of Affection (Edinburgh: Edinburgh University Press, 2008), 67-69.
} 
movement. He provides several useful examples of films that withhold the illusion of movement, including Nagisa Ôshima’s Band of Ninja (1967), Hollis Frampton's Poetic Justice (1972), and Michael Snow's One Second in Montreal (1969). For Carroll, "These are all films in the sense that they were constructed and disseminated by means of standard film apparatuses. They command a significant place in film history where the question of 'What is film?' is part of an ongoing conversation internal to the filmworld — one addressed by filmmakers and theorists alike." ${ }^{29}$ Carroll continues by offering a distinction between static films and works in other media that might involve a succession of stills (e.g. slide shows): "[Static] films use stasis as a stylistic choice. It is the fact that they are films that makes their stillness a pertinent, if not the pertinent, feature of the works in question. Had these films been slides, one would not remark upon their stillness. Movement is not a stylistic option with slides. But since these works are films, one is prompted to ask why there is no movement in them. What is the point? Any interpretation of these works has to offer an explanation of why the filmmakers under consideration have eschewed the possibility of movement." 30 To illustrate this point, consider Ôshima's Band of Ninja, a work composed entirely of static comic-book-style sketches in black and white (paradoxically making it a kind of static animated film). Until Band of Ninja is over, it is conceivable that one of the sketched ninjas will become animated and begin to run from one end of the screen to the other. But it would be absurd to wonder if a drawing of Superman in an actual comic book might begin to fly from one frame to another, or to think that the image of Fred Astaire in a photograph might begin dancing. ${ }^{31}$

\footnotetext{
${ }^{29}$ Noël Carroll, “The Essence of Cinema?” Philosophical Studies 89, no. 2/3 (1998): 327.

${ }^{30}$ Ibid, 327-328.

${ }^{31}$ Philosopher Arthur C. Danto also makes this point in his essay "Moving Pictures." He imagines screening a film in which the first page of Tolstoy's War and Peace is displayed for eight hours and then projecting a slide of the same page for eight hours. He concludes that "a perfectly legitimate right [to expect movement] is frustrated in the case of the film, whereas there is no legitimate expectation either to be frustrated or gratified in the case of the
} 
What then are the implications of such works for conceptualizing film? As Carroll astutely suggests, traditional definitions of cinema that foreground the illusion of movement may represent a "de facto disenfranchisement of much of the history of avant-garde film." ${ }^{32}$ For Carroll, what is critical is not that the illusion of movement is actually created in any given work, but only that "the relevant imagery be produced in a medium with the capacity to deliver movement," ${ }^{33}$ that "the possibility of movement is always technically available." ${ }^{34}$ Since potential movement is intrinsic to the cinematic apparatus, Carroll suggests that the label "moving picture" might be more useful than "film." 35 On this particular point, I find Carroll's argument puzzling. While I have no serious reservations with calling, say, Snow's One Second in Montreal a moving picture or a motion picture simply for ease of expression, strictly speaking, these would be misnomers, since Snow does not create any impression of movement in this work. Granted, it would be rather cumbersome to replace the term moving picture with picture in which the potential for movement is immanent. But it is misguided to suggest that only potential movement is implied by the traditional nomenclature. It seems rather like calling Stan Brakhage's Dog Star Man (1964) a talkie, reasoning that, although the film is completely silent, the potential for sound and speech are always technically present. Such an appellation would be more than a little misleading. Consequently, I will refer to individual works within the cinema of stasis as films (static films, to be more precise) rather than movies, motion pictures, or moving pictures. ${ }^{36}$

slide." See Danto, "Moving Pictures," in Philosophy of Film and Motion Pictures: An Anthology, eds. Noël Carroll and Jinhee Choi (Malden, MA: Blackwell, 2006), 102.

${ }^{32}$ Carroll, "The Essence of Cinema?" 330.

${ }^{33}$ Ibid., 329.

${ }^{34}$ Noël Carroll, "Defining the Moving Image," in Philosophy of Film and Motion Pictures, 126.

${ }^{35}$ Ibid., 126.

${ }^{36}$ Philosopher Robert Yanal also prefers the term film to moving picture, for similar reasons. See Robert Yanal, "Defining the Moving Image: A Response to Noël Carroll," Film and Philosophy 12 (2008): 136-137. I will continue to use the term cinema in relation to these films, even though it is etymologically derived from the Greek 
But there is a far more serious problem with Carroll's argument about cinematic movement. For Carroll, in order to qualify as a film, something must necessarily belong to "the class of things from which the impression of movement is technically possible." ${ }^{, 37}$ Carroll's definition usefully takes account of the existence of static films, since his emphasis is only on potential movement, whether or not this potential is actualized. However, as Robert Yanal points out, Carroll's definition is in need of further refinement. To illustrate his concern, Yanal borrows an idea from fellow philosopher Bruce Russell for a film called Spot, which only "projects a motionless spot of light, nothing more." 38 According to Yanal, "It is of course logically possible that Spot can, without any mechanical intervention, morph into Citizen Kane and thus begin to move. But is it technically possible that Spot-as it really is-can project motion? Not given real world conditions and laws. Carroll might respond that we don't know that nothing moves in Spot until the end. True, but late knowledge is still knowledge, and this epistemic accident does not bear on the actual technical possibilities of Spot." ${ }^{, 39}$ In other words, Yanal seems to suggest that motion-even potential motion-should not be considered a necessary condition of the cinema. To put it succinctly, "images move in most but not all films." ${ }^{40}$ Granted, motion is normative in cinematic praxis-and this is precisely what gives static films their aesthetic force-but motion is no more a necessary condition of cinema than sound or color are.

To further illustrate this critical point, let us move out of the realm of the hypothetical and into the realm of the actual. In 1970, Michael Snow arranged the first screenings of a

word for movement (kiné), since in its modern connotation, cinema does not seem as inextricably tied to movement as terms like motion picture and movie.

${ }^{37}$ Carroll, "Defining the Moving Image," 130.

38 Yanal, "A Response to Noël Carroll," 137. Yanal and Russell do not seem to be aware that a film very much like Spot has already been created: Situationist Gil Wolman's L'Anticoncept (The Anticoncept) (1951) visually consists of nothing more than a static illumination projected onto a weather balloon.

${ }^{39}$ Ibid., 137. Italics in original.

${ }^{40}$ Ibid., 137. 
conceptual work called A Casing Shelved, which was hailed by Jonas Mekas as "one of the great moments of cinema." ${ }^{41}$ In this work, a slide of a bookcase (the same one that appears in Wavelength) is displayed, while Snow's recorded voice is heard describing the objects that appear on it. As the voice describes an item, the viewer scans the bookcase to find it, so that, as Carroll points out, "the only movement" in this work is "the movement of our eyes." 42 Snow considers A Casing Shelved to be a film, even if it intentionally stretches our predefined notions of what "counts" as cinema, but Carroll takes issue with this designation: "I would argue that this 'film' is not a film at all; to be a film, properly so called, requires the literal possibility of movement. ${ }^{, 43}$ The problem here (to echo Yanal's perspicacious rebuttal of this claim) is that there is no "literal possibility of movement" in many films. If I have already seen Ôshima's Band of Ninja (or if I have read a detailed description of the film from a trusted source), then for all intents and purposes, I know there is no possibility of a ninja becoming animated and moving across the screen. It seems that what Carroll is ultimately suggesting is this: for a work to be considered a film, it must be delivered by a medium that offers the potential for movement, whether or not that potential is actualized in any particular work. But this seems like a dubious distinction. After all, if I choose to post a video of A Casing Shelved online (on YouTube, for example), would the slide show suddenly become a film in Carroll's view, since the medium now has the potential for movement? What if I were to show the work to a crowd who did not know whether I was displaying a slide, a film of a slide, or simply a film of a static bookcase?

\footnotetext{
${ }^{41}$ Jonas Mekas, "Expanded Cinema: Extracts from Village Voice 'Movie Journal," in Expanded Cinema: Art, Performance, Film, eds. A.L. Rees, Duncan White, Steven Ball, and David Curtis (London: Tate Publishing, 2011), 79.

${ }^{42}$ Noël Carroll, "Philosophizing through the Moving Image: The Case of 'Serene Velocity," The Journal of Aesthetics and Art Criticism 64, no. 1 (2006): 185.

${ }^{43}$ Ibid., 185.
} 
Would not the experience be essentially cinematic (albeit quite unorthodox), regardless of the answer to this question?

Carroll is concerned that categorizing A Casing Shelved as a film would necessarily "turn family albums into cineplexes," 44 since neither Snow’s work nor photographs in family albums has the capacity for motion. But there is a crucial difference: A Casing Shelved is 45 minutes in length, whereas a family album has no duration, no inherent temporal dimension. Thus, if one is intent on establishing necessary conditions for the cinema (and I will argue in Chapter 4 that there is no reason to do so), motion — even the potential for motion—should not be on the list. If cinema has any indispensible component, it would appear to be duration. Whether one is considering Gérard Courant's 150-hour Cinématon (1978-2010) or Thomas Edison's 5-second Fred Ott's Sneeze (1894), all films have a running length; there is no such thing as an atemporal film. Thus, while Mary Ann Doane (and many other film theorists, including Christian Metz) claim that "[t]he ability to represent movement" is "what distinguishes film from photography,"45 I would argue that the more fundamental distinction between cinema and photography (as well as other traditional visual arts) is not movement, but duration. As Maya Deren has noted, "the motion picture, though composed of spatial images, is primarily a time form. $" 46$

Carroll's emphasis on potential movement as a sine qua non of cinema is further problematized by works in which the spectator is simply unaware of whether or not this potential is present. Consider, for instance, James Coleman's film La tache aveugle (The Blind Spot) (1978-1990). Coleman borrows a very small amount of footage (less than a second) from James

\footnotetext{
${ }^{44}$ Ibid., 185.

${ }^{45}$ Mary Ann Doane, The Emergence of Cinematic Time: Modernity, Contingency, the Archive (Cambridge: Harvard University Press, 2002), 131. Christian Metz claims that movement is "one of the greatest differences, doubtless the greatest, between still photography and the movies." See Metz, 7.

${ }^{46}$ Maya Deren, “Cinematography: The Creative Use of Reality," Daedalus 89, no. 1 (1960): 160.
} 
Whale's The Invisible Man (1933) and stretches each individual frame out for about 20 minutes (the work as a whole lasts eight hours). The process is achieved through the use of two slide projectors which are computer driven. Is the potential for movement present here or not? Normally slide shows do not permit the illusion of movement, but is it not feasible that the technology running the slides could still invest them with movement? Again, the answers to such questions seem irrelevant. It is not at all clear why La tache aveugle's status as a film (or a slide show, or whatever other classification one might suggest) should be dependent on the technology that happens to be used to project it.

As works like La tache aveugle suggest, the phenomenology of duration is one of the foremost preoccupations of the cinema of stasis. Even though duration is intrinsic to the filmic medium, in traditional motion pictures, the goal is generally to confront the spectator with a barrage of engaging scenes which will make her "lose track of time" (to borrow a useful cliché). A moviegoer glancing at her watch during a film is usually seen as a bad sign, an indication that the cinematic experience is not proving to be as immersive as it was designed to be. But an awareness of time is often part of the raison d'etre of static films. In several works, this is literalized. For example, in James Riddle's 9 Minutes (1966), numbers appear on the screen to demarcate each second that passes, and in Gottfried Schlemmer's 8h01-8h11 (1968), the face of a digital clock is the sole image on the screen for the film's entire 11 minutes. But even if time itself is not the explicit subject of a work, many static films still call attention to their own duration. Consider, for example, Warhol's audacious Empire, in which a static shot of the Empire State Building dominates the frame for over eight hours. There is very little change onscreen throughout the film. To be sure, lights in the Empire State Building occasionally go on and off, and the reflections of Warhol and his associate Jonas Mekas can momentarily be 
glimpsed changing reels. But as a whole, nothing happens, and as a result, it is difficult to view the film without thinking about how many hours remain. This is, in fact, one of Warhol's goals. One watches Empire, he claims, "to see time go by."47

This description is suggestive, since witnessing "time go by" implies a kind of movement in spite of the stasis on the screen. Even though Empire (like many static films) seems immutable, the experience of viewing such films involves constant flux. This kind of paradox has been eloquently theorized by Henri Bergson. While it is true that Bergson displays little interest in film as an art form (being more interested in the philosophical implications of the cinematographic apparatus), he nevertheless maps out a phenomenology of duration which is apposite in understanding the cinema of stasis:

[T]here is no feeling, no idea, no volition which is not undergoing change every moment: if a mental state ceased to vary, its duration would cease to flow. Let us take the most stable of internal states, the visual perception of a motionless external object. The object may remain the same, I may look at it from the same side, at the same angle, in the same light; nevertheless the vision I now have of it differs from that which I have just had, even if only because the one is an instant older than the other. My memory is there, which conveys something of the past into the present. My mental state, as it advances on the road of time, is continually swelling with the duration which it accumulates: it goes on increasing - rolling upon itself, as a snowball on the snow. ${ }^{48}$

In other words, for Bergson, an experience of absolute stasis is impossible. Even if the object of my attention does not move (as is the case with static films), my subjective, phenomenological

\footnotetext{
47 Quoted in Karen Rosenberg, "A Controversy Over 'Empire," New York, 21 May 2005, http://nymag.com/ nymetro/arts/art/10422/. Empire's shot includes the top of the Metropolitan Life Insurance Tower, which does in fact flash at regular intervals to provide the time. Since the film was shot at 24 frames per second and projected at 16 , however, cinematic time here moves at only $2 / 3$ the speed of actual time.

${ }^{48}$ Bergson, Creative Evolution, 2.
} 
apprehension of the object is constantly evolving. This is a necessary consequence of the duration of experience. The spectator of a film like Empire witnesses movement: not the movement of the building on the screen, but the movement of time itself. ${ }^{49}$ This sense of the inevitability of perpetual motion prompts Bergson to make the Heraclitean assertion that "consciousness cannot go through the same state twice. The circumstances may be the same, but they will act no longer on the same person, since they will find him at a new moment in his history. Our personality, which is being built up each instant with its accumulated experience, changes without ceasing." ${ }^{, 50}$ Although Warhol's Empire State Building is essentially immutable, my conscious experience of it is not. For example, during just one minute or so of the film, the following questions begin to come to my mind: Is this a productive use of my time? Am I falling for some kind of Warholian prank by watching all eight hours? Would I get the gist of the film if I just watched 10 minutes? Or is that precisely missing the point? Is Warhol's goal to counter the capitalistic equation "Time equals money" by offering a space in which time can be observed, felt, and reflected upon, rather than hurriedly "spent"? And of course, similar questions surface and subside throughout the film's duration. By foregrounding stasis, films like Empire actually make the spectator more aware of the movement of time and consciousness, neither of which can be apprehended in the same way when one is absorbed in the movement of a cinematic image.

Roland Barthes makes a similar argument in his classic 1970 essay "The Third Meaning: Research Notes on Several Eisenstein Stills." While his object of investigation is the film still (that is, a frame extracted from a motion picture) rather than the still film, his formulations remain useful. Barthes is interested in interrogating "the filmic," which he defines as "what, in the film, cannot be described [...] the representation that cannot be represented. The filmic

\footnotetext{
${ }^{49}$ Wayne Koestenbaum makes this point in his monograph on Warhol: "The only thing moving, in much of Warhol's art, is time, lapping over icons." Wayne Koestenbaum, Andy Warhol (New York: Viking, 2001), 25.

${ }^{50}$ Bergson, Creative Evolution, 6.
} 
begins only where language and articulated metalanguage cease. ${ }^{„ 51}$ But paradoxically, Barthes argues that "to a certain extent," the filmic "cannot be grasped in the projected film, the film "in movement,' 'au naturel,"' but only in the still. ${ }^{52}$ Consequently, "the 'movement' which is taken for the essence of film is not animation, flux, mobility, 'life,' copy, but merely the armature of a permutational unfolding." ${ }^{, 53}$ Challenging conventional theorizations which see the movement of images as "cinema's sacred essence," ${ }^{, 54}$ Barthes instead astutely asserts that an experiential "unfolding" is the sine qua non of film, a conceptualization that is evocative of Bergson's phenomenological "snowball."

In fact, Barthes' argument mirrors Bergson's in another respect: for both, only that which is still can be conceptually grasped. As Bergson puts it, "Of immobility alone does the intellect form a clear idea. ${ }^{, 55}$ Even when one tries to imagine motion, Bergson perceptively argues, one invariably does so "by constructing movement out of immobiles put together." ${ }^{\text {,56 }}$ (Raymond Bellour makes a similar observation. He attempts to visualize in his mind's eye the movement of boats on the Bosporus Strait. The result: "If I shut my eyes and try to follow a vision turning in my memory, one boat passing another for example, a jerky succession of progressive flashes appears. ${ }^{.57}$ ) This may explain Barthes' claims that a motion picture must be stilled before its cinematic qualities can be cognitively grasped. And this is precisely what the cinema of stasis accomplishes: by halting the constant movement generally associated with motion pictures, the

\footnotetext{
${ }^{51}$ Roland Barthes, "The Third Meaning: Research Notes on Several Eisenstein Stills," in The Responsibility of Forms: Critical Essays on Music, Art, and Representation, trans. Richard Howard (Berkeley: University of California Press, 1985), 58.

${ }^{52}$ Ibid., 59.

${ }^{53}$ Ibid., 60-61.

${ }^{54}$ Ibid., 60.

${ }^{55}$ Bergson, Creative Evolution, 164. Italics in original.

${ }^{56}$ Ibid., 163.

${ }^{57}$ Bellour, "Concerning 'The Photographic,” 271.
} 
static film permits a more substantive understanding of cinema, foregrounding its temporal dimensions and the stillness that is pivotal to its ontology.

Ernie Gehr's minimalist film Serene Velocity (1970) serves as a striking verification of Barthes' contention that the filmic can only be grasped when cinematic motion is somehow stilled. The "object" being filmed is an empty corridor in a university. It is difficult to improve on P. Adams Sitney's description of Serene Velocity in Visionary Film: "The filmmaker positioned his tripod within the corridor and then proceeded to alter his zoom lens every four frames. At first the shifts are not dramatic. He alternates four frames at $50 \mathrm{~mm}$ with four at 55 $\mathrm{mm}$. After a considerable period the differential increases: $45 \mathrm{~mm}$ to $60 \mathrm{~mm}$. Thus, the film proceeds with ever increasing optical shocks. In this system the zoom never 'moves.' The illusion of movement comes about from the adjustment of the eye from one sixth of a second of a distant image to one sixth of a second of a nearer one." ${ }^{58}$ As Serene Velocity proceeds, it slowly evolves from a motion picture to a static film. That is, since there is initially little distance between the repeatedly alternating shots of the corridor (one appearing a bit closer than the other), it creates the impression of quickly moving forward and backward in the corridor, as if one were on some kind of perversely disorienting amusement park ride. Even though Gehr did not actually move his camera to create the experience (all of the changes in perception are created with Gehr's zoom lens), the spectator feels like a camera that is being incessantly "thrust" into the corridor (an experience with inescapable sexual undertones). However, as time goes on, the distance between the two repeating shots slowly starts to increase. At first, the mind tries to maintain its impression of movement on the screen, even if it is choppy, almost stroboscopic. But eventually, the distance is too great for the illusion of movement to be

58 P. Adams Sitney, Visionary Film: The American Avant-Garde, 1943-2000 (Oxford: Oxford University Press, 2002), 401. 
maintained, and the remainder of the film can only be processed as the perpetual succession of static shots. Only when the film has finally progressed from apparent motion to apparent stasis can the Barthesian "filmic" be grasped. That is, the spectator becomes increasingly aware that the entire film is composed of alternating static shots and that the impression of movement engendered from the earlier stills is an illusion stemming from their close proximity to each other. Watching the film is like seeing a magician reveal how a trick is done by performing the trick again and again and drawing attention to how the deception occurs. The "trick" of cinematic motion has never been easier to understand on an affective level (as opposed to an intellectual level) than it is in Serene Velocity.

Given Noël Carroll's interest in motion and stasis in cinema, it should come as no surprise that he has devoted an entire essay to Gehr's magnum opus. In it, Carroll argues that films can do more than simply parrot pre-existing philosophical views; they can also "do" philosophy by using the cinematic medium "to articulate some original conceptual point." 59 For Carroll, Serene Velocity is just such a film. While I have no serious qualms with these assertions, Carroll seems to draw precisely the wrong philosophical point from Gehr's film. He claims that "Gehr proposes movement as an essential feature of cinema, one that has special pride of place for the philosophical definition insofar as it signals the very species to which films belongmotion pictures or, as I prefer to say, moving images." ${ }^{\circ 0}$ But if anything, Serene Velocity is insistent on challenging definitions of cinema that privilege movement. After all, the impression of movement that Gehr creates eventually deteriorates, laying bare the static nature of every shot in the film (and by extension, the stasis at the heart of all cinema). ${ }^{61}$

\footnotetext{
${ }^{59}$ Carroll, "Philosophizing through the Moving Image," 176.

${ }^{60}$ Ibid., 179. Italics in original.

${ }^{61}$ For a somewhat different critique of Carroll's argument about Serene Velocity, see Bruce Russell, "Film's Limits: The Sequel," Film and Philosophy 12 (2008): 1-16.
} 
In many ways, in fact, Serene Velocity feels more like a succession of still photographs than a film. Of course, in a sense cinema really is nothing more than a succession of photographs (or other stills). But while this fact is carefully concealed in traditional motion pictures, static films often foreground this dimension of cinema's ontology. The cinema of stasis has profound affinities with traditional visual art, and consequently, an interrogation of static films necessitates an exploration of the dialectical tension between stasis and movement that has subtended visual art even prior to cinema's emergence.

Even though a painting, sculpture, or photograph cannot produce the perception of motion, there is often an implied motion in traditional visual art that is central to its aesthetic. As Gotthold Lessing points out, though paintings are "motionless," a painter can nevertheless "suggest motion." and His Sons) can be constructed so as to appear "always animated." ${ }^{\prime 63}$ Arthur C. Danto gives the useful example of Gian Lorenzo Bernini's sculpture David (1623-1624) (see Figure 2), which is designed to suggest that David is in the process of slinging a stone at Goliath. The sculpture itself is obviously still, yet the work is necessarily participatory - the assumption is that the viewer will cognitively vivify the work by imagining the completion of the movement and the launching of the stone. As Danto puts it, "In describing our experience with David, we might say that we see he is in movement, but we don't see him move." ${ }^{44}$

\footnotetext{
${ }^{62}$ Gotthold Ephraim Lessing, Laocoön, trans. Edward Allen McCormick (Baltimore: John Hopkins University Press, 1984), 112.

${ }^{63}$ Johann Wolfgang von Goethe, "Observations on the Laocoön” (trans. unknown), in Goethe on Art, ed. John Gage (Berkeley: University of California Press, 1980), 81.

${ }^{64}$ Danto, "Moving Pictures," 109. For more on the depiction of movement in traditional visual art, see Sergei Eisenstein, "Laocoön" (trans. Michael Glenny) in Selected Works, Volume 2: Towards a Theory of Montage, eds. Michael Glenny and Richard Taylor (London: I.B. Tauris, 2010), 109-202.
} 


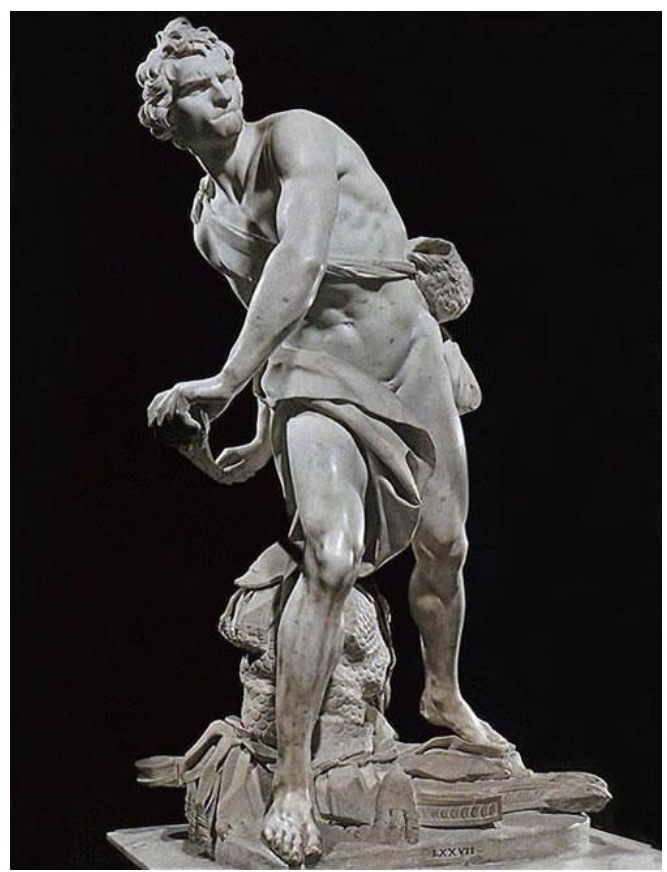

Figure 2: Gian Lorenzo Bernini, David (1623-1624)

Another useful example of implied motion is Marcel Duchamp's Nude Descending a Staircase, No. 2 (1912) (see Figure 3), a work that was likely inspired, in part, by the chronophotographs of Étienne-Jules Marey. With its succession of abstract shapes at different points along a staircase, the painting suggests a body in constant motion. Again, the viewer must actively carry out Duchamp's intention by visualizing the nude body moving from one end of the canvas to the other. As with Bernini's David, the spectator is prompted to imagine movement, but no actual phenomenon of movement presents itself. Still, the inherent motion of works like Duchamp's serves as a verification of Giorgio Agamben's claim that "paintings are not immobile images, but stills charged with movement, stills from a film that is missing."65

\footnotetext{
${ }^{65}$ Giorgio Agamben, "Difference and Repetition: On Guy Debord's Films" (trans. Brian Holmes), in Guy Debord and the Situationist International: Texts and Documents, ed. Tom McDonough (Cambridge: MIT Press, 2002), 314.
} 


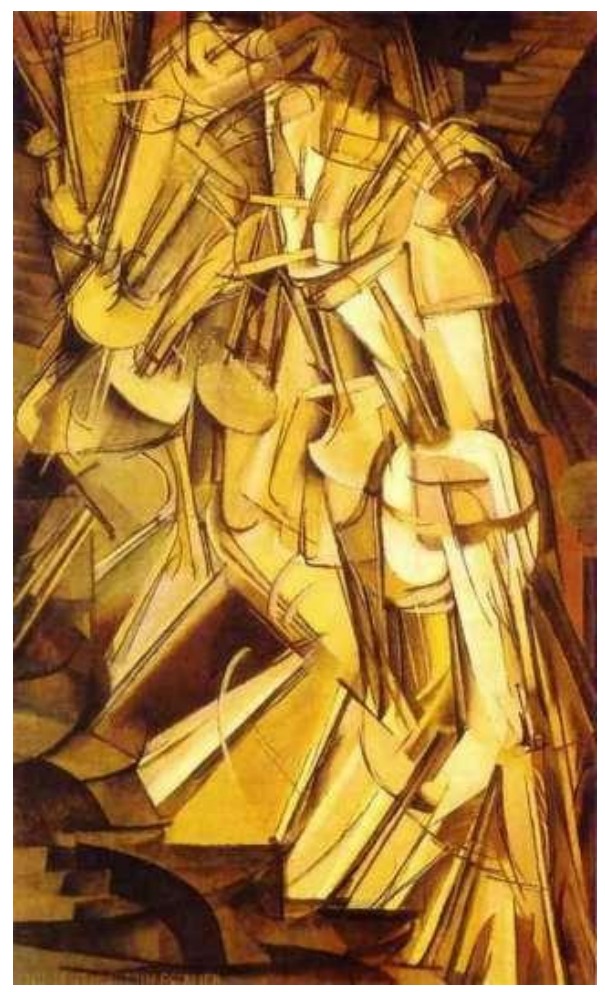

Figure 3: Marcel Duchamp, Nude Descending a Staircase, No. 2 (1912)

Obviously, the impression of movement in motion pictures is phenomenologically distinct from mere implied motion. As Danto points out, "[W]ith the movies, we do not just see that they move, we see them moving. ${ }^{, 66}$ But just as sculptures and paintings can produce a kind of illusion of movement while remaining perfectly still, so films can produce an illusion of stasis, even though this stasis is the result of the constant movement of the film stock (at least in traditional cinematic praxis). As Mulvey puts it, stasis in film is produced by "a series of identical frames repeated in order to create an illusion of stillness to replace the illusion of movement."67 (Of course, this conception is becoming increasingly problematized by new methods of watching films, such as streaming videos online, which do not rely on the movement

\footnotetext{
${ }^{66}$ Danto, "Moving Pictures," 110. Italics in original.

${ }^{67}$ Mulvey, 81.
} 
of film stock, but instead on the transfer of digital information. I will explore the theoretical ramifications of this development in my concluding chapter. ${ }^{68}$ )

Cinema and traditional visual art clearly engage with movement in different ways, but many see another vital difference between the two traditions. For example, in his seminal essay "The Work of Art in the Age of Mechanical Reproduction," Walter Benjamin offers the following observation: "The painting invites the viewer to contemplation; before it, he can give himself up to his train of associations. Before a film image, he cannot do so. No sooner has he seen it than it has already changed. It cannot be fixed on." ${ }^{69}$ Benjamin proceeds to quote the French writer Georges Duhamel: "I can no longer think what I want to think. My thoughts have been replaced by moving images."70 Although Benjamin admits, by way of a caveat, that Duhamel "detests the cinema and knows nothing of its significance," he nonetheless agrees with Duhamel on this point, asserting, "[T]he train of associations in the person contemplating these images is immediately interrupted by new images."71 While Benjamin is right to suggest that the constant fluctuations of traditional motion pictures often preclude a contemplative stance vis-àvis the images on the screen, this view is radically challenged by films that do arrest images for prolonged periods of time, films that often change very little-if at all. In fact, one could argue that static films are even more insistent on spectatorial contemplation than traditional visual art. After all, it is possible for an individual to visit a museum and glance at Salvador Dalí's painting

\footnotetext{
${ }^{68}$ For more on the technological processes underlying streaming video, see David Austerberry, The Technology of Video and Audio Streaming, $2^{\text {nd }}$ ed. (Amsterdam: Focal Press, 2005).

${ }^{69}$ Walter Benjamin, "The Work of Art in the Age of Its Technological Reproducibility," Third Version (trans. Harry Zohn and Edmund Jephcott), in Walter Benjamin: Selected Writings, 1938-1940, eds. Howard Eiland and Michael W. Jennings (Cambridge: Harvard University Press, 2003), 267.

${ }^{70}$ Ibid., 267.

${ }^{71}$ Ibid., 267. It is worth noting that there is no mention of Duhamel at all in the second version of this essay, which Benjamin considered the "master version." Nevertheless, Benjamin's argument regarding the differences between painting and film remains effectively intact. See Walter Benjamin, "The Work of Art in the Age of Its Technological Reproducibility" (trans. Edmund Jephcott and Harry Zohn), in Walter Benjamin: The Work of Art in the Age of Its Technological Reproducibility and Other Writings on Media, ed. Michael W. Jennings, Brigid Doherty, and Thomas Y. Levin (Cambridge: The Belknap Press of Harvard University Press, 2008), 19-55.
} 
Sleep (1937) for a few seconds before moving on to look at other works. The spectator could then honestly tell others, "I saw Dalí's Sleep." But compare this to Andy Warhol's film Sleep, which shows the poet John Giorno sleeping (and moving very little) for over five hours. One could certainly watch just a few seconds of the film, but could one then say, "I saw Warhol's Sleep"? Given the temporal dimensions of film, which do not permit the cursory perception of an entire work in a single moment, this would seem to be a problematic assertion. ${ }^{72}$ Consequently, evoking a contemplative stance is one of the primary goals of static films, many of which demand prolonged engagement and meditation in a way that is often only encouraged by traditional visual art.

Of course, such encouragement is generally only implicit. In other words, artists often hope that spectators will immerse themselves in their works, staring at them and reflecting on them for extended periods of time. (Lessing puts it this way: "[T]he works of both painter and sculptor are created not merely to be given a glance but to be contemplated-contemplated repeatedly and at length."73) Occasionally, this implicit expectation is made explicit, however, as in Marcel Duchamp's To Be Looked at (from the Other Side of the Glass) with One Eye, Close to, for Almost an Hour (1918) (see Figure 4). The work consists of (accidentally) shattered glass, a strip of metal, various geometric shapes, and a convex lens. The title is somewhat humorous, since it is hard to imagine that many visitors to a museum will actually stare at a single work for an hour (especially if this involves being close to the work, thus blocking the gazes of other spectators). Still, the title represents Duchamp's attempt to inject duration (and by extension,

\footnotetext{
${ }^{72}$ This is even more obvious if one substitutes a Hollywood film for Warhol's avant-garde fare. Imagine telling a friend that you have seen Alfred Hitchcock's Psycho (1960) after watching only two seconds of it on television. Interestingly, the rules for television programming itself are somewhat more flexible. One could honestly claim to have seen Star Trek without watching every single episode (although only a few seconds of viewing would still be insufficient).

${ }^{73}$ Lessing, Laocoön, 19.
} 
engagement and reflection) into traditional visual art. Given Duchamp's explicit instructions, could one still claim to have seen this work after glancing at it for just a moment? This is a rather difficult question to answer.

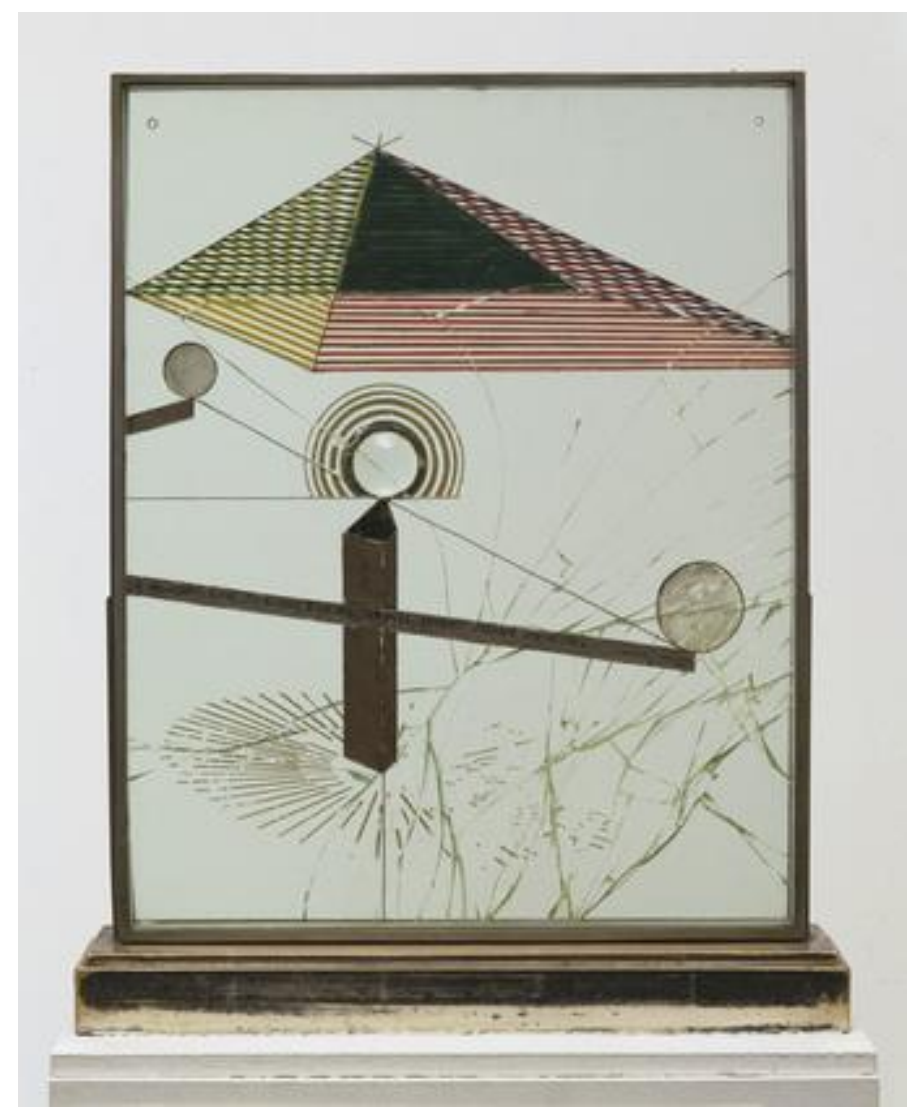

Figure 4: Marcel Duchamp, To Be Looked at (from the Other Side of the Glass) with One Eye, Close to, for Almost an Hour (1918)

In any case, the fixed gaze at the fixed object (which Duchamp is clearly interested in engendering) is also a paramount concern in static cinema. The Benjaminian "shock effect," a critical element in most motion pictures, is usually bypassed in static films. Unlike "the cinema of attraction" so perceptively theorized by Tom Gunning (and before him, by Eisenstein), the 
cinema of stasis generally aims to engender introspection, not shock. ${ }^{74}$ If there is a shock, it is merely the subtle shock of subverted expectations. To borrow Gunning's terminology, static films are generally interested neither in the startling "confrontation" of early cinema (or of the avant-garde films of Luis Buñuel or Jack Smith), nor in the "diegetic absorption" of mainstream cinema. $^{75}$

The fact that there are exceptions to this rule is unsurprising, given the diversity of static cinema. For instance, James Broughton and Joel Singer's Hermes Bird (1979) features a penis becoming erect in extreme slow motion for 11 minutes, a gesture that, in its violation of taboo, seems closely allied with the exhibitionistic and confrontational "cinema of attractions" theorized by Gunning. ${ }^{76}$ (Interestingly, however, the prolonged exposure to the male member in this work makes it less shocking than the fleeting, split-second shots of penises in films like Ingmar Bergman's Persona [1966] and David Fincher's Fight Club [1999].) Furthermore, in terms of "diegetic absorption," not all static films forgo narrativity; for example, Ôshima’s Band of Ninja features a salient plot. Still, very few static films are interested in overt shock or narrativity. Instead, the majority of works within the cinema of stasis aim to create a space for meditation, for immersion in an image, for sober reflections on the nature of movement and stasis, time and space, cinema and art.

The yearning for stillness and meditation so characteristic of static cinema may well have arisen as a response to historical and cultural forces. In particular, it is worth noting that static

\footnotetext{
${ }^{74}$ See Tom Gunning, "The Cinema of Attraction: Early Film, Its Spectator, and the Avant-Garde," in Film and Theory: An Anthology, eds. Toby Miller and Robert Stam (Oxford: Blackwell Publishers, 2000), 229-235. See also Sergei Eisenstein, "The Montage of Attractions" and "The Montage of Film Attractions," in The Eisenstein Reader, ed. Richard Taylor, trans. Richard Taylor and William Powell (London: British Film Institute, 1998), 29-52.

${ }^{75}$ Gunning, "The Cinema of Attraction," 232.

${ }^{76}$ Amos Vogel has memorably claimed that, for the censor, "the erect penis" is "the most dangerous image in the known universe." Amos Vogel, Film as a Subversive Art (New York: Random House, 1974), 219.
} 
films only begin appearing in the post-WWII era. ${ }^{77}$ This may simply reflect the fact that in the early decades of cinema, movement was a kind of novelty, something that distinguished films from older media, such as photography. Perhaps only after movement had become codified, deeply entrenched as the status quo, did it make sense to radically break with this tradition, to challenge the hegemony of motion in cinematic practice. But David Campany also offers a compelling theoretical framework in the introduction to his edited volume The Cinematic. According to Campany, "The advanced photography and film of the first half of the twentieth century was shaped profoundly by modern ideas of speed. To be contemporary and progressive was to make use of the latest media and be reactive, instantaneous, fast." This fascination with speed, in Campany's view, is embodied in films like Walter Ruttmann's Berlin: Symphony of a Great City (1927) and Vertov's Man with a Movie Camera. (And there are numerous other preWWII films that exemplify the centrality of speed for early directors, particularly within the avant-garde. Consider, for example, the rapid succession of mobile quasi-abstract objects in Man Ray's Le retour à la raison [The Return to Reason] [1923], the dizzying movements at the end of René Clair's Entr'acte [1924], and the lightning-fast montages featured in Kenneth MacPherson's Borderline [1930]). But for Campany, there is an important aesthetic shift in the post-WWII era: "After the Second World War, European and North American culture began to be dominated by the ideologies of mainstream cinema, television, lifestyle culture, saturation advertising, and mass distraction. In this new situation speed lost much of its critical edge and most of its artistic credentials. To be radical in this new situation was to be slow. A stubborn resistance to the pace of spectacle and money-driven modernization seemed the only creative

\footnotetext{
${ }^{77}$ The only unambiguous exception to this rule that I am aware of is Walter Ruttmann's Weekend (Wochenende) (1930), which appears to be the first static film ever made. Weekend features a rich, evocative sound track of voices, clocks, alarms, and other "found" sounds, but the screen remains blank and motionless for the work's entire elevenminute duration.
} 
option and it came to characterize the landmarks of art and film in the latter decades of the last century." While Campany seems to be primarily thinking of directors of "slow" feature-length films, such as Vittorio de Sica, Robert Bresson, and Chantal Akerman, he also acknowledges that a "[r]esistance to speed" was central to the aesthetics of avant-garde filmmakers like Warhol, Snow, and Frampton — pivotal figures in the cinema of stasis. ${ }^{78}$ (Campany's suggestion that slow [and by extension, static] films were a counterpoint to the "mass distraction" of advertising and popular culture seems especially plausible when one remembers that some of the earliest static films—-such as Gil Wolman's L'Anticoncept and Guy Debord's Hurlements en faveur de Sade [Howls for Sade] [1952]—were created by Situationists, who were openly engaged in a struggle against "the society of the spectacle.")

Deleuze provides a similar chronology in Cinema 2: The Time Image. Again, he focuses primarily on art cinema (neo-realism, the new wave, etc.) rather than the avant-garde; nevertheless, he correctly notes a general trend in post-WWII cinema wherein "movement can tend to zero [and] the character, or the shot itself, remain immobile." ${ }^{, 79}$ In contrast to the constant permutations of early cinema, there arose in this era "a cinema of the seer and no longer of the agent [de voyant, non plus d'actact]." ${ }^{, 80}$ For Deleuze, these new filmmakers sought to represent time directly (rather than indirectly through the medium of movement). ${ }^{81}$ It could be argued that static filmmakers simply took this "cinema of the seer" to its logical extreme, removing agency and movement from its privileged position to engage more immediately with duration itself.

While the category of static cinema is a useful one, the boundaries delineating this modality are by no means clear-cut — in fact, many individual works reside in the interstices

\footnotetext{
${ }^{78}$ David Campany, ed. The Cinematic (Cambridge: MIT Press, 2007), 122.

${ }^{79}$ Gilles Deleuze, Cinema 2: The Time-Image, trans. Hugh Tomlinson and Robert Galeta (Minneapolis: University of Minnesota Press, 1989), 128.

${ }^{80}$ Ibid., 126.

${ }^{81}$ Ibid., 129.
} 
between traditional motion pictures and static films. Consider, for instance, Tony Conrad's The Flicker (1965), which consists only of static white and black frames. There is no on-screen movement in any conventional sense (e.g. a person or even an abstract shape moving from one end of the screen to the other), yet the carefully constructed rhythm of the alternating frames creates an almost hallucinatory sense of pulsation (as well as the illusion of kinetic phosphenes, at least in my viewing of the film). While the dividing line between traditional motion pictures and static films is clearly porous, creating rough distinctions between the two remains useful. There is a continuum of motion in cinema, from films that are essentially motionless (like Larry Gottheim's Fog Line and Andy Warhol's Empire) to films that are replete with movement (like René Clair's Entr'acte and the majority of Hollywood films). My aim is to interrogate those films that fall somewhere on the "still" end of this continuum.

Throughout this dissertation, I will attempt to grapple with the aesthetic, affective, cultural, historical, and philosophical dimensions of static films. However, this is not to suggest that these films form any kind of unified genre, school, or movement. Since it is exceedingly difficult to make coherent generalizations about static cinema, one of the aims of this dissertation will be to emphasize the richness and range of this tradition. Static films are occasionally designed to serve as the backdrop for other activities (as in the early films of Warhol), but they can also be immersive, encouraging a meditative gaze (this is the case, I will argue, in many Fluxus films). Static films can exploit film's unique ability to structure time (as in Michael Snow's So Is This [1982]); they can also foreground frequently overlooked elements of cinema—such as color, sound, and embodied perception (as in Derek Jarman's Blue [1993]). In other words, cinematic stasis is just as malleable and multivalent as cinematic movement. In 
spite of this heterogeneity, however, all static films inherently challenge widespread essentialist conceptions of cinema by broadening our conception of what a film can be or do.

In Chapter 2, I will analyze the early films of Andy Warhol. Warhol's "stillies" are often conceptualized as experiments in boredom. However, I will suggest that films like Sleep and Empire are not designed to be viewed in silence from beginning to end (an experience that would likely bore even the most ardent fan of Warhol's cinema), but are best understood as furniture films, works designed to be viewed partially and distractedly. By repudiating movement, Warhol creates films that do not demand close attention, and so his stillies can be enjoyed in conjunction with other experiences, such as conversing, eating, drinking, and dancing. I will argue that in Warhol's cinema, the rigid and predetermined temporality of traditional motion pictures gives way to one that is open-ended and amorphous.

Chapter 3 will engage with protracted films - works which use extreme slow motion to create the impression of stasis_-giving especially close attention to Disappearing Music for Face (1966), a Fluxus film by George Maciunas and Mieko Shiomi. Films like Disappearing Music can be profitably theorized as interrogations of microtime, since they foreground interstitial moments which are generally below the threshold of perception. I will argue that protracted films reveal film's unique capacity to offer affective access to alternate temporalities. I will further connect these films with musical experiments by artists like Yves Klein and La Monte Young, which also use extended duration as an aesthetic strategy.

In Chapter 4, I will examine textual films, works which forgo conventional cinematic imagery in favor of letters, words, numbers, and other typographical text. Giving close attention to Michael Snow's So Is This (a film comprised entirely of individual words, displayed one at a time) this chapter explores the implications of remediating written text in film. I claim that, by 
drawing attention to the differences between cinematic reading and more conventional forms of reading, textual films foreground the unique ability of cinema to structure duration. I also contend that textual films implicitly challenge orthodox ontologies of film that rely on necessary conditions, instead positing a more Wittgensteinian approach (i.e. one based on "family resemblances.”)

Chapter 5 gives consideration to the monochrome film. In these works, a single static color dominates the screen for lengthy periods of time. I will engage in a close reading of the most well known monochrome film—Derek Jarman's Blue — a work in which all that is visible is a striking blue color field. I will also try to address the following questions: What is the relationship between these films and monochrome paintings (such as the works of Kazimir Malevich, Robert Rauschenberg, and Yves Klein)? What role is played by the sound track (often, though not always, present in monochrome films), especially since there is no person or image on the screen to complement what is heard? Finally, how can these films be understood within the context of philosophical debates regarding absence and "the void"? 


\section{CHAPTER 2}

\section{SERIOUS IMMOBILITIES:}

\section{ANDY WARHOL, ERIK SATIE, AND THE FURNITURE FILM}

"When people think they've seen enough of something, but there's more, and no change of shot, then they react in a curiously livid way. They think there must be justification for it, but it never occurs to them that the fact that you happen to like whatever is in the shot is sufficient justification." - Wim Wenders ${ }^{1}$

Joseph Gelmis - "Your films are just a way of taking up time?"

Andy Warhol - "Yeah."2

In 1893, Erik Satie composed Vexations, a delicate and haunting piece of music that would eventually come to be seen as his most radical composition. While the sheet music at first appears relatively straightforward, it includes a bizarre performance note in which Satie suggests that if the performer decides "to play this phrase 840 times in a row, it will be as well to prepare oneself in advance, and in the deepest silence, through serious immobilities." 3 While there is nothing at all unusual about the use of repetition in music, Satie's uncompromising and unrelenting repetition was entirely unprecedented. It anticipated the minimalism that would come to prominence in the second half of the $20^{\text {th }}$ century, with composers like La Monte Young,

\footnotetext{
${ }^{1}$ Wim Wenders, "Time Sequences, Continuity of Movement," in Campany, The Cinematic, 89.

${ }^{2}$ Andy Warhol, I'll Be Your Mirror: The Selected Andy Warhol Interviews, ed. Kenneth Goldsmith (New York: Carroll and Graf, 2004), 169.

${ }^{3}$ Quoted in Robert Orledge, “Understanding Satie's Vexations," Music \& Letters 79, no. 3 (1998): 386. It is generally assumed that Vexations is a piece for piano; however, the score does not specify what instrument should be used.
} 
Philip Glass, Steve Reich, and John Adams. (In fact, the piece's lack of a tonal center also foreshadowed the atonality pioneered by Arnold Schoenberg, Anton Webern, and Alban Berg in the first half of the century.)

On September 9, 1963, John Cage staged the first complete performance of Vexations at the Pocket Theatre in New York. Ten pianists took turns playing the repetitions, and the piece lasted from 6:00 p.m. until 12:40 p.m. the following day. ${ }^{4}$ Among those present for the performance was Andy Warhol, who would go on to promote a strikingly similar aesthetic in his early films, works in which a relatively static object or person is filmed for a very lengthy period of time. ${ }^{5}$ In his first film, Sleep (1963), the poet John Giorno is shown sleeping nude from various angles for almost five and a half hours (with numerous individual shots being repeated over and over again), while in Empire (1964), a single static shot of the Empire State Building is maintained for over eight hours (see Figure 1). ${ }^{6}$ Warhol's early films (which he called "stillies") are often theorized as explorations of boredom. While I do not necessarily take issue with this approach, it strikes me as somewhat limiting. I want to argue that Warhol is following the lead of Satie, who developed the concept of furniture music (musique d'ameublement). Satie was interested in music that was not meant to be closely listened to, but which was instead designed to serve as a backdrop for other activities. Along similar lines, I will argue that Warhol's stillies

\footnotetext{
${ }^{4}$ Sources that describe the event are divided as to whether the number of pianists was ten or twelve. In any case, Cage's decision to use a team of pianists was probably a wise one, as individual pianists who have attempted to perform Vexations in its entirety have often encountered problems. For example, in 1970, Peter Evans was forced to terminate his performance after fifteen hours of playing, when he began to experience "frightful hallucinations." See Alan M. Gillmor, Erik Satie (Boston: Twayne Publishers, 1988), 103.

5 I should briefly note that there is some disagreement as to whether or not Warhol actually attended the performance, and if so, for how long. See Gary Comenas, "Notes on John Cage, Erik Satie's Vexations, and Andy Warhol's Sleep," http://www.warholstars.org/ news/johncage.html. See also Branden W. Joseph, "Andy Warhol's Sleep: The Play of Repetition," in Masterpieces of Modernist Cinema, ed. Ted Perry (Bloomington and Indianapolis: Indiana University Press, 2006), 180, 202. While it seems likely to me that Warhol was present for at least part of the performance, the arguments I present in this essay are not contingent on this claim.

${ }^{6}$ The idea for Empire was suggested to Warhol by the filmmaker John Palmer, whose reflection can be briefly glimpsed in the film's last reel. See Callie Angell, Andy Warhol Screen Tests: The Films of Andy Warhol Catalogue Raisonné, Volume One (New York: Harry N. Abrams, Inc., 2006), 153.
} 
are best understood as furniture films, works which open up new ways of thinking about cinematic reception by inviting a series of distracted glances rather than a focused and comprehensive gaze.

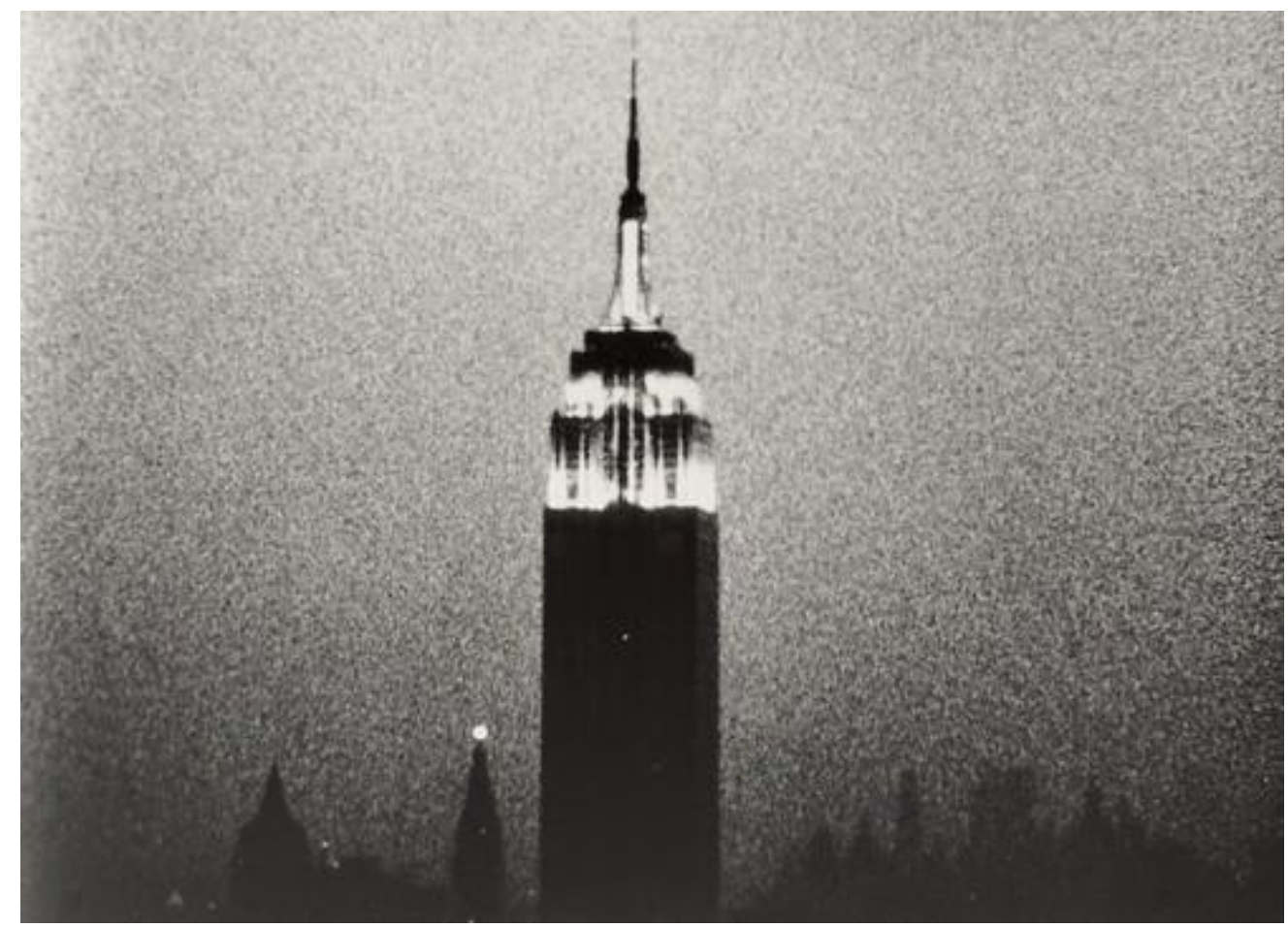

Figure 1: Andy Warhol, Empire (1964)

I would like to begin with a frequently quoted (and frequently misunderstood) remark from Francis Bacon's 1612 essay "Of Studies": "Some books are to be tasted, others to be swallowed, and some few to be chewed and digested; that is, some books are to be read only in parts; others to be read, but not curiously; and some few to be read wholly, and with diligence and attention." Many assume that the point of Bacon's metaphor is to lavish praise on those rare "great" books which are worthy of close analysis. In fact, he is drawing attention to the need for

\footnotetext{
${ }^{7}$ Francis Bacon, "Of Studies," in Francis Bacon: The Major Works, ed. Brian Vickers (Oxford: Oxford University Press, 1996), 439. As Vickers points out, "curiously" here means "with minute attention" (773).
} 
a diversity of approaches to reading texts. Not every book is designed to be "read wholly, and with diligence and attention"-for many texts, a casual and cursory engagement is more apropos. $^{8}$

Satie was intent on fighting for a similar kind of diversity in the consumption of musical compositions. While the normative stance vis-à-vis music in Satie's day often involved "chewing" and "digesting" (that is, attending a performance and becoming engrossed in each musical development), Satie was interested in composing music that could be merely tasted (or at most, swallowed). Here is how he described it: "[T]here's a need to create furniture music, that is to say, music that would be a part of the surrounding noises and that would take them into account. I see it as melodious, as masking the clatter of knives and forks without drowning it completely, without imposing itself. It would fill up the awkward silences that occasionally descend on guests. It would spare them the usual banalities. Moreover, it would neutralize the street noises that indiscreetly force themselves into the picture." ${ }^{9}$ For Satie, such furniture music would be pleasant, yet unobtrusive, serving as the backdrop for other experiences (conversing, eating, appreciating visual art, etc.). In the words of John Cage, "Furniture Music was Satie's most far-reaching discovery, the concept of a music to which one did not have to listen." 10

Among the Satie compositions that are generally considered furniture music are Forged Iron Tapestry (Tapisserie en fer forgé) (1917), Phonic Floor Tiles (Carrelage phonique) (1917), and Wall Hanging for a Prefectural Office (Tenture de cabinet préfectoral) (1923), as well a

\footnotetext{
${ }^{8}$ For this insight, I am indebted to Ann Blair's discussion of Bacon in "Reading Strategies for Coping with Information Overload," Journal of the History of Ideas 64, no. 1 (2003): 13-14.

${ }^{9}$ Quoted in Gillmor, 232.

${ }^{10}$ John Cage, Conversing with Cage, $2^{\text {nd }}$ ed., ed. Richard Kostelanetz (New York: Routledge, 2003), 51. While this chapter focuses on manifestations of the "furniture" aesthetic in music and film, analogues can be found in all the arts. For example, in painting the most prominent advocate of this approach is Henri Matisse, who asserted, "What I dream of is an art without any disquieting or preoccupying subject, which would be...something analogous to a good armchair." Quoted in Roger Shattuck, The Banquet Years: The Origins of the Avant-Garde in France, 1885 to World War I, rev. ed. (New York: Vintage, 1968), 169.
} 
piece which easily has one of the strangest titles in the history of music: Fanfare for Waking Up the Big Fat King of the Monkeys (Who Always Sleeps with One Eye Open) (Sonnerie pour réveiller le bon gros roi des singes [lequel ne dort toujours que d'un oeil]) (1921). However, Satie's only public performance of furniture music took place during the intermission of a play (written by his friend Max Jacob) at the Galerie Barbazanges in Paris on March 8, 1920. Satie arranged for a small band to continually play repeated figures from Camille Saint-Saëns's Danse macabre and Ambroise Thomas's Mignon. He had hoped that the music would fade into the background while the audience conversed and enjoyed the picture exhibition in the theater hall. Contrary to Satie's explicit instructions, however, audience members found themselves engrossed in the music, listening to it carefully and deliberately. An aggravated Satie began to scream, "Go on talking! Walk about! Don’t listen!"11

Even though Satie only used the label furniture music for a handful of his works, the appellation seems applicable for a substantial swath of his oeuvre. For example, Satie's composition for René Clair's film Entr'acte (1924) is inconspicuous and repetitive, and its various speeds and moods serve to complement the Dadaist spectacles that fill the screen. ${ }^{12}$ And even though Satie did not coin the term furniture music until 1917, it seems clear that the idea was already in its formative stages in 1893 when he composed Vexations. The piece is subtle and brooding, and its unyielding repetitions begin to create a vacuum of auditory stimuli, a numbing

\footnotetext{
${ }^{11}$ Quoted in Gillmor, 233. For more on this incident, see the excerpt from Arnold Schoenberg's Harmonielehre (1911) in Modernism and Music: An Anthology of Sources, ed. Daniel Albright (Chicago: University of Chicago Press, 2004), 66-70, and Joseph Lanza, Elevator Music: A Surreal History of Muzak ®, Easy-Listening, and Other Moodsong ${ }^{\circledR}:$ Revised and Expanded Edition (Ann Arbor: University of Michigan Press, 2004), 14-21.

${ }^{12}$ For more on this composition, see Douglas W. Gallez, "Satie's Entr'acte: A Model of Film Music," Cinema Journal 16, no. 1 (1976): 36-50.
} 
sameness that forces one to seek stimulation elsewhere (even if only through daydreaming —or in extreme cases, hallucinating). Vexations is furniture music avant la lettre. ${ }^{13}$

Andy Warhol shared Satie's interest in the furniture aesthetic. However, this crucial component of Warhol's vision has received remarkably little scholarly attention. Many discuss films like Sleep and Empire as if it were a foregone conclusion that they must be watched from beginning to end in reverent silence. Consequently, boredom has come to seen as the dominant theme of Warhol's stillies. To provide just one example, consider the comments made by A.R. Warwick in a recent issue of Artwrit. Warwick sees it as "a simple reality" that films like Empire and Sleep are "boring": "These are not films to be watched, but endured. [...] The cultural cachet of watching [them] comes from one's ability to sit through the entire screening, to endure the inevitable tedium of watching a virtually unchanging image for hours at a time. [...] Warhol's audiences either fled or stayed, either struggling to remain engaged or succumbing to the tedium of his films that offer no conclusions, only experiences." ${ }^{\text {14 }}$ Since this is a fairly common way of describing Warhol's stillies, it is hardly surprising that many have dismissed these films without feeling the need to see them. After all, why would a filmmaker deliberately set out to bore an audience? And why would anyone knowingly attend a boring film? It is almost as if, in addition to exploring the theme of torture in films like Vinyl (1965), Warhol wanted to literally torture his audience, as well.

However, evidence suggests that Warhol had no desire to bore (much less torture) those who attended his films. His stillies had a very different raison d'être. In a 1963 interview, Warhol described the then-untitled Sleep this way: “[I]t's a movie where you can come in at any

\footnotetext{
${ }^{13}$ It is not uncommon to see Vexations conceptualized as a kind of proto-furniture-music. In fact, some writers (such as Alan Gillmor) go so far as to suggest that all of Satie's compositions could be called furniture music. See Gillmor, 232.

${ }^{14}$ A.R. Warwick, "Spending Time/Wasting Time: In Praise of Boredom and Confusion (Part I)," Artwrit 7 (2011): www.artwrit.com/article/spending-time-wasting-time/.
} 
time. And you can walk around and dance and sing. [... It just starts, you know, like when people call up and say 'What time does the movie start?' you can just say 'Any time.",15 (One sees here a precursor to many of the compositions of John Cage: "The early works have beginnings, middles, and endings. The later ones do not. They begin anywhere, last any length of time."16) A few years later, Warhol emphasized that audience dynamics were more important to him as a filmmaker than what was on the screen: "My first films using the stationary objects were also made to help the audiences get more acquainted with themselves. [...] You could do more things watching my movies than with other kinds of movies: you could eat and drink and smoke and cough and look away and then look back and they'd still be there." ${ }^{17}$ And in 1975, Warhol was asked, "Did you try to make boredom chic with some of your early movies like Empire?" to which he responded, "No. What I was trying to do is make comedy in the audience. People always have a better time, have more fun together than watching what is on the screen."18 In other words, Warhol advocated a distracted, fragmentary, and unfocused mode of spectatorship. When Paul Arthur laments the fact that decades after the release of Warhol's films "the audience still cannot sit still for them," ${ }^{19}$ he fails to answer the critical question: Why should they? One can imagine Warhol seeing spectators silently immersing themselves in his early films and reacting in much the same way that Satie reacted to the audience at the Galerie Barbazanges (sans the exclamation marks, of course): "Go on talking. Walk about. Don't watch."

This represents a radical break from traditional modes of cinematic spectatorship. As Noël Burch has pointed out, ever since the days of early silent cinema, the dominant logic of the

\footnotetext{
${ }^{15}$ Warhol, I'll Be Your Mirror, 41, 44.

${ }^{16}$ John Cage, Silence: Lectures and Writings by John Cage (Middleton, CT: Wesleyan University Press, 1973$), 31$.

${ }^{17}$ Warhol, I'll Be Your Mirror, 92.

${ }^{18}$ Ibid., 225.

${ }^{19}$ Paul Arthur, "Resighting the Warhol Catechism," in Andy Warhol: Film Factory, ed. Michael O'Pray (London: British Film Institute, 1989), 148.
} 
cinema has been that of the "motionless voyage"-in other words, the on-screen movements offer a kind of journey, even though the viewer does not leave his seat. ${ }^{20}$ As Burch rightly notes, however, there are a "few avant-garde films that reject these conditions." ${ }^{21}$ While he does not specify what films he has in mind, one immediately thinks of Warhol's stillies, which turn the logic of the motionless voyage on its head. With works like Sleep and Empire, it is now the film that is motionless and the spectator who is ambulatory. And Warhol's ideal audience does more than simply move about - they sing, dance, smoke, and converse. In most cinematic venues, speaking during a film (not to mention singing and dancing) is seen as rude and classless, and is often met with exasperated hushes. For example, in his 1922 book The Art of the Moving Picture, the poet Vachel Lindsay advocates talking during films, but he admits that this approach can lead to disastrous results. Specifically, he recounts one occasion in which a discussion he had with a friend during a movie deeply offended two women sitting in front of them, so much so that they stormed out of the theater, with one being reduced to tears. Consequently, Lindsay recommends proceeding with caution: "[I]n our present stage of civilization, sit on the front seat, where no one can hear your whisperings but Mary Pickford on the screen. She is but a shadow there, and will not mind." 22 Of course, Lindsay is writing before the sound era, so there is little danger of missing important plot points through occasional chatter. And many of Warhol's early films eschew dialogue for precisely the same reason: the silence enables spectators to "do more things."

\footnotetext{
${ }^{20}$ See Noël Burch, Life to those Shadows, trans. and ed. Ben Brewster (London: British Film Institute, 1990), especially the chapter entitled "The Motionless Voyage: Constitution of the Ubiquitous Subject," 202-233. For more on Burch's theory of cinema (and its relevance in understanding other visual media, such as comic strips), see "The Motionless Voyage of Little Nemo," the second chapter of Scott Bukatman's The Poetics of Slumberland: Animated Spirits and the Animating Spirit (Berkeley: University of California Press, 2012), 77-105.

${ }^{21}$ Burch, 230.

${ }^{22}$ Vachel Lindsay, The Art of the Moving Picture (Kessinger Publishing, 2007), 9. For a more thorough exploration of the phenomenon of talking during movies, see Janet Staiger, Perverse Spectators: The Practices of Film Reception (New York: New York University Press, 2000), 44-51.
} 
In fact, one of the primary functions of Warhol's stillies (and by extension, much of static cinema) is to direct the viewer's attention away from the screen. Warhol's early films are meant to be looked at, but not seen. A failure to realize this has, I believe, prevented some from seeing the value of Warhol's cinema. In some cases, this has manifested itself as outright hostility. For instance, Jonas Mekas recalls the outrage that accompanied the premiere of Empire: "Ten minutes after the film started, a crowd of thirty or forty people stormed out of the theater into the lobby, surrounded the box office, Bob Brown, and myself, and threatened to beat us up and destroy the theater unless their money was returned. 'This is not entertainment! This movie doesn't move!' shouted the mob." ${ }^{23}$ And even sophisticated spectators have often diminished Warhol's stillies due to a failure to understand the furniture aesthetic. No less an avant-garde luminary than Tony Conrad has remarked, "I have never been able to cure myself of suspicions that Andy Warhol's static films [...] are incurably opportunistic and basically devoid of the intrinsic interest or freshness that I feel to be the real challenge of static work. ${ }^{24}$ However, there is a sense in which Warhol's early films are not supposed to be interesting in and of themselves - what is interesting is the cinematic experience that they engender (as well as their conceptual originality). Warhol films things which are emphatically not intrinsically interesting - a building, a haircut, an empty chair (the latter is all that can be seen for several minutes in the Warhol film Paul Swan [1965]). But precisely for this reason, the cinematic image becomes just one of many objects available for visual consumption, and it is eventually casually

${ }^{23}$ Jonas Mekas, The Walden Book, $2^{\text {nd }}$ English ed., eds. Pip Chodorov and Christian Lebrat (Éditions Paris Expérimental, 2009), 59. The premiere of Sleep was less dramatic: only nine people were in attendance, and two of them left during the first hour. See Warhol, I'll Be Your Mirror, 21.

${ }^{24}$ Quoted in P. Adams Sitney, "Structural Film," in Film Culture Reader, ed. P. Adams Sitney (New York: Praeger, 1970), 343. 
and distractedly noticed the way one might notice the Empire State Building itself_-or a couch. ${ }^{25}$ Since, as Rudolf Arnheim has pointed out, "Motion is the strongest visual appeal to attention"26 (a fact well known to anyone who owns a cat and a laser pointer), static films often encourage viewers to direct their attention elsewhere. And this is generally what Warhol's audiences did. Consider Stephen Koch's description of the early screenings of Sleep: "People would chat during the screening, leave for a hamburger and return, greet friends and talk over old times."27 To call a film like Sleep boring or "devoid of [...] intrinsic interest," then, is, in a sense, to miss the point. The film is only as boring as the audience who watches it. Warhol draws our attention to the manifold components of the cinematic experience (eating, conversing, moving in and out of the theatrical space, etc.) that are so often overlooked in film theory. As Koch goes on to say, "Even if one only glances at the image from time to time, it plunges one into a cinematic profundity; in a single stroke, that image effects a complete transformation of all the temporal modes ordinarily associated with looking at a movie." 28

This is why Amy Taubin has claimed that the "message" of Warhol's early films is "My time is not your time." 29 But one should recognize the full import of this suggestion. The alternate temporality that Warhol creates is not merely the consequence of his use of slight slow motion ( 24 frames per second slowed down to 16 frames per second) - it is also the result of the fact that his stillies do not monopolize the audience's time, but free them to use their time however they see fit. Recall that Warhol insisted that films like Sleep do not start at a precise,

\footnotetext{
${ }^{25}$ In fact, Warhol made a film entitled Couch in 1964. While it could certainly be conceptualized as a furniture film (in more ways than one), its graphic portrayal of a variety of sexual encounters on a couch in the Factory offers more on-screen movement than most of Warhol's early films.

${ }^{26}$ Rudolf Arnheim, Art and Visual Perception: A Psychology of the Creative Eye: The New Version (Berkeley: University of California Press, 2004), 372.

${ }^{27}$ Stephen Koch, Stargazer: The Life, World and Films of Andy Warhol (New York: Marion Boyars Publishers, 1991), 39.

${ }^{28}$ Ibid., 39.

${ }^{29}$ Amy Taubin, “****," in Who Is Andy Warhol?, eds. Colin MacCabe, Mark Francis, and Peter Wollen (London: British Film Institute, 1997), 27.
} 
predetermined time, but simply start "any time," whenever a spectator feels like showing up. As Vivienne Dick points out, "In one instant Warhol makes us aware that our time and the time on the screen is different, that we have control over how we are seeing - we can let ourselves be absorbed in into a meditative state or we can withdraw. The film will go on nevertheless in its own sweet time." ${ }^{30}$ This open-ended temporality is a clear precursor to the video installations that would come to prominence in the 1970s. (In fact, J. Hoberman has claimed that Sleep and Empire "might be considered the original video installations." ${ }^{31}$ ) Warhol did, in fact, venture into video art on two occasions. One is his film Outer and Inner Space (1965), a film/video hybrid that displays four images of Edie Sedgwick rambling (often incoherently) about boredom, bullshit, and blowfish. The other work (less well known) is Water (1971) (it is sometimes called Water Piece for Ono, since the videotape was produced for Yoko Ono's "This is Not Here" exhibition in Syracuse, New York). The video is simply a 32-minute fixed shot of the Factory watercooler, with sounds of chatting and gossip in the background. Not only is Water a furniture film, but it calls attention to its status as a furniture film. A watercooler is a quintessential site of sociality, a locus of snacking, drinking, chatting, joking, and so on. As such, it is precisely the kind of object that Warhol's stillies yearn to be. By offering spectators nothing but a watercooler, Warhol is going out of his way to emphasize that it is the interactions of the audience members - not the film itself - that is of central importance. Warhol rarely seemed particularly interested in the content of his early films; instead, he claimed, "I'm interested in audience reactions to my films." 32

\footnotetext{
${ }^{30}$ Vivienne Dick, “Warhol: Won't Wrinkle Ever: A Film-maker's View,” in O’Pray, 156.

31 J. Hoberman, "Nobody's Land: Inside Outer and Inner Space," in From Stills to Motion and Back Again: Texts on Andy Warhol's Screen Tests and Outer and Inner Space (Vancouver: Presentation House Gallery, 2003 ), 22.

${ }^{32}$ Warhol, I'll Be Your Mirror, 92. Italics added. For more on Water, see Callie Angell, "Andy Warhol: Outer and Inner Space," in From Stills to Motion and Back Again, 16. Malcolm Le Grice is one of the few writers who has acknowledged the overriding importance of audience reaction in Warhol's aesthetic. In Le Grice's assessment, "Warhol has always been more concerned with impact than form-formal innovation being a by-product of impact.
} 
True to the contours of video installation art, Warhol wanted spectators to begin and end their viewing experiences whenever they desired. This applied not only to an actual video installation like Water, but even to films like Sleep and Empire. Of course, this has always technically been an option, but before Warhol, rarely (if ever) had a director encouraged this kind of sporadic and incomplete reception. As Koch puts it, "Warhol is perhaps the first filmmaker ever to concede that his audience might not wish to see every minute of his work."33 Almost fifty years after Warhol's early films were released, many are still struggling to come to terms with this mode of cinematic spectatorship. It is difficult to imagine arriving late to a film without feeling the need to ask someone, "What did I miss?" It is even more difficult to imagine walking out in the middle of a film that one actually likes. (Personally, I feel incapable of walking out of any film that I have started, even when it is one I despise-it always feels like some kind of unforgivable coitus interruptus.) Even if dominant models of spectatorship still demand complete viewings, the more fractional Warholian approach has become fairly commonplace within the avant-garde. For example, in the program notes for his film Diaries, Notes, and Sketches (a.k.a. Walden) (1969), Jonas Mekas writes (in the third-person), “[T]he Author won't mind (he is almost encouraging it) if the Viewer will choose to watch only certain parts of the work (film), according to the time available to him, according to his preferences, or any other good reason."34 Takahiko Iimura makes a similar assertion regarding his textual film 1 to 60 Seconds (1973): "[I]t is fine if you go out and come back, or never come back, or stay

He is essentially a neo-Dadaist attempting to provoke response." See Malcolm Le Grice, Abstract Film and Beyond (London: Studio Vista, 1976), 93.

${ }^{33}$ Koch, 39.

${ }^{34}$ Quoted in David E. James, "Film Diary/Diary Film: Practice and Product in Walden," in To Free the Cinema: Jonas Mekas and the New York Underground, ed. David E. James (Princeton: Princeton University Press, 1992), 170. Italics in original. 
outside watching without seeing what's going on."35 Or for a more recent example, consider Abbas Kiarostami's comments on his static film Five: Dedicated to Ozu (2003), an experimental documentary consisting of five prolonged shots of natural settings: "You know how annoyed some directors get on finding out that someone has fallen asleep while watching their film. I will not be annoyed at all. I can confidently say that you would not miss anything if you had a short nap. [...] I declare that you can nap during this film.",36

Like Mekas, Iimura, and Kiarostami after him, Warhol was an advocate of fragmentary forms of spectatorship. This became especially evident in 1964 at the second annual New York Film Festival. Here Warhol produced an installation which I will call (for ease of expression) the Quartet Installation. Four of Warhol's stillies (Sleep, Haircut [No. 2] [1963], Kiss [1964], and Eat [1964]) were simultaneously shown on Fairchild 400 projectors (which permitted the screening of $8 \mathrm{~mm}$ films on small TV-like screens). Warhol simply borrowed three minutes of footage from each film and put them on a continuous loop, resulting in films that were (according to a press release) "endless." ${ }^{37}$ No longer was it necessary (or even possible) for one to see a film from beginning to end. A film could be dropped in on distractedly for a few moments before moving on to a new film. (And this is precisely the point of the split screen that

\footnotetext{
${ }^{35}$ Scott MacDonald, “An Interview with Taka Iimura," Journal of the University Film Association 33, no. 4 (1981): 38. Interestingly, Iimura goes on to compare 1 to 60 Seconds to Warhol's Empire.

${ }^{36}$ The quotation comes from Kiarostami's Around Five (2005), a documentary on the making of Five.

${ }^{37}$ Haircut (No. 2) displays a visit to the barber, Kiss is comprised of a series of close-ups of couples kissing, and Eat shows the artist Robert Indiana munching on a mushroom. While these three films are, in their original versions, each under an hour in length (unlike the more prolonged Empire and Sleep), all of these works feature no sound, no narrative or teleological development, and very little movement (and the minimal movement that is seen is slowed down to 16 frames per second). In other words, these are all furniture films, works which invite a partial, momentary, and distracted glance.

The multiplicity of screens used in the Quartet Installation would eventually be revisited in Warhol's EPI (Exploding Plastic Inevitable productions) (1966-1967), which featured several film and slide projectors running simultaneously, along with numerous records playing, lights flashing, and a barrage of other visual and auditory stimuli. While the EPI sessions themselves were certainly immersive, the Warhol film clips that were used for these productions were called EPI Background reels, a title which further hints at Warhol's interest in the furniture aesthetic. See Branden W. Joseph, "'My Mind Split Open': Andy Warhol's Exploding Plastic Inevitable," Grey Room 8 (2002): 81-107. See also Angell, Andy Warhol Screen Tests, 264-287.
} 
Warhol would later use in Chelsea Girls [1966]: "I put two things on the screen [...] so you could look at one picture if you were bored with the other." ${ }^{38}$ ) This practice is in some ways an institutionalization of the Surrealists' mischievous habit of theater-hopping, in which they would enter a theater, begin watching a movie in media res, only to leave abruptly at the first hint of boredom to intrude on another film, and so on. But Warhol's Quartet Installation also has deep affinities with a common form of reception associated with the medium of television: channel surfing. Here, one derives pleasure not from immersing oneself in a particular program, but rather, from distractedly sampling from numerous programs (or to use Bacon's term, "tasting" several shows). ${ }^{39}$

Given Warhol's love of television, it should come as no surprise that he sought to create films and installations with televisual properties. As Warhol put it, "[I]n the late 50s I started an affair with my television which has continued to the present, when I play around in my bedroom with as many as four at a time." ${ }^{40}$ (Notice how Warhol's own viewing habits serve as the basis for his Quartet Installation, in which spectators are given precisely four film loops to perceptually "play around" with.) And Warhol said, "I've always believed in television,"41 a devotional statement of almost religious fervor. Not only did the Quartet Installation enable the spectator to "jump" from one screen to another, but the "endless" duration of Warhol's film loops also echoes the interminability of TV programming. As Greg Uhlin points out in his essay on Warhol and television, "Televisual time can be first characterized as the experience of

\footnotetext{
${ }^{38}$ Warhol, I'll Be Your Mirror, 166.

${ }^{39}$ This kind of spectatorial sampling has become more widespread than ever in the modern era-think, for example, of the way computer users often navigate between a multiplicity of websites, programs, and interfaces simultaneously.

${ }^{40}$ Andy Warhol, The Philosophy of Andy Warhol: From A to B and Back Again (New York: Harvest/HBJ, 1975), 26.

${ }^{41}$ Warhol, I'll Be Your Mirror, 187. Italics in original.
} 
infinitude," adding, "[T]he extended duration of Warhol's early films indicates a desire for the

process of recording to be continuous and unending." 42

What are the implications of Warhol's intermedia experiment? In part, it serves to complicate facile taxonomies that have long emphasized the supposed gulf between cinema and television. The most famous theorization of the distinctions between film and TV was written in 1964 - the same year that Warhol created his Quartet Installation. I am speaking, of course, of Marshall McLuhan's book Understanding Media. McLuhan asserts that film is a "hot" medium (one that is "high definition," or filled with information), while TV is a "cool" medium (one that is "low definition," leaving much to be "filled in or completed by the audience." found McLuhan's categories to be particularly helpful. He seems to suggest that the limited information provided by TV screens (which traditionally offered a mere 480 scan lines) requires the viewer to complete the image in a way that is not necessary in cinema. It is difficult to take this distinction seriously, since as Noël Carroll points out in his perceptive rebuttal of McLuhan, “We don't do anything to 'fill in' or to 'complete' the TV image; we just look.",44

Contra McLuhan, many media theorists argue that while cinema invites a gaze, television merely invites a glance. ${ }^{45}$ Clearly, such distinctions are becoming increasingly problematic in our

\footnotetext{
${ }^{42}$ Graig Uhlin, "TV, Time, and the Films of Andy Warhol," Cinema Journal 49, no. 3 (2010): 6. Seemingly endless films were a constant fascination for Warhol. **** (Four Stars) (1967) (shown only once) is twenty-five hours in length, and many of Warhol's unrealized projects sought to push cinematic duration to even more extreme levels. For example, he considered making a thirty-day-long stillie called Warhol Bible, as well as a film that would last six months entitled Building.

${ }^{43}$ Marshall McLuhan, Understanding Media: The Extensions of Man (Cambridge: MIT Press, 1994), 22.

${ }^{44}$ Noël Carroll, "TV and Film: A Philosophical Perspective," Journal of Aesthetic Education 35, no. 1 (2001): 28. While many media theorists interpret McLuhan's hot/cool distinction more charitably, seeing it as a commentary on the immersiveness of film (and the non-immersiveness of television), Carroll's view is that McLuhan's "coolness" claim is simply based on TV's limited number of scan lines. Carroll is correct. McLuhan was insistent that television is immersive, a point most clearly spelled out in The Medium is the Massage: "Television demands participation and involvement in depth of the whole being. It will not work as a background. It engages you." See Marshall McLuhan and Quentin Fiore, The Medium is the Massage (Corte Madera, CA: Gingko Press, 2001), 125. McLuhan's assertion that television "will not work as a background" strikes me as both bizarre and baseless.

${ }^{45}$ See, for example, John Ellis, Visible Fictions: Cinema, Television, Video, rev. ed. (New York: Routledge, 1992), 127-144.
} 
"post-medium" age, ${ }^{46}$ in which some spectators gaze at large, looming high-definition TV screens, while others distractedly glance at movies on computer screens and iPods. Still, there is a kernel of truth in such theorizations: TV viewing is, in general, less immersive than film viewing (which suggests a greater sense of agency on the part of the TV viewer). I find Steven Shaviro's formulation (in his reading of McLuhan) especially persuasive: "[Television] is a part of our everyday experience; it quietly insinuates itself into our personal lives. We get so deeply involved with television precisely because it doesn't imperiously demand our attention. It is simply there, day in and day out, like wallpaper or a piece of furniture." ${ }^{47}$ With his Quartet Installation, Warhol sought to "cool" down the medium of film so that it would be less intrusive and more participatory. His early films and installations challenged deeply held assumptions about cinematic spectatorship by appropriating the furniture aesthetic so closely associated with television. While many spectators (such as the Surrealists) had approached film this way before, Warhol was creating some of the first films that demanded this kind of reception. ${ }^{48}$

As the Quartet Installation suggests, one of the most pivotal components in the furniture aesthetic is radical repetition. When a composition or a film takes some unexpected turn, our attention is piqued-we become interested in what the next development will be. But when a musical phrase or cinematic shot is repeated again and again, ad infinitum, the artwork fades into the background and our attention becomes focused elsewhere. In visual art, this repetition often leads to a degradation of signification. This was Warhol's goal: “[T]he more you look at the

\footnotetext{
${ }^{46}$ I borrow the term post-medium from Rosalind Krauss's book A Voyage on the North Sea: Art in the Post-Medium Condition (London: Thames and Hudson, 2000).

${ }^{47}$ Steven Shaviro, "The Life, After Death, of Postmodern Emotions," Criticism 46, no. 1 (2004): 128. Italics added.

${ }^{48}$ Throughout his career, Warhol undermined simplistic (and arbitrary) dividing lines between media through a process of blending and appropriation. As Uhlin astutely notes, "Warhol's artwork [...] frequently interrogated the properties of one medium by use of another-photography as painting, film as portraiture, and tape recording as novel." See Uhlin, 3. Warhol's Quartet Installation adds another media hybrid to this list: film as television.
} 
same exact thing, the more the meaning goes away, and the better and emptier you feel."49 Whether it is serial repetition (painting after painting of the Campbell's soup can) or repetition within a single work (100 Coke Bottles [1962], 100 Dollar Bills [1962], 100 Soup Cans [1962]), Warhol obsessively repeats images until they are drained of all meaning, producing a kind of perceptual catatonia. It is reminiscent of Gertrude Stein's famous "a rose is a rose is a rose is a rose, ${ }^{, 50}$ in which the word rose, through repetition, loses its semantic content and becomes a hollow phoneme. Warhol's furniture films operate on the same principle. Identical shots are repeated again and again in Sleep, and while no shot is repeated in Empire, a quick glance at the filmstrip reveals frame after frame with essentially the same content. ${ }^{51}$ Ron Padgett's poem "Sonnet: Homage to Andy Warhol" (which was inspired by Sleep) brilliantly captures the centrality of repetition in Warhol:

\author{
Z Z Z Z Z Z Z Z Z Z Z Z Z Z Z Z Z Z Z Z Z Z Z Z Z Z Z Z Z Z Z Z Z Z Z \\ Z Z Z Z Z Z Z Z Z Z Z Z Z Z Z Z Z Z Z Z Z Z Z Z Z Z Z Z Z Z Z Z Z Z Z \\ Z Z Z Z Z Z Z Z Z Z Z Z Z Z Z Z Z Z Z Z Z Z Z Z Z Z Z Z Z Z Z Z Z Z Z \\ Z Z Z Z Z Z Z Z Z Z Z Z Z Z Z Z Z Z Z Z Z Z Z Z Z Z Z Z Z Z Z Z Z Z Z \\ Z Z Z Z Z Z Z Z Z Z Z Z Z Z Z Z Z Z Z Z Z Z Z Z Z Z Z Z Z Z Z Z Z Z Z \\ Z Z Z Z Z Z Z Z Z Z Z Z Z Z Z Z Z Z Z Z Z Z Z Z Z Z Z Z Z Z Z Z Z Z Z \\ Z Z Z Z Z Z Z Z Z Z Z Z Z Z Z Z Z Z Z Z Z Z Z Z Z Z Z Z Z Z Z Z Z Z Z \\ Z Z Z Z Z Z Z Z Z Z Z Z Z Z Z Z Z Z Z Z Z Z Z Z Z Z Z Z Z Z Z Z Z Z Z
}

Z Z Z Z Z Z Z Z Z Z Z Z Z Z Z Z Z Z Z Z Z Z Z Z Z Z Z Z Z Z Z Z Z Z Z

\footnotetext{
${ }^{49}$ Warhol and Hackett, Popism, 64.

50 See Gertrude Stein, Gertrude Stein: Selections, ed. Joan Retallack (Berkeley: University of California Press, 2008), 186.

${ }^{51}$ The Empire State Building's lights occasionally turn on and off, and Warhol and Jonas Mekas can be briefly seen changing reels. Apart from such minor changes, however, the film repeats the same photogram obsessively. For more on Warhol's use of repetition in Sleep, see Joseph, “Andy Warhol's Sleep: The Play of Repetition.”
} 
Z Z Z Z Z Z Z Z Z Z Z Z Z Z Z Z Z Z Z Z Z Z Z Z Z Z Z Z Z Z Z Z Z Z Z

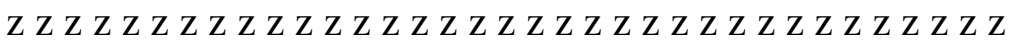

Z Z Z Z Z Z Z Z Z Z Z Z Z Z Z Z Z Z Z Z Z Z Z Z Z Z Z Z Z Z Z Z Z Z Z

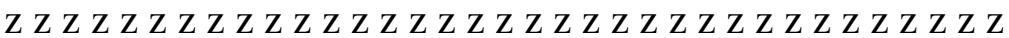

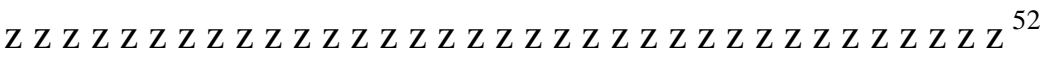

Of course, on one level, "Sonnet: Homage to Andy Warhol" simply offers a comically literal onomatopoeic evocation of the sound of snoring. But beyond this, Padgett's poem subverts conventional modes of reading literature (in much the same way that Warhol's films subvert conventional modes of cinematic spectatorship). How does one "read" this poem, exactly? Should one carefully consider each line, one at a time, or simply glance at the poem holistically? Is the sight of the repeated $z$ 's what is important here (a sight which, when focused on for several seconds, inevitably makes the reader drowsy)? Or is the sound crucial, as well? (In other words, should the poem be "read" aloud? And what might such a reading sound like?) However these questions are answered, Padgett's use of extreme repetition creates a strikingly Warholian aesthetic. When one looks at the $z$ 's for more than a moment, they lose their status as semantic or graphemic indicators. Like Warhol's incessant shots of Giorno's sleeping body, Padgett's repetition results in a deflection of the attentive eye: one can glance at the work momentarily, but giving it focused and thorough consideration is exceedingly difficult.

Many critics have been intent on finding a "deeper" meaning in Warhol's repetitions, seeing his art and cinema as critiques of capitalism, for example, or commentaries on the emotional blankness of the postmodern era. However, Shaviro rightly insists that one should resist the temptation to search for a "message" or pre-packaged "meaning" in Warhol's

${ }^{52}$ See Film Culture 32 (1964): 13. Callie Angell mistakenly describes the poem as "thirty-five lines of z's"; however, true to the form of the sonnet, the poem has only fourteen lines, each with thirty-five $z$ 's. See Callie Angell, Andy Warhol Screen Tests, 150. 
repetitions. In his book The Cinematic Body, Shaviro astutely notes, “[Warhol's] surfaces are impenetrable precisely because there is nothing beneath them, no depth into which one could penetrate. $[\ldots][\mathrm{A}] 11$ we see is a mask, but there is nothing behind the mask." ${ }^{, 53}$ And, of course, Warhol himself consistently frustrated any attempts to tease meaning out of his work:

"What is Pop Art trying to say?"

"I don’t know."

"What do your rows of Campbell soup cans signify?"

"They're things I had when I was a child."

"What does Coca Cola mean to you?"

"Pop." 54

Soup cans, coke bottles, skyscrapers - none of these things "means" anything. They simply form the backdrop of our everyday experiences, and Warhol's art draws our attention to the ubiquity of these objects (and their representations). One is reminded of Samuel Beckett's response to a query about the meaning of his play What Where: "I don't know what it means. Don't ask me what it means. It's an object." 55 Warhol manufactures objects which are deliberately empty, devoid of meaning. As Michel Foucault puts it, "A day will come when, by means of similitude relayed indefinitely along the length of a series, the image itself, along with the name it bears, will lose its identity. Campbell, Campbell, Campbell, Campbell." ${ }^{, 56}$

Warhol's fascination with repetition extends well beyond his paintings and films, however-it is also one of the most striking features of his writing. His notorious $a$ : A Novel (1968) consists almost entirely of transcriptions of cassette tapes featuring the discursive,

\footnotetext{
${ }^{53}$ Steven Shaviro, The Cinematic Body (Minneapolis: University of Minnesota Press, 1993), 205.

${ }^{54}$ Warhol, I'll Be Your Mirror, 5.

${ }^{55}$ Samuel Beckett, Conversations with and about Beckett, ed. Mel Gusow (New York: Grove Press, 1996), 42.

${ }^{56}$ Michel Foucault, This Is Not a Pipe, trans. and ed. James Harkness (Berkeley: University of California Press, 1983), 54.
} 
amphetamine-fueled tirades of Factory superstars. Critical treatments of $a$ generally focus on its status as an intermedia artifact, its Joycean stream-of-consciousness style, or its Cagean renunciation of authorial control (the ubiquitous errors and typos committed by the novel's four typists are retained, reminding one of the ink blots of Warhol's silkscreens, or the sprocket holes and white flares that often punctuate his films). But what is often overlooked in $a$ is its unrelenting repetitiveness. Occasionally, this takes the form of the repetition of a single grapheme:

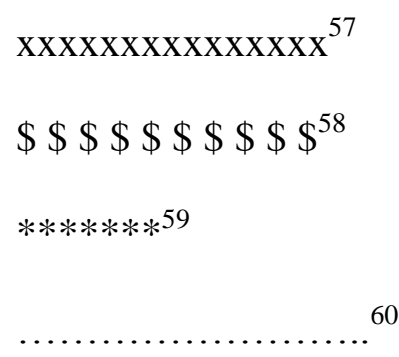

Mmmmmmmm mmmmm mmmmmm ${ }^{61}$

O0000000000000000000000-00000000000000000000000Oooooooooooooooooooooooo ${ }^{62}$

On other occasions onomatopoeic words are repeated - or even entire sentences:

I love amphetamine I love amphetamine I love a mphetamine ${ }^{63}$

Oh oh oh oh oh oh oh oh oh oh oh $\operatorname{ohh}^{64}$

plop plop plop plop plop plop plop ${ }^{65}$

shuffle shuffle shuffle shuffle shuffle shuffle ${ }^{66}$

\footnotetext{
${ }^{57}$ Andy Warhol, a: A Novel (New York: Grove Press, 1998), 17.

58 Ibid., 41.

${ }^{59}$ Ibid., 86.

${ }^{60}$ Ibid., 221.

${ }^{61}$ Ibid., 315.

${ }^{62}$ Ibid., 387.

${ }^{63}$ Ibid., 87.

${ }^{64}$ Ibid., 114.

${ }^{65}$ Ibid., 374.
} 
And in one case, the repetition results in a sequence that could easily be mistaken for a sequel to Padgett's "Sonnet: Homage to Andy Warhol":

SNORE / SNORE / SNORE / SNORE / SNORE / SNORE SNORE / SNORE / (Pr elude t o sn o ri ng) SNIFF / SNIFF / SNIFF / Sniff / Sniff ${ }^{67}$

The textual repetitions that permeate $a$-along with the absence of narrativity-discourage the reader from paying close attention to the text. To return to Bacon's formulation, one quickly realizes that Warhol intends $a$ to be tasted, not swallowed or digested. When reading the novel, I am often captivated, but at other times, the repetitive constructions prompt me to simply scan the text while letting my mind wander. Of course, such cognitive diversions are not uncommon when reading, but in most cases (for example, when one is reading a classic novel like The Great Gatsby), one feels the need to re-read passages that were not given careful attention in order to catch plot points or details that might be important. In a furniture novel like $a$, on the other hand, everything is deliberately irrelevant, as trivial and mundane as a can of soup or a building. There is no fear of missing something in $a$, for there is nothing there to miss.

In films like Sleep and Empire, there is also nothing to miss, since the incessant repetition of what is essentially the same photogram results in an unrelenting stasis. If a salient visual difference were introduced at some point in the film (if, for example, King Kong suddenly appeared and began climbing up the side of the building), the work would cease to be a furniture film, and would instead become immersive. But Warhol wanted as little action as possible. It is no wonder that Warhol preferred the term stillie to movie for his early films, since there is little or no movement in these works. This helps to explain why, in a 1969 interview, Warhol

\footnotetext{
${ }^{66}$ Ibid., 424.

${ }^{67}$ Ibid., 447.
} 
maintained, "We haven't made a movie yet." ${ }^{, 6}$ When he was asked what he had been doing, exactly, he simply responded, "Just photographing what happens." ${ }^{, 9}$ In other words, Warhol's furniture films are not only televisual, they are also photographic. Apart from the emulsion grain that reminds one of the movement of the projector, the film is largely indistinguishable from a photograph. (As Arthur Danto puts it, in his monograph on Warhol, "Two screens, one showing Empire, the other a still of Empire, look as much alike as Brillo Box looks like a box of Brillo!"70) A film like Empire mimics the immobility of a photograph, and indeed, one would be tempted to label it as such, if it were not infused with duration - the most pivotal distinction between film and photography. ${ }^{71}$

None of this is to suggest that a distracted viewing is the only "correct" way to view Warhol's early films. As Paul Arthur notes, “Depending on what we make of the image, we may leave the theatre, doze off, fantasise, yell at the screen, [or] treat it like a 'normal' movie experience. The list is not endless but it is distinctly Warholian."72 There is obviously nothing wrong with giving furniture art one's close and undivided attention. I sympathize with the audience at the Galerie Barbazanges who found Satie's furniture music too mesmerizing to ignore. I also sympathize with those rare cineastes who have sat alone and watched Empire in its entirety, overwhelmed by the originality and beauty of Warhol's monomaniacal vision. To a large extent, the distinction between furniture art and its antithesis (immersive art) is in the eye of the beholder, not an immanent part of the work itself. Some listeners have found themselves entranced by the minimalistic splendor of Satie's Vexations; others have put on a recording of a

\footnotetext{
${ }^{68}$ Warhol, I'll Be Your Mirror, 163. Italics in original.

${ }^{69}$ Ibid., 163. Italics added.

${ }^{70}$ Arthur C. Danto, Andy Warhol (New Haven: Yale University Press, 2009), 79.

71 As mentioned in Chapter 1, many film theorists have seen movement as the distinguishing feature of cinema; however, Empire makes this argument unsustainable. Jean Cocteau got it right. When he was asked to explain the difference between a photograph of a still object and a film of that same object, he responded that in the film "time courses through it." Quoted in David Campany, Photography and Cinema (London: Reaktion Books, 2008 ), 18.

${ }^{72}$ Arthur, 152. Italics added.
} 
more intricate composition (say, Wagner's Tristan und Isolde [1859]) to listen to distractedly while reading the newspaper, getting dressed, and washing the dishes. Some spectators have watched Warhol's Sleep with an alert and fascinated eye; others have watched a seemingly more demanding film (like Howard Hawks' The Big Sleep [1946]) while simultaneously eating dinner, going through mail, and tidying up the living room. (Of course, watching a film in a movie theater rather than at home makes a distracted viewing experience somewhat more difficult, but it does not preclude this option altogether-after all, it is hardly uncommon to see spectators in a theater whispering to neighbors, playing with their cell phones, and necking.) My goal is not to prescribe a certain mode of spectatorship, but merely to draw attention to a dimension of static films (and of cinema more broadly) that is often overlooked: the way viewers can derive pleasure from components of a cinematic experience that have little to do with the film itself.

But does this mean that boredom can be summarily dismissed as a component of Warhol's vision? Not necessarily. Warhol was fond of saying, "I like boring things"—although it should be noted that he was somewhat fickle on this point: on one occasion, he left a screening of Sleep after only a few minutes (much to the chagrin of his colleague Jonas Mekas), reasoning, “Sometimes I like to be bored, and sometimes I don't—it depends what kind of mood I'm in. Everyone knows how it is, some days you can sit and look out the window for hours and hours and some days you can't sit still for a single second." ${ }^{73}$ Warhol does seem to imply that he finds Sleep boring. But one must tread carefully here, resisting simplistic dichotomies (e.g. the stillies are either interesting or boring). Warhol's films are interesting precisely because they are boring. Or, to put it another way, the content of Warhol's films is boring, but this is what makes the

\footnotetext{
73 Andy Warhol and Pat Hackett, POPism: The Warhol Sixties (San Diego: Harvest/HBJ, 1990), 64. In Stephen Koch's version of the story, Mekas ties Warhol down with rope at the Sleep screening, only to find out later that he has escaped. This anecdote is likely apocryphal, however, since Warhol tells a similar story involving Mekas forcing someone else to see Sleep by tying him to a chair. See Koch, 35-36, and Warhol, Popism, 64.
} 
experience of watching them so potentially interesting. The viewer is no longer bound by the terms of the conventional spectatorial contract. As Michael Snow has argued, there is usually an implicit "social contract that a spectator makes in going to a cinema theatre. This, of course, comes from the theatre (plays, live performances), but the 'contract' is: Events which will have determined durations usually take place on the screen (stage) and I will sit here and experience these durations." 74 In fact, Lev Manovich has gone so far as to compare movie theaters to "large prisons," insofar as they demand "institutionalized immobility," forbidding audience members from leaving their seats or talking. ${ }^{75}$ Warhol offers a new contract: spectators are no longer tied to their seats with rope (either literally or metaphorically), but are free to look at the image as much or as little as they please, much the way they would a photograph or a painting. The duration of the film may be predetermined, but the duration of its viewing is indeterminate. Further, the silence of Warhol's stillies allows spectators to communicate freely without the fear of missing anything. They can discuss the static images on the screen, the accompanying rock music that Warhol often employed, or anything else that might be of interest. Warhol frees his audiences from the confines of the spectatorial contract.

Unfortunately, this aim is often entirely overlooked by those who reductively see Warhol's films as explorations of boredom. After all, no one would call the Empire State Building itself boring, nor is it likely that this term would be directed at a photograph of the same building. So why does a film of this structure suddenly create such outrage ${ }^{76}$ The hostility that

\footnotetext{
${ }^{74}$ Michael Snow, e-mail to author, October 21, 2011.

${ }^{75}$ Lev Manovich, The Language of New Media (Cambridge: MIT Press, 2001), 107. Manovich here follows the lead of Jean-Louis Baudry, who emphasizes the "[f]orced immobility" of cinema, comparing it to Plato's cave. See Jean-Louis Baudry, "The Apparatus," Camera Obscura 1 (1976): 104-126.

${ }^{76}$ Michael O'Pray makes a similar observation in his discussion of Empire: "While a painting of a mundane object had been perfectly acceptable since the impressionists of the nineteenth century (although it had at the time attracted similar objections), the idea of a film-maker filming an object over a lengthy period of time without any attempt at film construction or story or even drama was anaethema." See Michael O'Pray, Avant-Garde Film: Forms, Themes, and Passions (London: Wallflower Press, 2003), 86.
} 
many have expressed towards the very idea of films like Empire and Sleep is often inextricably connected with the assumption that these films are supposed to be watched in their entirety and with close concentration. But consider the incisive remarks of avant-garde filmmaker Barbara Rubin (who helped organize the first performances of what would later be called The Exploding Plastic Inevitable). After calling Empire “the most beautiful movie I've ever seen," Rubin added, "I'm waiting till we project it in the sky."77 The idea that the film could be projected in the sky rather than in a theater suggests that Rubin appreciated Warhol's furniture aesthetic. She realized that the beauty of the film could best be apprehended when viewed casually and at leisure, the way one views an actual work of architecture. And the fact that Warhol uses a work of architecture to encourage a form of distracted spectatorship is especially compelling in light of Walter Benjamin's remarks on architecture in his famous "Work of Art" essay: "Architecture has always offered the prototype of an artwork that is received in a state of distraction and through the collective." Benjamin adds that "the optical reception of architecture [...] takes the form of casual noticing rather than attentive observation"- precisely the form of reception that Warhol sought. ${ }^{78}$ When it is understood that a film like Empire is not (or at least, not only) a practical joke, but a furniture film that encourages a free and open-ended mode of visual consumption, the hostility directed at it tends to dissolve. ${ }^{79}$ I have witnessed this distinction in the classroom. When I have asked my students to watch just ten minutes or so of a static film from beginning to end in silence, the experience tends to be awkward and arduous. But when I have shown such films while conversing with students, telling jokes, sipping on beverages, and so on, everyone

\footnotetext{
${ }^{77}$ Quoted in Jonas Mekas, “Movie Journal,” The Village Voice (February 9, 1967): 29.

${ }^{78}$ See Benjamin, "The Work of Art in the Age of Its Technological Reproducibility" in Walter Benjamin: The Work of Art in the Age of Its Technological Reproducibility and Other Writings on Media, 40.

${ }^{79}$ By conceptualizing Warhol's stillies as furniture films, I do not wish to downplay their status as mischievous practical jokes. Recall that Warhol wanted his early films to engender "comedy in the audience." One can easily imagine the type of conversation that Warhol might have wanted to provoke: Q: "What could be more boring than watching a film of a static building?" A: "Watching a film of a static building shot in slow motion."
} 
suddenly finds themselves enjoying the screening. This is the kind of spectatorial shift that Warhol was interested in creating: "[T]hat had always fascinated me, the way people could sit by a window or a porch all day and look out and never be bored, but then if they went to a movie or a play, they suddenly objected to being bored. I always felt that a very slow film could be just as interesting as a porch-sit if you thought about it the same way." 80

This observation highlights another problem with seeing Warhol's films as explorations of boredom: the term is generally used as a pejorative. When we call something boring, we often mean that it is laborious, even painful. When Warhol says that he likes boring things, however, he is not confessing to being some kind of masochist-he is expressing a fondness for the quotidian, the inconspicuous, the uneventful. This is the kind of "boredom" that one encounters when sitting on one's porch, and it is a pleasant experience. Warhol is fascinated by those elements which recur ad infinitum in daily life, yet which are (or at least were) tacitly prohibited from being represented in art: soup cans, dollar signs, kitschy flowers, cartoon characters, wallpaper designs, consumer advertisements. And his films work in much the same way. Everything that is generally excised from cinematic representation becomes dominant in Warhol's vision. When seeing a James Bond film, for example, one expects only the exciting parts of Bond's life to be portrayed: shootouts, explosions, sexual liaisons. One can imagine what the audience reaction might be if - in the interest of realism - a film devoted a substantial amount of time to Bond sleeping, eating a meal, getting a haircut, and using the restroom. And yet, these uneventful events constitute the fabric of our existence. One is reminded here of E.M. Forster's insight in A Passage to India: "Most of life is so dull that there is nothing to be said about it, and the books and talk that would describe it as interesting are obliged to exaggerate, in

\footnotetext{
${ }^{80}$ Warhol and Hackett, 260.
} 
the hope of justifying their own existence." ${ }^{81}$ Warhol has little interest in exaggeration (and for that matter, little interest in justifying the existence of his art and films). He simply presents, without embellishment or commentary, the quotidian objects and routines that we usually seek to escape through art. ${ }^{82}$ This may be boring for some, but as Malcolm Le Grice emphasizes, Warholian boredom is "a functional boredom," 83 one which is deliberately employed to create a new kind of audience dynamic. The only reason that Warhol's stillies are likely to evoke a painful kind of boredom is if one attends a screening expecting a traditional motion picture and waits for something to happen. ${ }^{84}$ But if one realizes that one is watching an uneventful furniture film, the experience is quite different. As Frances Colpitt contends, it is often the case that when an audience becomes bored in the face of conceptual art (and Warhol is mentioned here as an example), "[t] he root of the problem is in the unpreparedness of the audience." 85

Susan Sontag's remarks on boredom in her 1965 essay "One Culture and the New Sensibility" are apposite here. For Sontag, boredom is a problematic - and imprecise-term, particularly when used in the context of avant-garde art. It is often used simply to express dissatisfaction with works which run counter to audience expectations. As Sontag puts it, "There

\footnotetext{
${ }^{81}$ E.M. Forster, A Passage to India (San Diego: Harvest, 1984), 146.

${ }^{82}$ Again, one sees a precursor to Warhol's aesthetic in the plays of Beckett, which often feature only the most uneventful and routine human actions. (Think of Act Without Words II [1956], for example, in which the two characters do nothing more than sleep, eat carrots, brush their teeth, pray, get dressed, etc.) Further, like Warhol, Beckett consistently manifested an interest in stasis. Theater, like film, is a medium that comes with expectations of movement, but Beckett's plays often feature none-and many of his characters are completely immobilized. In Happy Days (1960), the protagonist, Winnie, is buried in earth; in Play (1963), all three characters are trapped in urns; and Breath (1969) displays only a dimly lit stage littered with garbage for roughly thirty seconds. For an extended comparison of Warhol and Beckett that focuses on their abandonment of meaning, see Enoch Brater, "The Empty Can: Samuel Beckett and Andy Warhol," Journal of Modern Literature 3, no. 5 (1974): 1255-64. Peter Gidal also notes several affinities between these artists in his book Andy Warhol: Films and Paintings: The Factory Years (New York: Da Capo Press, 1971).

${ }^{83}$ Le Grice, 94.

${ }^{84}$ To say that nothing happens in Warhol's stillies should not be seen as an insult. As Warhol himself writes, with great pride, "When I'm there, they tell me, nothing happens. I make nothing happen." See Warhol, The Philosophy of Andy Warhol, 50.

${ }^{85}$ Frances Colpitt, "The Issue of Boredom: Is It Interesting?," The Journal of Aesthetics and Art Criticism 43, no. 4 (1985): 359-365.
} 
is, in a sense, no such thing as boredom. Boredom is only another name for a certain species of frustration. And the new languages which the interesting art of our time speaks are frustrating to the sensibilities of most educated people." ${ }^{, 86}$ In Sontag's view, then, artists do not want their audiences to be bored by their work - although this may be a necessary byproduct of creating something which is truly new. It may take time for spectators to become acclimated to the radically heterogeneous, but once this is done, boredom will be replaced by interest. This is why Sontag claims that "the purpose of art is always, ultimately, to give pleasure-though our sensibilities may take time to catch up with the forms of pleasure that art in a given time may offer." 87 This "catching up" may take months or years, but it may also occur over the course of a single work. John Cage hoped for just such an epiphanic reversal when he staged the performance of Satie's Vexations. He realized that some in the audience might initially be bored, but as he notes in his book Silence, "In Zen they say: If something is boring after two minutes, try it for four. If still boring, try it eight, sixteen, thirty-two, and so on. Eventually one discovers that it's not boring at all but very interesting." ${ }^{, 88}$ Or as Dick Higgins puts it, "Is [Vexations] boring? Only at first." As time passes, Higgins argues, Vexations simply becomes a part of the “environment," eventually engendering an ever-intensifying "euphoria." ${ }^{89}$ Similarly, it may take a few minutes to resign oneself to the fact that nothing will happen in a film like Empire, but once one does so, the film moves into the background, and one is left with a startlingly unique cinematic experience, one that is potentially very interesting. As Wayne Koestenbaum puts it,

\footnotetext{
${ }^{86}$ Susan Sontag, "One Culture and the New Sensibility," in Against Interpretation and Other Essays (New York: Farrar, Straus, and Giroux, 1964), 303.

${ }^{87}$ Ibid., 303.

${ }^{88}$ Cage, Silence, 93.

${ }^{89}$ Dick Higgins, "Boredom and Danger," in Breaking the Sound Barrier: A Critical Anthology of the New Music, ed. Gregory Battcock (New York: Dutton, 1981), 21. Ina Blom also discusses this kind of aesthetically satisfying boredom, pointing out its "capacity to cause disappearance on two different levels which must be experienced as reciprocal: the work will disappear into the surroundings, and the spectator will disappear into the work." See Ina Blom, "Boredom and Oblivion," in The Fluxus Reader, ed. Ken Friedman (London: Academy Editions, 1998), 66.
} 
"Warhol's images can seem stupid, mute, until you stare at them long enough to travel through stupefaction to illumination." 90 So if one insists on using the term boring to describe furniture art, then a clarification is in order: Vexations is not boring in the same way that the music of Andrew Lloyd Webber is boring, and the boredom evoked by Empire is not comparable to the kind engendered by a Paul W.S. Anderson film. This is not some snobby jeremiad about high and low art (both Satie and Warhol were intent on complicating such dichotomies). However, a fundamental distinction must be acknowledged: Webber and Anderson are trying to excite and captivate their audiences with works that are meant to be engrossing; Satie and Warhol are trying to create furniture art, works which can be casually tasted rather than greedily consumed. ${ }^{91}$

To further illustrate this point, it will be useful to examine a recent screening of Empire at The Museum of Modern Art. On February 19, 2011, the film was shown in its entirety to an audience who tweeted their responses to the experience (each tweet has been recorded in Mark Leach's book \#Empirefilm). ${ }^{92}$ Many of the tweets are cinephile wisecracks, very much in line with Warhol's desire to "make comedy in the audience": "I for one welcome today's announcement that Michael Bay is on board to direct the 3D IMAX remake of Warhol's 'Empire,",93 "[S] ay what you want, but it still has a more sensible plot than [A]vatar,"94 etc. But many of the tweets also suggest the highly participatory nature of the cinematic experience. There are several discussions that suggest the pleasure the audience is deriving from watching the film while doing other things: whispering, telling jokes, eating popcorn, drinking whiskey, taking acid, and cheering. In fact, the audience seems to cheer-as if at a sporting event-

\footnotetext{
${ }^{90}$ Koestenbaum, 11.

${ }^{91}$ For extended analyses of the multivalence and complexity of boredom, see Patricia Meyer Spacks, Boredom: The Literary History of a State of Mind (Chicago: University of Chicago Press, 1995) and Lars Svendsen, A Philosophy of Boredom (London: Reaktion Books, 2011).

${ }^{92}$ See Mark Leach, \#Empirefilm (Lexington, KY: CreateSpace, 2011).

${ }^{93}$ Ibid., 15-16.

${ }^{94}$ Ibid., 37.
} 
whenever there is any miniscule change on the screen: “[B]uilding's floodlights went on!!! (The crowd erupts!!!)" 95 Some have difficulty adjusting to this furniture aesthetic, particularly in an institution of high art — as one spectator tweeted, "I can't believe I just shouted outloud [sic] in a @MuseumModernArt theater." 96 And it is striking how many tweets suggest that the experience was not boring (as many anticipated), but interesting and even (somewhat surprisingly) fastpaced:

We thought \#empirefilm would be endurance but it's gone by so fast—and with great entertainment. It's really almost over? ${ }^{97}$

[T]ime has gone by surprisingly fast!! ${ }^{98}$

But seriously, I don't find this boring at all. ${ }^{99}$

And of course, the very idea of encouraging the audience to tweet during Empire (rather than directing them to turn their cell phones off, a standard injunction preceding screenings in mainstream venues) further suggests the central role of audience participation. (One spectator even asks, contra McLuhan, “[I]s film still a hot medium?"100) I suspect that Warhol would have been delighted to see the "cool," active, participatory approach of the MoMA audience, an approach that made the experience of watching Empire anything but boring.

\footnotetext{
${ }^{95}$ Ibid., 83. This is a common response to Warhol's stillies: since there are so few changes in his mises en scène, those which do occur are often greeted with great enthusiasm. Consider Dave Hickey's description of a screening of Haircut. After the audience has witnessed several minutes of a barber clipping away at a man's head, a minor change is introduced: "Then it happened. The guy getting the haircut reached into his shirt pocket, pulled out a pack of cigarettes and casually lit one up! Major action! Applause. Tumultuous joy and release! Chanting even." See Dave Hickey, Air Guitar: Essays on Art and Democracy (Los Angeles: Art Issues, 1997), 97. One is also reminded of David Bourdon's description of Warhol's cinema: "Suddenly, the performer blinks or swallows, and the involuntary action becomes in this context a highly dramatic event, as climactic as the burning of Atlanta in Gone with the Wind." See David Bourdon, Warhol (New York: Harry N. Abrams, 1989), 178.

${ }^{96}$ Ibid., 55.

${ }^{97}$ Ibid., 11.

${ }^{98}$ Ibid., 44.

${ }^{99}$ Ibid., 47.

${ }^{100}$ Ibid., 16.
} 
The furniture aesthetic that Warhol attempted to bring to the cinema was almost certainly inspired by his own habit of listening to the radio and watching TV distractedly. This habit was a crucial element in Warhol's creative process: when painting, he found it useful to "have the radio blasting opera [or in some cases, rock and roll], and the TV picture on (but not the sound)." ${ }^{101}$ (This configuration served as the basis for the premiere screening of Sleep, for which the silent image, televisual in its interminability, was accompanied by a radio tuned to a pop station: "[I]f a person were bored with the movie, he could just listen to the radio."102) In other words, Warhol was intensely interested in — and inspired by — the furniture aesthetic in a broad range of media. Like Satie, he was committed to the value of artworks which could be attended to casually and intermittently, works which could be tasted rather than digested. As Satie passionately asserted, furniture music "fills the same role as light, warmth, and comfort in all its forms. [...] A man who has not heard 'Furniture Music' does not know happiness." ${ }^{103}$ One is tempted to say the same of the furniture film.

\footnotetext{
${ }^{101}$ Warhol and Hackett, 8.

${ }^{102}$ Warhol, I'll Be Your Mirror, 165.

${ }^{103}$ Erik Satie, A Mammal's Notebook, trans. Antony Melville, ed. Ornella Volta (London: Atlas Press, 1996), 200.
} 


\section{CHAPTER 3}

STASIS IN FLUXUS:

\section{DISAPPEARING MUSIC FOR FACE AND PROTRACTED CINEMA}

"Is the flight of a butterfly music?" - Milan Knížák ${ }^{1}$

“The face is a veritable megaphone." - Gilles Deleuze and Félix Guattari ${ }^{2}$

In the Fluxus film Disappearing Music for Face (based on an idea by Mieko Shiomi), the spectator is confronted by a single static shot of a mouth filmed in black and white. Since most of the face falls outside the shot, the mouth dominates the screen. The shot is intentionally offcenter, and consequently, only the left side of the face (including the cheek and a prominent dimple) is visible. The mouth is frozen into an open smile, revealing a significant gap between the front teeth (see Figure 1). Minutes pass. Nothing seems to change. One begins to wonder if the work is nothing more than a filmed photograph, since it seems devoid of any traces of movement (apart from the movement suggested by the imperfections of the film stock). After several minutes, however, a slight change becomes noticeable. The smile is still there, but it seems less pronounced. One cannot help but question this perception, since at no point has the mouth (or anything else in the mise-en-scène) moved-or has it? Could it be that staring at this static face for a lengthy period of time has produced an illusion of change?

\footnotetext{
${ }^{1}$ Milan Knížák, “An Action for My Mind," in Critical Mass: Happenings, Fluxus, Performance, Intermedia, and Rutgers University 1958-1972, ed. Geoffrey Hendricks (New Brunswick, NJ: Rutgers University Press, 2003 ), 115.

${ }^{2}$ Gilles Deleuze and Félix Guattari, A Thousand Plateaus: Capitalism and Schizophrenia, trans. Brian Massumi (Minneapolis: University of Minnesota Press, 1987), 179.
} 


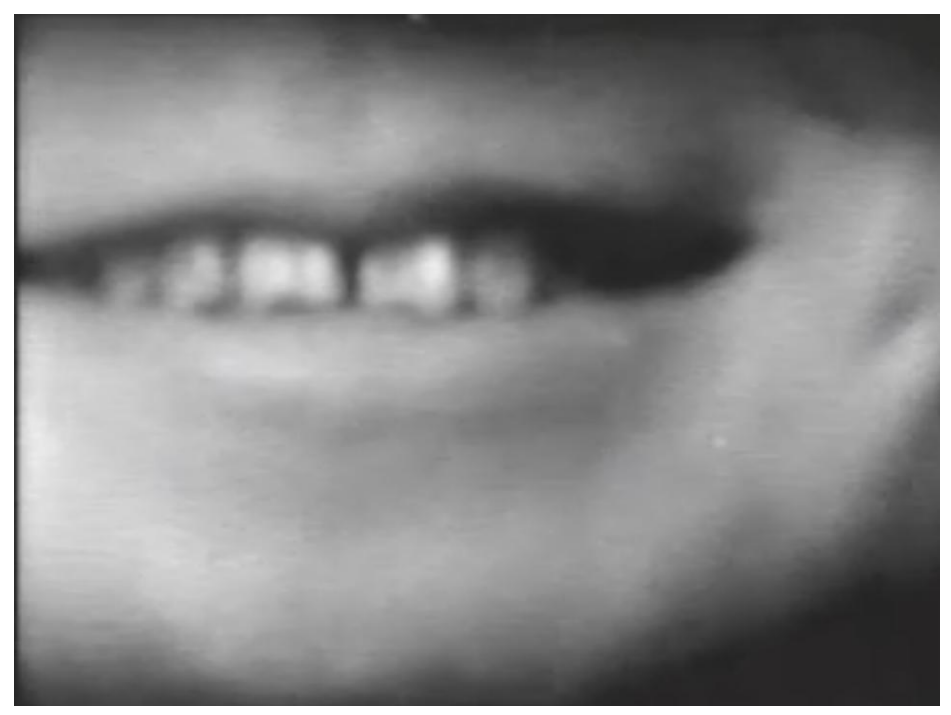

Figure 1: George Maciunas and Mieko Shiomi, Disappearing Music for Face (1966)

After about five minutes, it becomes increasingly evident that the mouth (which belongs to Yoko Ono) has been moving, albeit at rate too slow to be perceived. (As Scott MacDonald describes it, "[V]iewers never actually see Ono's mouth move; they only see that it has moved."3) The smile is almost gone now, leaving only a trace of the original pleasure-it is evocative of the forced half-smiles that often appear in family photographs. Several minutes later, the smile has faded entirely, as has the dimple on the left cheek. The mouth is still slightly open, but the teeth can barely be seen. Eleven minutes into the film, the teeth have disappeared and the mouth that once smiled now curves slightly downward, in a pose that can be read as either neutral or melancholy (see Figure 2). The face is abruptly replaced by a black screen and the film ends.

\footnotetext{
${ }^{3}$ Scott MacDonald, Avant-Garde Film: Motion Studies (Cambridge: Cambridge University Press, 1993), 23.
} 


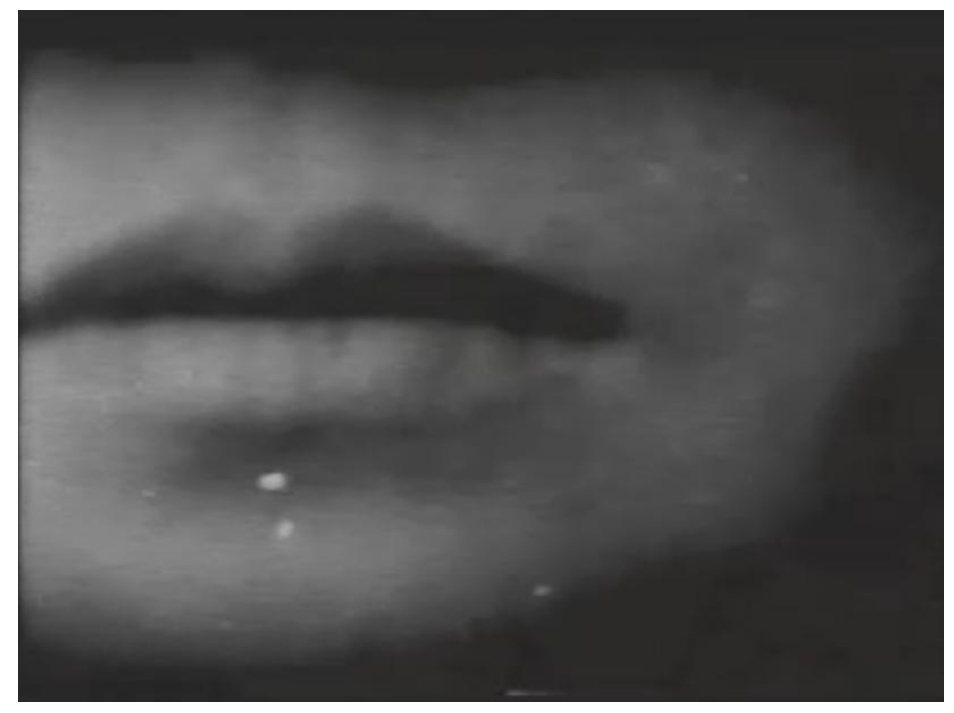

Figure 2: George Maciunas and Mieko Shiomi, Disappearing Music for Face (1966)

In addition to being fascinating, strange, and (as Tony Conrad asserts) "beautiful,"4 Disappearing Music for Face offers useful ways of thinking about cinematic stasis. It displays a fascination with stillness that was ubiquitous, not only in the works of Mieko Shiomi, but in the works of Fluxus artists more generally. In this chapter, I will attempt to map out the aesthetic and temporal dimensions of protracted films, works which (like Disappearing Music) use extreme slow motion to create the perception of stasis. I want to argue that, in addition to blurring the lines between cinema and photography, these experiments enable access to a series of interstitial moments which are generally hidden from perception. Further, it is my assertion that by manufacturing alternate temporalities, protracted films foreground the plasticity and contingency of time itself.

It will be useful to begin by contextualizing Disappearing Music and exploring its relationship to the other static films that were created by Fluxus artists. The brief opening credits claim that Disappearing Music is "by Chieko Shiomi”" (who would later change her first name to

\footnotetext{
${ }^{4}$ Interview with Tony Conrad, in Scott MacDonald, A Critical Cinema 5: Interviews with Independent Filmmakers (Berkeley: University of California Press, 2006), 73.
} 
Mieko), and the (rather scant) scholarship on the film generally echoes this attribution. It is true that the film was based on one of Shiomi's "action poems" of the same name (she later called them "event scores"). However, the film was actually made by George Maciunas, the leading figure in the Fluxus collective. ${ }^{5}$ The Shiomi event score which inspired the film reads as follows: Change gradually from a smile to no smile.

In concert performers begin the piece with a smile, and during the duration of the piece, change the smile very slowly and gradually to no smile. Conductor indicates the beginning with a smile and determines the duration by his example which should be followed by the orchestra. ${ }^{6}$

Shiomi did not authorize Maciunas' film version of her event score; in fact, she had already returned to Japan when the film was made in New York in $1966 .^{7}$ When she first saw it, she was disappointed with the interpretation because "the mouth is not the only body part which can smile." However, she has since come to accept that "George had no choice," since if he had shown the entire face, the slow-motion blinking of Ono's eyes might have become a humorous distraction from the smile itself. (Still, she emphasizes that the Maciunas film is just one possible cinematic interpretation of her work, and she hopes that other interpretations will arise in the future. ${ }^{9}$ )

\footnotetext{
${ }^{5}$ Mieko Shiomi, e-mail to author, May 20, 2011. The central role that Maciunas played in Fluxus has been well documented; as Fluxus artist Joe Jones puts it, "Fluxus = Maciunas $=$ Fluxus = Maciunas = Fluxus." Quoted in Hannah Higgins, "Fluxus Fortuna," in Friedman, The Fluxus Reader, 39.

${ }^{6}$ Quoted in Ken Friedman, "Events and the Exquisite Corpse," in The Exquisite Corpse: Chance and Collaboration in Surrealism's Parlor Game, ed. Kanta Kochhar-Lindgren, Davis Schneiderman, and Tom Denlinger (Lincoln, NE: University of Nebraska Press, 2009), 55. An alternate version of Shiomi's event score simply reads, "smile / stop smiling." See David T. Doris, "Zen Vaudeville," in Friedman, The Fluxus Reader, 99, 132.

${ }^{7}$ Shiomi also did not authorize the Fluxus flip-book version of Disappearing Music for Face. See Sally Kawamura, "Appreciating the Incidental: Mieko Shiomi's 'Events," Women \& Performance: A Journal of Feminist Theory 19, no. 3 (2009): 333.

${ }^{8}$ Quoted in Midori Yoshimoto, Into Performance: Japanese Women Artists in New York (New Brunswick, NJ: Rutgers University Press, 2005), 229.

${ }^{9}$ Shiomi, e-mail to author, May 20, 2011.
} 
Stasis is a central component in Shiomi's event scores. For example, Music for Two Players I (1963) instructs two performers to look at each other, face to face, for an extended period of time (a gesture which is reminiscent of the staring games often played by children). Piece for a Small Puddle (1964) suggests gazing at one's own reflection in a puddle. And Shadow Piece II (1964) reads as follows:

1

Project a shadow over the other side of this page.

\section{2}

Observe the boundary line between the shadow and the lighted part.

3

Become the boundary line. ${ }^{10}$

In all of these pieces, the reader (or performer) is instructed to stare at an essentially static person or object for a substantial period of time (the instructions for Music for Two Players I involve sustaining a gaze for a total of 20 minutes). Shiomi's insistence on stillness provides an opportunity for quiet contemplation—as she puts it, "To concentrate you need stasis." ${ }^{.11}$ But why should one's concentration be directed at such ordinary objects? This is, in fact, part of the raison d'être of Fluxus: by dissolving arbitrary boundaries between art and life, Fluxus artists sought to reveal the beauty of mundane objects (faces, puddles, shadows, etc.), objects that we frequently look at without seeing. In this sense, Fluxus has a clear precursor in Duchamp's objets trouvés (his bicycle wheel, bottle rack, urinal, etc.). However, Fluxus goes one step further. As Wolf Vostell notes, Duchamp may have seen the ordinary urinal as an artwork, but the

\footnotetext{
${ }^{10}$ See Ken Friedman, Owen Smith, and Lauren Sawchyn, eds. The Fluxus Performance Workbook (A Performance Research e-Publication, 2002), 96-97, http://www.thing.net/ grist/ld/fluxusworkbook.pdf.

${ }^{11}$ Shiomi, e-mail to author, May 20, 2011.
} 
fundamental insight of Fluxus was that "using the urinal was equally an artistic activity."12 Thus, it is not just the smile (and its absence) that Shiomi foregrounds, but the act of smiling (along with the cessation of this act). She sought to produce a "conversion of trivial actions into artistic performances."13

I witness the disappearance of smiles several times each day, but until encountering Shiomi's work, I never really experienced a disappearing smile as such. I would only notice the smile itself, or perhaps the pleasant statement or situation which occasioned it. However, the suggested protraction of this action in Shiomi's event score (and its later realization in Maciunas' film) enables one to see the smiles that are encountered on a daily basis as performances teeming with aesthetic value. The smile can be seen as a smile, freed of its contextual contingencies. In this sense, Shiomi is carrying on the tradition of John Cage (who was, along with Duchamp, one of the most important influences on Fluxus). As Cage states at the conclusion of his book Silence, "It behooves us [...] to see each thing directly as it is, be it the sound of a tin whistle or the elegant [mushroom] Lepiota procera."14

Shiomi's dedication to the aesthetic value of stasis can be seen in the work of other Fluxus artists, as well. For example, several of Yoko Ono's film scripts foreground stillness. Film No. 6 (A Contemporary Sexual Manual: 366 Sexual Positions) consists of nothing but a man, a woman, and their four-year-old daughter sleeping on a bed for an hour and a half. (As Ono mischievously remarks in the script, "[T]he 366 sexual positions are all in the mind of the audience."15) And Ono's Film No. 2 (Mona Lisa and Her Smile) script simply reads, “Ask audience to stare at a figure (ANY FIGURE) for a long time and then immediately turn their

\footnotetext{
${ }^{12}$ Quoted in Dorothée Brill, Shock and the Senseless in Dada and Fluxus (Hanover, NH: University Press of New England, 2010), 134. Emphasis added.

${ }^{13}$ Shiomi, e-mail to author, May 20, 2011. Emphasis added.

${ }^{14}$ Cage, Silence, 267.

${ }^{15}$ See Scott MacDonald and Yoko Ono, "Ideas on Film: Interview/Scripts," Film Quarterly 43, no. 1 (1989): 18.
} 
eyes to the screen and see their reflection." ${ }^{\prime 16}$ But perhaps the most infamous example of stasis in Fluxus is provided by Jackson Mac Low, who in 1964 published a film script (of sorts) for a piece he called Tree Movie:

Select a tree*. Set up and focus a movie camera so that the tree* fills most of the picture. Turn on the camera and leave it on without moving for any number of hours. If the camera is about to run out of film, substitute a camera with fresh film. The two cameras may be alternated in this way any number of times. Sound recording equipment may be turned on simultaneously with the movie cameras. Beginning at any point in the film, any length of it may be projected at a showing.

* For the word "tree," one may substitute "mountain," "sea," "flower," "lake," etc. 17

Like the aforementioned scripts by Ono and Mac Low, Maciunas' Disappearing Music for Face is a part of the cinema of stasis, since it subverts the spectatorial expectations of movement and dynamism that are so central to most films. Unlike the scripts by Ono and Mac Low, however, the stasis in Disappearing Music is not achieved by giving attention to a static person or object. Rather, it finds stasis in flux, taking movement as its starting point and then slowing it down drastically to engender a sense of immobility. The filming of Ono's disappearing smile with a high speed camera (along with the use of extreme slow motion) drains the action of its original vitality. Ono's smile becomes — as far as the eye can tell —a static

\footnotetext{
${ }^{16}$ Ibid., 17.

${ }^{17}$ Quoted in Friedman, "Events and the Exquisite Corpse," 61. Mac Low's concept may be seen as the forerunner of films like Stan Brakhage's Song 27, My Mountain (1968) and James Benning's 13 Lakes (2004), in which still natural objects are displayed for lengthy periods of time. Hannah Higgins even suggests that Tree Movie may have paved the way for Warhol's static films, although it is difficult to determine which came first: Mac Low's idea for Tree Movie or Warhol's idea for Sleep (1963). See Hannah Higgins, Fluxus Experience (Berkeley: University of California Press, 2002), 123-124.
} 
object. ${ }^{18}$ For this reason, Disappearing Music is best understood as a protracted film, a work of cinema which uses extreme slowness to create the impression of stasis.

Several Fluxus artists, in fact, made use of this cinematic device. For example, Yoko Ono's Eyeblink (1966) consists of a close-up of an eye blinking in extreme slow motion, and her film One (Match) (1966) applies the same process of protraction to the lighting of a match. Pieter Vanderbeck's Five O'Clock in the Morning (1966) shows chestnuts and rocks falling at a drastically reduced speed, while in Joe Jones' Smoking (1966), the simple and brief act of exhaling cigarette smoke is radically protracted so that it takes almost five minutes to complete. ${ }^{19}$ Not only do these films generally deprive the viewer of any perception of movement, they do not even provide any implication of motion through montage (what Deleuze calls "pure mobility." ${ }^{20}$ )

How might one account for Fluxus artists' fascination with stillness? Dorothée Brill provides a cogent theoretical framework. She notes that even though Fluxus has many affinities with Dada, its historical precursor, there is a crucial distinction. While Fluxus, like Dada, was not afraid to use sudden shock as an aesthetic strategy (e.g. Nam June Paik's placement of a cow's head hanging from the ceiling at one of his exhibitions in 1963), Fluxus also often moved in the

\footnotetext{
${ }^{18}$ Even though the film is based on an event score, the disappearing smile no longer seems to be an event at all, at least if we take seriously Rudolf Arnheim's distinction between events and objects. Arnheim suggests that the presence of the event entails the perception of movement, a sense that something is happening before our eyes. On the other hand, "a cloud [...], a lobster turning red, [or] a potato getting tender" are not experienced as events, but as "object[s] in transformation." See Arnheim, Art and Visual Perception, 373.

19 Peter Moore operated the camera in the aforementioned protracted films, and they were later compiled by Maciunas into a single work called Fluxfilms (1966-1967). (Vanderbeck's Five O'Clock in the Morning is the only protracted film in this compilation in which the movement, while decelerated, is still recognizable as movement.) While I have mentioned all of the protracted films that appear in this compilation, several other static films are also included here, e.g. Nam June Paik's Zen for Film (1962-1964).

In fact, Fluxus artists remained interested in cinematic stasis well after the production of Fluxfilms. For instance, in 1975, Fluxus advertised an event called 12! Big Names! (Some of the names mentioned on the distributed flyers included Ono, Warhol, Snow, and Philip Glass.) Those who attended expecting to see these well known artists ended up seeing a film which displayed only their names, one at a time. The names were "big," as promised, filling up the entire screen. (Each one lingered for about five minutes before being replaced.) While this was clearly an impudent prank, it still exemplifies Fluxus artists' fascination with static cinema.

${ }^{20}$ Deleuze, Cinema 1, 25.
} 
opposite direction, using a kind of boredom to produce a very different kind of experience: "By deliberately producing impulses that can be characterized as either unexpectedly strong or unexpectedly weak, Fluxus works attempt to resist their casual or incidental reception through the one or the other extreme. [...] Since both shock and boredom run counter to the audience's expectations, both were legitimate means for Fluxus artists either to jolt or drag the recipient into a mode of productive or engaged reception through a moment of irritation. ${ }^{21}$ In other words, by offering stillness to an audience expecting movement, Fluxus artists deliberately engendered boredom as a strategy of subversion. As Paik put it (in his discussion of Mac Low's Tree Movie), Fluxus was interested in generating a "meaningful boredom."22

Additionally, by using stasis, Fluxus artists prompt the spectator to become more aware of the movement of her own body. Recall, for example, John Cage's famous visit to Harvard's anechoic chamber in 1952. Cage expected complete silence, but he was instead surprised to experience a heightened awareness of the sounds of his own body, the almost inaudible sounds of his "nervous system in operation" and his "blood in circulation," moving him to remark, "Until I die there will be sounds.",3 (This experience, of course, inspired him to compose his landmark 4'33', later that year.) Similarly, the static mouth of Disappearing Music makes the spectator more aware of the subtle, often involuntary movements of her own mouth, while the static eye of Eyeblink heightens the viewer's awareness of her own blinking. This attunement to the sounds and movements of one's own body is a goal that Fluxus shares with Zen Buddhism (which Cage studied). As David T. Doris notes, in Zen Buddhism, "The act of sitting is perceived as a 'dynamic stillness' — one sits in a rigorously prescribed posture, unmoving, yet

\footnotetext{
${ }^{21}$ Brill, 141.

${ }^{22}$ Quoted in Brill, 144. For more on the strategic use of boredom by Fluxus, see Dick Higgins, "Boredom and Danger," 20-27. As is the case with Warhol's cinema, I hasten to point out that the Fluxus artworks being discussed here are certainly not boring in the sense of being uninteresting. They are, however, restrained and uneventful.

${ }^{23}$ Cage, Silence, 8.
} 
constituted by interior processes in constant motion: the heart beats, the blood courses through its vessels, air enters and is expelled through the lungs, the stomach churns away at its food..."24 The protracted Fluxus films consequently encourage the spectator to become attuned to her own bodily movements, rather than seeking pleasure or engagement in the movements of others.

It is difficult to find many precedents for the unrelenting (and unsettling) quasiphotographic stasis of these Fluxus films. Of course, Warhol's early films (much like Disappearing Music) often focus on faces in stasis, as in his numerous screen tests, which frequently feature a stationary individual staring at the camera for several minutes. But the effect is quite different. Warhol's subjects do move occasionally, however slight and subtle those movements might be (the blinking of the eyes, the shifting of the head, a slight quiver of the lips), while the image in Disappearing Music seems to never move-it only changes. Further, even though both Warhol and Fluxus use slow motion to engender a kind of immobility, they use it in radically different ways (although neither uses the type of slow motion that is generally employed in commercial cinema). I would not categorize Warhol's stillies as protracted films, since the slow motion is so slight, it barely registers as slow motion. This is why many viewers of Warhol's early cinema assume that what they are watching is "real time," until they discover through research that his stillies were shot at 24 frames per second and screened at 16 (or sometimes 18) frames per second. (Of course, with certain Warhol films, the misperception is almost inevitable - in Empire, for example, how could one determine whether the Empire State Building is being shot at normal speed or slow motion?) Once one is aware of the slight protraction, however - particularly in a film that studies the human face, like Blow Job (1964)the temporal shift becomes palpable, inescapable. Each subtle movement performed becomes infused with lethargy and ennui. In Disappearing Music, the effect is of a different order. Here

\footnotetext{
${ }^{24}$ Doris, “Zen Vaudeville,” 108.
} 
too the viewer may not initially realize that the film is in slow motion, but this is only because the motion is so slow that it no longer seems to be motion at all. Disappearing Music (along with the other protracted Fluxus films) was shot at 2,000 frames per second, so that a few seconds of real time become stretched almost indefinitely, to the point that time seems to freeze altogether. ${ }^{25}$

The technological process used to create Disappearing Music results in an extreme slow motion - a hyperstasis. Not only is it distinct from the less pronounced slow motion used by Warhol, or even that used by more mainstream filmmakers (such as Scorsese in Raging Bull [1980]), it is also distinct from the extreme slow motion used in many other experimental films. Take, for example, Douglas Gordon's 24 Hour Psycho (1993), in which Hitchcock's Psycho (1960) is slowed down dramatically (and stripped of its soundtrack); a film that initially had a running length of 109 minutes now takes a full day to view in its entirety. Even though both Disappearing Music and 24 Hour Psycho are protracted films, there is a crucial difference. Since Psycho was shot at a standard speed (24 frames per second), slowing it down dramatically deconstructs its continuity. The film becomes a series of still photographs in sequence, and what was initially perceived as movement now appears fragmentary. With Disappearing Music, however, the continuity is maintained-one no longer gets the impression of looking at a series of photographs, but at a single photograph. Consequently, the film places itself squarely at the intersection between cinema and photography. It is ontologically cinematic, phenomenologically photographic.

There is another crucial difference between these two protracted films that is worth noting: while the inordinate length of 24 Hour Psycho (like Warhol's early stillies) elicits a

\footnotetext{
${ }^{25}$ Shiomi's Disappearing Music for Face (along with many of her other event scores) shares striking similarities with Warhol's static films: for example, both collapse distinctions between art and the "real world," and both traffic in individual static objects. While Shiomi acknowledges the affinity, she was not aware of Warhol's films when she wrote her event scores. E-mail to author, May 20, 2011.
} 
partial and distracted form of spectatorship, the protracted Fluxus films are brief, encouraging a close meditative gaze. Such an approach enables the spectator to see dimensions of everyday objects and experiences that are ordinarily invisible. For Bergson, this is the function of art: "to make us see what we do not naturally perceive. ${ }^{, 26}$ And as James Broughton has argued, cinema is uniquely positioned to do just this: "Film is a way of seeing what has been looked at by everyone else and never really seen." 27 This is precisely the effect of the protracted Fluxus films. The extreme slowness of these works exposes us to elements of our everyday viewing experience which are always present, but which never present themselves to us. As such, they offer a rare glimpse into microtime, the infinitesimal intervals of duration which form the backdrop of every experience. ${ }^{28}$ For most of human history, these temporal interstices existed beneath the threshold of perception-only with the advent of the cinematographic apparatus did microtime become affectively accessible. The title of Shiomi's event score-Disappearing Music for Face — hints at her interest in such interstitial moments. It is not necessarily the smile itself that interests Shiomi, nor is it the non-smile-rather, it is the disappearance, the space between the two affective states. While disappearing normally involves making the visible invisible, the film version of Disappearing Music for Face does just the opposite: it offers access to the hidden dimensions of a visual experience, and consequently makes the invisible visible. (This tradition is carried on in numerous video installations by Bill Viola, such as Anima [2000] and Dolorosa [2000], in which extreme slow motion is again used to access temporal interstices. Viola's comments on these protracted installations could apply with equal force to a film like Disappearing Music: "I was most interested in opening up the spaces between the emotions. I wanted to focus on gradual

\footnotetext{
${ }^{26}$ Henri Bergson, The Creative Mind: An Introduction to Metaphysics, trans. Mabelle L. Andison (Mineola, NY: Dover Publications, 2007), 112.

${ }^{27}$ Quoted in Follow Your Own Weird: The World of James Broughton (Chicago: Facets Cine-Notes, 2006$), 31$.

${ }^{28}$ For an excellent history of scientific and philosophical treatments of microtime, see Jimena Canales, $A$ Tenth of $a$ Second: A History (Chicago: University of Chicago Press, 2009).
} 
transitions - the idea of emotional expression as a continual fluid motion. This meant that the transitions, the ambiguous time when you shift from being happy to sad, is [sic] just as important as the main emotion itself.",29)

One is reminded here of Deleuze's theorization of the evental. The event, in Deleuze's view, is not merely the moment that something happens-rather, "events always involve periods when nothing happens. It's not even a matter of there being such periods before and after some event, they're part of the event itself." ${ }^{30}$ For Deleuze, these periods in which "nothing happens" are routinely overlooked by the mass media, and so they are best interrogated by art. (Interestingly, he cites the films of Ozu and Antonioni as examples here-among the most static films outside of the avant-garde - since in these works, "the periods in which nothing happens don't fall between two events, they're in the events themselves, giving events their depth." ${ }^{, 1}$ ) Through their use of extreme slow motion, protracted films like Disappearing Music are especially well suited to plumb these Deleuzian depths. They posit ordinary events as both actions and non-actions, movements and non-movements. If, as Deleuze asserts, "People miss the amazing wait in events they were least awaiting,"32 Disappearing Music reinstates this immanent (albeit overlooked) period of waiting that undergirds the evental. As a consequence of the inordinate slowness of protracted films, one no longer waits for an event - rather (as in the plays of Beckett) waiting becomes the event.

\footnotetext{
${ }^{29}$ Bill Viola, "A Conversation," interview with Hans Belting, in Bill Viola: The Passions, ed. John Walsh (Los Angeles, 2003), 200. For an extensive analysis of "the odd stasis" of Viola's protracted video installations, see Mark Hansen, "The Time of Affect, or Bearing Witness to Life," Critical Inquiry 30 (Spring 2004): 584-626. While Hansen's interrogation is both compelling and philosophically rich, he problematically emphasizes "the capacity of new media to broker a technical enlargement of the threshold of the now" (589). As the Fluxus films demonstrate, the traditional cinematographic medium is just as capable of extending duration as Viola's digital video technology. Of course, this is not to say that the two mediums are identical. For example, unlike the Fluxus films, Viola's installations lack the emulsion grain that potentially reminds the viewer of the movement of the projector. Nevertheless, by suggesting that temporal protraction is a function unique to new media, Hansen overplays his hand. ${ }^{30}$ Gilles Deleuze, “On Leibniz," in Negotiations, trans. Martin Joughin (New York: Columbia University Press, 1995), 160.

${ }^{31}$ Ibid., 160.

${ }^{32}$ Ibid., 160. Italics in original.
} 
Pudovkin was one of the first film theorists to note the great cinematic potential of slow motion; he was excited by "[t]he disconcerting strangeness of retarded movements on the screen, the possibility of perceiving forms that ordinarily are imperceptible and invisible, yet none the less existent in actuality."33 (This sentiment is precisely what inspired Gordon to make 24 Hour Psycho; when he first began to watch Psycho at a reduced speed, he remarked, "It was as if the slow motion revealed the unconscious of the film." ${ }^{34}$ ) Maya Deren was similarly enthusiastic about the aesthetic possibilities of slow-motion. Since art forms like dance and theater were already capable of utilizing motion for artistic purposes, Deren believed that it was incumbent on serious filmmakers to use cinema to "discover a new dimension altogether of movement." For Deren, slow motion represented one such new dimension, since it could be "brought to the most casual activities to reveal in them a texture of emotional and psychological complexes." Just as the close-up enabled one to excavate the recesses of space, slow motion enabled the excavation of new temporalities. In Deren's view, "Slow-motion is the microscope of time."35

Of course, Disappearing Music offers not only a temporal "close-up," but a spatial one, as well: the slow-motion photography works in conjunction with the extreme close-up of Ono's face to amplify the sense that one is perceiving the imperceptible. By distorting both the size and speed of an everyday experience, Disappearing Music confronts the spectator with the manifold nuances that lurk beneath ostensibly atomistic actions. While the film's slowness enables one to

\footnotetext{
${ }^{33}$ Vsevolod Illarionovich Pudovkin, "Close-Ups in Time," in Film Technique and Film Acting, trans. and ed. Ivor Montagu (New York: Grove Press, 1976), 180.

${ }^{34}$ Quoted in Amy Taubin, "Douglas Gordon," in Spellbound: Art and Film, ed. Philip Dodd and Ian Christie (London: British Film Institute, 1996), 70. Gordon's statement echoes Benjamin's famous assertion that the camera enables the discovery of "the optical unconscious." See Benjamin, "The Work of Art in the Age of Its Technological Reproducibility," in Walter Benjamin: The Work of Art in the Age of Its Technological Reproducibility and Other Writings on Media, 37.

${ }^{35}$ Maya Deren, "An Anagram of Ideas on Art, Form, and Film," in Maya Deren and the American Avant-Garde, ed. Bill Nichols (Berkeley: University of California Press, 2001), 47-48. Deren wrote this in 1946, about 14 years before Siegfried Kracauer made much the same observation in his Theory of Film: "Slow-motion shots [...] are, so to speak, temporal close-ups, achieving in time what the close-up proper is achieving in space." See Siegfried Kracauer, Theory of Film: The Redemption of Physical Reality (Princeton: Princeton University Press, 1997), 53.
} 
see the interstices of temporal duration, the sheer size of Ono's mouth permits an entrance into what Béla Balázs called "the world of microphysiognomy," permitting the perception of elements of the human face "which even the most observant partner would never perceive." ${ }^{\text {, }}$ In addition to providing a heightened sense of visual perception, the extreme close-up results in a face that is imposing, even overwhelming. (One is reminded of Sergei Eisenstein's Kafkaesque observation that "the laws of cinematographic perspective are such that a cockroach filmed in close-up appears on the screen one hundred times more formidable than a hundred elephants in medium-long shot." ${ }^{, 37}$ )

But the fact that the object being filmed in Disappearing Music is a human face (rather than anything else) amplifies its affective intensity. In A Thousand Plateaus, Deleuze and Guattari challenge conventional theorizations of the face which see it as a locus of compassion and humanity. Instead, they argue that the human face is "a horror story," 38 adding, "The face is not animal, but neither is it human in general; there is even something absolutely inhuman about the face. [...] The inhuman in human beings: that is what the face is from the start." ${ }^{, 39}$ Deleuze and Guattari are quick to note that they are speaking of the face as such, not merely one which has been modified or magnified in some way; in fact, they insist that the face is "by nature a close-up." ${ }^{40}$ Nevertheless, a film like Disappearing Music, by offering an extreme close-up of this close-up, infinitely magnifies the face's immanent inhumanity. As Mary Ann Doane asserts, "The scale of the close-up transforms the face into an instance of the gigantic, the monstrous: it overwhelms." ${ }^{, 4}$ This description is especially apropos for the face of Disappearing Music, since

\footnotetext{
${ }^{36}$ Béla Balázs, "The Close-Up,” in Film Theory and Criticism, 318-319.

${ }^{37}$ Quoted in Mary Ann Doane, "The Close-Up: Scale and Detail in the Cinema," differences: A Journal of Feminist Cultural Studies 14, no. 3 (2003): 92.

${ }^{38}$ Deleuze and Guattari, A Thousand Plateaus, 168.

${ }^{39}$ Ibid., 171.

${ }^{40}$ Ibid., 171.

${ }^{41}$ Doane, "The Close-Up," 94.
} 
the magnification is even more extreme than the kind used in a traditional close-up. We are so close to the face that much of it falls outside the frame. All that remains is an enormous, grotesque, disembodied mouth. Its size on the cinema screen is so formidable that one can imagine being devoured by it, in much the same way that Judas, Brutus, and Cassius are eaten by Satan at the end of Dante's Inferno. ${ }^{42}$

All of this is to suggest that one experiences a peculiar intensity when watching Disappearing Music. The film's minimalism, its stark simplicity, may seem to be deliberately boring, but those who view it in its entirety are often surprised to find just how gripping the film is. Michael Kirby (in an article on the ontological-hysteric theater of Richard Foreman) discusses the powerful affective responses engendered by temporal protraction. While Kirby is primarily concerned with theatrical (rather than cinematic) slow motion, his remarks remain relevant in theorizing protracted cinema:

[A]rtificially slowing down the rate of change in the perceptual field may $[\ldots]$ create what can be thought of as intensification through analogy. When the mind is involved with a crisis situation, things often seem to be happening in slow motion. The mind responds so actively that the progress of the skidding car seems retarded; each detail seems more sharply defined than it would be normally. A performance done in slow motion can create, by analogy, the same sense of crisis. The amount of information and the complexity of detail perceived are much greater than would be registered unless the mind were responding rapidly to a crisis situation. Even when the occurrences observed

\footnotetext{
${ }^{42}$ Since Disappearing Music, several films have exploited the disconcerting intensity of the massive mouth. I am thinking here of the opening of Jim Sharman's The Rocky Horror Picture Show (1975), as well as the film versions of Samuel Beckett's Not I (1972), including a filmed performance of the play from 1973 (starring Billie Whitelaw) and a more recent version directed by Neil Jordan in 2000.
} 
are not dangerous or threatening, the retardation of flow creates psychic intensification. ${ }^{43}$ Even if the slow motion of the protracted Fluxfilms is too extreme to evoke a sense of crisis per se, the temporal shift does nonetheless engender "psychic intensification." The face's eerie quiescence becomes absorbing, unnerving. As Deleuze and Guattari rightly assert, "[T]he slowest of movements [...] is not the least intense."44

But describing the visual dimensions of Disappearing Music is insufficient. As the title of Shiomi's event score implies, the fading smile is meant to have an auditory dimension as well. Music represented a major influence (and a point of departure) for Fluxfilms. (This is unsurprising, since many of the Fluxus filmmakers, such as Joe Jones, were primarily known as avant-garde musicians.) Shiomi could have titled her work Disappearing Smile, but by calling it Disappearing Music for Face (and by calling her writings event scores) she draws attention to the profound affinities that her work shares with music. Of course, the difficulty of clearly taxonomizing the event scores of Shiomi is due in part to their status as interventions in intermedia. But this difficulty is also part of their aesthetic. Some of the instructions in Shiomi's event scores could easily be performed (it is not particularly difficult to stare at a puddle), but other event scores command the performer to engage in actions which are clearly impossible: Star Piece (1963), for example, instructs the reader to find "[ $\mathrm{t}]$ he third biggest star" and "[s]hoot it with a gun." 45 (Nam June Paik's event scores also frequently offer instructions for actions that must surely be carried out only in the mind, such as his famous admonition to "climb into the vagina of a live whale" 46 an action that is, if not technically impossible, at least wildly

\footnotetext{
${ }^{43}$ Michael Kirby, "Richard Foreman's Ontological-Hysteric Theatre," The Drama Review 17, no. 2 (1973): 28.

${ }^{44}$ Deleuze and Guattari, A Thousand Plateaus, 172.

${ }^{45}$ Quoted in Friedman, Smith, and Sawchyn, 96.

${ }^{46}$ Quoted in Hannah Higgins, Fluxus Experience, 114. This kind of absurd imagery has clear precursors in the stories of Zen Buddhism, as in the Master who claimed that "Zen is an elephant copulating with a flea." Quoted in Osho, Zen: The Path of Paradox (New York: St. Martin's Griffin, 2001), 119.
} 
improbable.) Of course, a score that cannot actually be performed would seem to veer more towards poetry than music; after all, it is possible to perform a Chopin étude, but it is not possible to literally "eat men like air." But Fluxus artists were intent on subverting such tidy distinctions. In this, they took their lead from Cage. When he was asked why he wrote musical scores that were too long to actually be performed, he responded, "Composing's one thing, performing's another, listening's a third. What can they have to do with one another?"47 The synaesthetic title of Shiomi's event score (and the film it inspired), then, prompts the viewer to see a fading smile as a kind of musical performance, one that anyone can perform. It also encourages one to listen to a fading smile.

This may seem like an meaningless admonition. Can a smile (and its subsequent disappearance) be heard? In the absence of laughter, it is difficult to imagine literally hearing the smile of another person. Still, the Shiomi score certainly might inspire an individual to listen to his own smile, which could potentially produce barely audible sounds (changes in breathing, the movement of one's saliva, etc.). It is true that Maciunas' film version of Disappearing Music is completely silent, so any attempts to listen to Ono's fading smile will be fruitless; nevertheless, the very act of attempting to listen to something which makes no noise can effect a kind of aesthetic enlightenment. Fluxus composer La Monte Young was well aware of this. This is why his Composition 1960 \#5 (1960) consists only of "[t]urn[ing] a butterfly (or any number of butterflies) loose in the performance area." While this may seem like an worthwhile piece of experimental theater or conceptual art, Young insisted on calling it as a musical composition. When a puzzled Tony Conrad admitted that he did not understand this work, Young responded,

\footnotetext{
${ }^{47}$ Cage, Silence, 15.
} 
“Isn't it wonderful if someone listens to something he is ordinarily supposed to look at?"48 On another occasion, Young asserted, “[I]t didn't seem to me at all necessary that anyone or anything should have to hear sounds [...] it is enough that they exist for themselves."49 Like other Fluxus artists (and like Cage himself) Young was intent on radically expanding the definition of music. Any event—whether it produced sound or not—had a certain musicality. As George Brecht would later put it, "Music isn't just what you hear or what you listen to, but everything that happens...Events are an extension of music." ${ }^{50}$ Disappearing Music, then, can be conceptualized as a kind of silent music. (Of course, if one attempts to listen to Maciunas' and Shiomi's film, one may still come to appreciate the sounds of one's immediate environment: the hum of the film projector, for example, or-for the true Cagean - the noise of one's own nervous system and blood flow.)

Like Cage, Young, and Brecht, what interests Shiomi about music is not aurality but temporality. She claims that "the essence of music" is "the very recognition of time itself - the duration of time that is not necessarily realized as sound." ${ }^{51}$ A Shiomi event often causes one to "feel the slow process of a banal action as a static musical duration." musical duration," then, can be seen as important precursors to the protracted Fluxfilms. Again, the composer most closely associated with "static" music is almost certainly La Monte Young. His Composition 1960 \#7 (1960) is simply a sustained open fifth (a B and an F\#) "held for a long time," while the score for his Composition 1960 \#9 (1960) consists only of a horizontal line (this

\footnotetext{
${ }^{48}$ La Monte Young, "Lecture 1960," The Tulane Drama Review 10, no. 2 (1965): 77-78. As Dorothée Brill, points out, this philosophy is reminiscent of the Zen master who raises his hand and asks his students to listen to its sound. See Brill, 137-138.

${ }^{49}$ Young, 75.

${ }^{50}$ Quoted in Liz Kotz, Words to Be Looked At: Language in 1960s Art (Cambridge: MIT Press, 2010), 76.

${ }^{51}$ Quoted in Yoshimoto, 146.

${ }^{52}$ Shiomi, e-mail to author, May 20, 2011.
} 
is generally performed as a single tone sustained for a significant duration). ${ }^{53}$ However, over a decade before these compositions, Yves Klein paved the way for static music with his seminal Monotone Symphony (1949), in which a single chord is heard without interruption over the course of 20 minutes (followed by another 20 minutes of proto-Cagean silence). In traditional music, a chord is merely a link in a musical chain, one which takes on meaning only in the context of other chords or notes. But here, the chord is stripped of any contextualization and exists for its own sake. The listener hears a chord as such, and appreciates its aesthetic value in a way that would be impossible if it were part of a melody. In much the same way, Shiomi and Maciunas take an action that would normally occur only fleetingly and allow it to exist purely, without cause, effect, or justification. Of course, Klein's chord (like the fading smile of Maciunas' film) must occur for a significant duration of time in order for its import to be appreciated. A chord or a smile lasting only a second or two will not be fully apprehended. But by stretching time, both Klein and Maciunas create aesthetic experiences in which time loses meaning, both as an organizing principle and as a phenomenological constant. In both works, time seems to stretch to the point of tearing, leaving only naked duration in its wake. While Aristotle asserted that "thinking that time does not exist [...] happens when we do not distinguish any change,"54 I would argue that this statement only holds true for chronological time. Psychological time, on the other hand (that is, Bergsonian durée), is at its most salient when no

\footnotetext{
${ }^{53}$ In 1964, Young agreed to provide his Composition $1960 \# 9$ as a soundtrack to Andy Warhol's Quartet Installation. The composition was realized as a very loud recording of a sustained tone produced by a bowed brass mortar. When officials asked Young to turn down the volume, he withdrew his composition altogether, leaving Warhol's four films to continue playing in silence. See Joseph, "My Mind Split Open," 83-86. For an exemplary analysis of Young's oeuvre and its aesthetic significance, see also Branden W. Joseph's Beyond the Dream Syndicate: Tony Conrad and the Arts after Cage (New York: Zone Books, 2008).

${ }^{54}$ Aristotle, Physics, trans. Robin Waterfield (Oxford: Oxford University Press, 1999), 105.
} 
change is perceived. This is what enables both static cinema and static music to engender a corporealized sense of duration. ${ }^{55}$

In fact, I would argue that films like Disappearing Music offer profound insights about time itself, laying bare its plasticity and contingency. As many philosophers have noted, conceptualizing - or even defining-time has proven to be notoriously problematic. (Recall Saint Augustine's formulation: "What then is time? Provided that no one asks me, I know. If I want to explain it to an inquirer, I do not know." ${ }^{, 56}$ ) The immediate temptation is to hypostatize time by conceptualizing it as a river. But as J.J.C. Smart points out in his seminal 1949 essay "The River of Time," this metaphor begs the question, how fast does the river run? And to speak of the river of time moving quickly or slowly presupposes that time itself exists in time. ${ }^{57}$ As Smart puts it, "[J]ust as we thought of the first time-dimension as a stream, so will we want to think of the second time-dimension as a stream also; now the speed of flow of the second stream is a rate of change with respect to a third time-dimension, as so we can go on indefinitely postulating fresh streams without being any better satisfied."58 (Deleuze makes a similar observation in his second Cinema book: "[E]verything that changes is in time, but time does not

\footnotetext{
${ }^{55}$ Another notable composer of static music is Steve Reich. In his Four Organs (1970), the titular instruments continually repeat a chord that gradually extends in duration until it (and its constituent notes) transmute into a seemingly static wall of sound. Interestingly, Reich has conceptualized Four Organs as "a sort of slow motion music," which suggests that extreme slowness (whether in music or film) can effectively engender a sense of stasis, one that permits the experience of duration as such. See Steve Reich, Writings on Music, 1965-2000, ed. Steve Reich (Oxford: Oxford University Press, 2002), 44.

Given Reich's saliently cinematic description of Four Organs, one cannot help but wonder if it was in any way inspired by Michael Snow's famous protracted film Wavelength, in which the camera's move from one end of a room to another takes 45 minutes to complete. Reich saw the film and wrote about it in 1968. See Steve Reich, "Wavelength by Michael Snow," in Campany, The Cinematic, 106-107.

${ }^{56}$ Saint Augustine, Confessions, trans. Henry Chadwick (Oxford: Oxford University Press, 2008), 230.

${ }^{57}$ J.J.C. Smart, "The River of Time," Mind 58, no. 232 (1949): 483-494. This kind of assumption is ubiquitous in popular discourse. For example, astrophysicists are frequently asked, "What existed before the big bang?" But since the big bang represents the advent of spacetime, this may be a meaningless question. To ask what came before time itself assumes the existence of some kind of metatime. As Stephen Hawking has famously suggested, asking what existed before the Big Bang may be comparable to asking what is south of the South Pole. See Stephen Hawking, "Hawking on the Future of Mankind," BBC News, January 6, 2012, http://news.bbc.co.uk/today/hi/today/ newsid_9672000/9672233.stm

${ }^{58}$ Smart, 484.
} 
itself change, it could itself change only in another time, indefinitely." ${ }^{, 59}$ ) As Smart notes, to ask “[H]ow fast am I advancing through time?" or "How fast did time flow yesterday?" is almost incomprehensible: "What sort of measurements ought we to make? We do not even know the sort of units in which our answer should be expressed. 'I am advancing through time at how many seconds per — ?' we might begin, and then we should have to stop. What could possibly fill the blank? Not 'seconds' surely. In that case the most we could hope for would be the not very illuminating remark that there is just one second in every second."

But by constructing an alternate temporality, a film like Disappearing Music offers one way of thinking through this paradox. It provides a point of departure, a temporal counterpoint that enables us to imagine other speeds at which time could flow. The film advances through time at approximately 1 second per 83 seconds (and so, in contrast, one could argue that "real" time is now moving at 83 seconds per second, at least if Disappearing Music is used as the measuring rod). While Kant emphasized that "different times are not simultaneous, but successive," ${ }^{61}$ Disappearing Music allows one to provisionally experience different temporalities simultaneously. Of course, the film can only be viewed in "real" time, but one's perception of duration is inescapably altered by staring at this universe in which time has been radically transmogrified. That is, the extreme slowness of time in the film seems to bleed through to the real world, and the viewer's own bodily movements unconsciously decelerate in response to Ono’s impossibly slow smile.

One of the most thoughtful analyses of the temporality of film is provided by Jean Epstein, in a short essay entitled "Timeless Time." For Epstein, the cinematograph, by extending

\footnotetext{
${ }^{59}$ Deleuze, Cinema 2, 17.

${ }^{60}$ Smart, 485.

61 Immanuel Kant, Critique of Pure Reason, trans. Paul Guyer and Allen W. Wood (Cambridge: Cambridge University Press, 1998), 179.
} 
or condensing duration, "demonstrates the variable nature of time."62 "[B]y 'laminating' time to demonstrate its extreme malleability," film "seems to free us of terrestrial—that is, solar-time, from whose rhythm, it seemed, nothing would ever dislodge us. We feel introduced to a new universe, to another continuum in which $[\ldots]$ a special time reigns, a local time which constitutes an enclave within earth time, which is itself merely a local time." ${ }^{, 63}$ For Epstein, the fluid temporality of cinema implicitly undermines any attempt to reify time. Film exposes the destabilizing truth that "[t]ime contains nothing that can be called time-in-itself any more than space is comprised of space-in-itself. They are only composed, one as much as the other, of relationships, variable in their essence, between appearances which are produced successively or simultaneously. That is why there can be thirty-six different times and twenty kinds of space just as there can be innumerable specific perspectives depending upon the infinitely diverse positions of objects and their observer." ${ }^{64}$ In other words, cinema is uniquely positioned to expose the contingency (even the arbitrariness) of our temporal coordinates. By radically protracting movement, one imagines other speeds at which the river of time could (perhaps even does) flow. Of course, the fact that time is relative has been understood since Einstein, but film is capable of offering affective access to these radically different temporalities in a way that is unrivaled by any other art form. When viewing Disappearing Music, one does not simply imagine time slowing down - one feels the temporal protraction. As the spectator becomes immersed in a new timescape-one in which there is no movement, only change-bodily processes begin to slow down, and one feels weightless. The screen's unrelenting stasis provokes a hypnagogic reverie in which time itself seems to melt (as if one has entered Dalí's painting The Persistence of Memory [1931]).

\footnotetext{
${ }^{62}$ Jean Epstein, "Magnification and Other Writings," trans. Stuart Liebman, October 3 (1977): 16.

${ }^{63}$ Ibid., 18-19.

${ }^{64}$ Ibid., 20.
} 
Ever since the slow-motion experimentation of Fluxfilms, protracted films have remained a vital and provocative modality within avant-garde cinema. For example, James Broughton and Joel Singer's Hermes Bird displays a penis becoming erect over the course of 11 minutes ("the slowest ascension of a penis that has ever been seen," in Broughton's words ${ }^{65}$ ), while in Michael Snow's See You Later/Au Revoir (1990), an ordinary 30-second farewell is stretched out to over 17 minutes. And in recent years, some filmmakers have taken this process of temporal protraction to new extremes. For example, in James Coleman's film La tache aveugle (The Blind Spot), a very small amount of footage (less than a second) from James Whale's The Invisible Man is slowed down so that each individual frame remains on screen for about 20 minutes (the work as a whole lasts eight hours). Douglas Gordon ups the ante still further with 5 Year DriveBy (1995), in which John Ford's western The Searchers (1956) is radically protracted, resulting in a film that would take an entire five years to screen. ${ }^{66}$ While the Fluxus artists construct an alternate temporality in which it takes over a minute for a second to pass, in La tache aveugle and 5 Year Drive-By, it takes several hours for a second to pass. Obviously, there are crucial distinctions to be made between Disappearing Music and a film like 5 Year Drive-By: for example, the protracted Fluxus films were designed to be seen in their entirety, but it would be practically impossible to see 5 Year Drive-By from beginning to end. Still, several important commonalities inhere in protracted cinema. These experiments in filmic duration all use extreme slow motion to derive stasis from flux, thus opening up opportunities to reflect on microtime, interstitial moments which regularly escape our perceptual awareness. Protracted films also manufacture alternate temporalities which modulate the experience of duration, effectively

\footnotetext{
${ }^{65}$ James Broughton, All: A James Broughton Reader, ed. Jack Foley (Brooklyn: White Crane Books, 2006), 162.

${ }^{66} 5$ Year Drive-By was meant to be displayed on a drive-by movie screen in Utah's Monument Valley. However, Gordon's ambitious desire to display the film in its entirety has not yet come to fruition-only part of the work has been screened.
} 
unmasking the contingency of time itself. If, as André Bazin asserts, "[F]ilm delivers baroque art from its convulsive catalepsy, ${ }^{, 67}$ protracted cinema represent a renewed embrace of the cataleptic. By stilling the incessant movement of mainstream cinematic praxis, these films eschew momentum, and instead seek to excavate the multiplicity of the momentary.

${ }^{67}$ André Bazin, "The Ontology of the Photographic Image," in What Is Cinema? Volume I, trans. Hugh Gray (Berkeley and Los Angeles: University of California Press, 2005), 14-15. 


\section{CHAPTER 4}

\section{STRUCTURING TIME: MICHAEL SNOW'S SO IS THIS AND THE TEXTUAL FILM}

"Unlike a book in your hand, a film keeps on going whether you like it or not. For it has an existence of its own. A microcosm larger than life, its boundaries are boundless." - James Broughton $^{1}$

"The film of tomorrow will be lettrist and composed of subtitles. If at its conception cinema was by virtue of its images an attack on reading, the day will come when the cinema will be a mere form of reading." - Isidore Isou ${ }^{2}$

Marcel Duchamp's Anémic Cinéma (1926) is one of the most unusual films ever made, even by the standards of the early European avant-garde. It is partly comprised of a series of filmed roto-reliefs, vertiginous rotating spirals moving at variety of speeds. If this were Anémic Cinéma's sole content, it would be a compelling abstract film in the tradition of Walter Ruttmann's Lichtspiel Opus I (1921), Hans Richter's Rhythmus 21 (1921), and Viking Eggeling's Symphonie Diagonale (1924). However, the shots of the roto-reliefs are interspersed with shots of ostensibly nonsensical written text: spinning phrases replete with alliteration, puns, and sexually suggestive double entendres (see Figure 1). Here is a sampling of Duchamp's Dadaist wordplay:

\footnotetext{
${ }^{1}$ Quoted in Follow Your Own Weird, 31.

2 Quoted in Thomas Y. Levin, "Dismantling the Spectacle: The Cinema of Guy Debord," McDonough, 441-442. Italics in original. The passage is taken from Isou's obscure 1954 film Apology of a Unique Personality (Apologie d'un personnage unique).
} 
The child who nurses is a sucker of hot flesh and does not like the cauliflower of the hot glass-house.

If I give you a penny, will you give me a pair of scissors [i.e. a fuck]?

Incest or family passion, in blows too drawn out.

Have you ever put the marrow of the sword into the stove of the loved one $?^{3}$

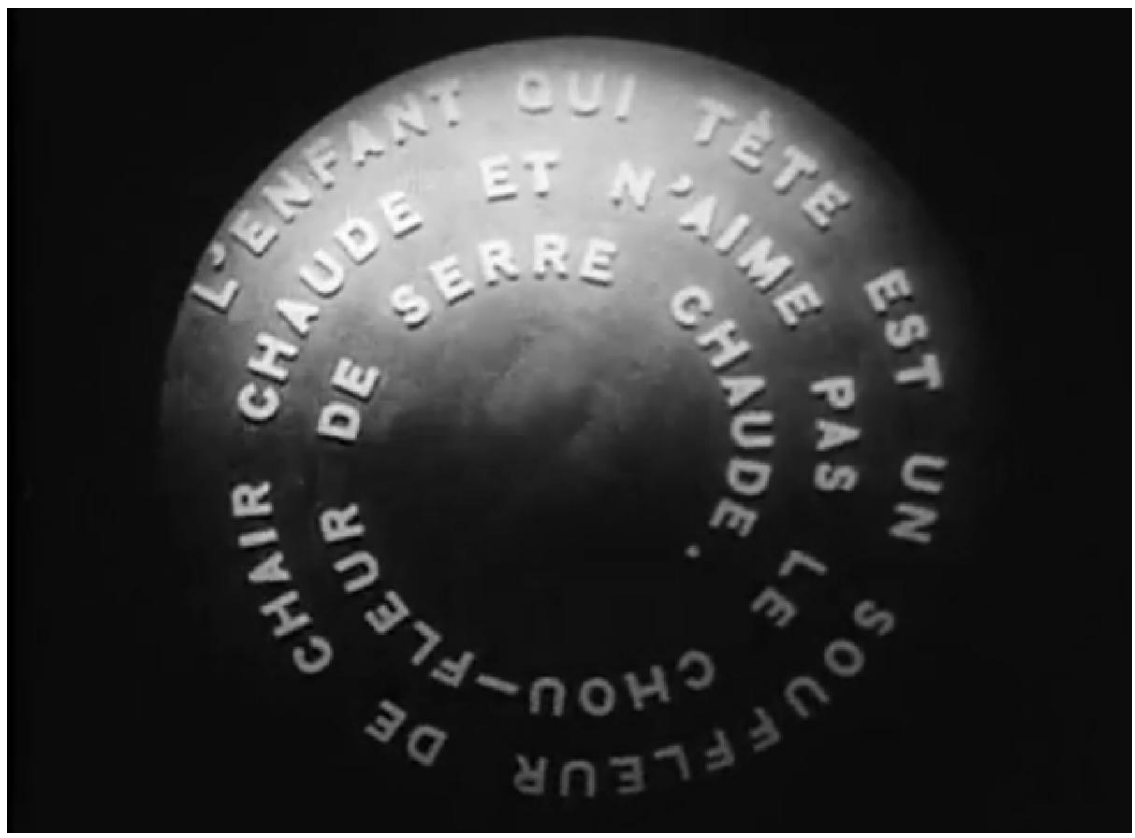

Figure 1: Marcel Duchamp, Anémic Cinéma (1926)

The centrality of language in Anémic Cinéma challenged the widespread assumption that imagery—whether abstract or representational—was to be film's sole currency. Duchamp's cinematic vision was far more inclusive. He clearly sided with Surrealist poet Robert Desnos,

\footnotetext{
${ }^{3}$ Translations from the French text are taken from Katrina Martin, "Marcel Duchamp's Anémic Cinéma," Studio International 189, no. 973 (1975): 53-60. Given the complexity and polysemy of the original French text, Martin correctly points out that a faithful English translation of Anémic Cinéma is "impossible."
} 
who asserted, "Everything that can be projected on the screen belongs in the cinema, letters as well as faces."4

Written text in a film was nothing new, of course - text had frequently been used in cinematic introductions, credit sequences, and intertitles. Indeed, intertitles were so ubiquitous in the era of silent cinema that the handful of films that disavowed from them-such as F.W. Murnau's The Last Laugh (1924), Dimitri Kirsanoff's Ménilmontant (1926), and Dziga Vertov's Man with a Movie Camera-were the exceptions that proved the rule. ${ }^{5}$ Still, Anémic Cinéma's use of text departed dramatically from its predecessors. Unlike conventional cinematic text, Duchamp's language served no narrative (or even paratextual) purpose. Instead, the function of the words was primarily poetic (or, in the spirit of Dadaism, anti-poetic). Text no longer needed to be relegated to a subservient role-in the post-Duchampian world, the written word could be just as central to a film as imagery. ${ }^{6}$ The door had been opened for a new kind of cinema: the textual film. Rather than being composed of photographic or animated imagery, these works would foreground letters, words, numbers, punctuation marks, and other forms of written or typographical text — challenging what Hollis Frampton has called the "logophobia" endemic to cinema and other visual arts. ${ }^{7}$

\footnotetext{
${ }_{5}^{4}$ Quoted in P. Adams Sitney, "Image and Title in Avant-Garde Cinema," October 11 (1979): 102.

5 And silent films without intertitles did not necessarily forgo written text altogether. For example, as Scott MacDonald points out, Murnau still managed to smuggle written language into The Last Laugh "within the imagery." See Scott MacDonald, ed. Screen Writings: Scripts and Texts by Independent Filmmakers (Berkeley: University of California Press, 1995), 2.

${ }^{6}$ Although P. Adams Sitney has called Anémic Cinéma "[t]he first film within the tradition of the avant-garde to claim equality of title and image" (see Sitney, "Image and Title," 102), there is arguably a precursor to Duchamp's experiment in Charles Sheeler and Paul Strand's Manhatta (1921), which combines documentary footage of Manhattan with poetic intertitles. One might reasonably contend, however, that the text of Manhatta serves as a commentary on the film's images, and is thus more closely allied with traditional narrative intertitles — ones which are subservient to cinematic imagery - than Duchamp's more autonomous text.

Interestingly, Man Ray, who assisted Duchamp in the filming of Anémic Cinéma, would go on to make several films of his own that used written text for poetic (rather than diegetic) effect, such as L'Étoile de Mer (The Starfish) (1928) and Les Mystères du Château de Dé (The Mysteries of the Chateau of Dice) (1929).

${ }^{7}$ Hollis Frampton, "Film in the House of the Word," October 17 (1981): 61.
} 
The prominence of text in avant-garde film has received a fair amount of scholarly attention. $^{8}$ However, the implications of these intermedia experiments have not yet been adequately theorized. I want to argue that text-based cinema both challenges widespread preconceptions of what a film can do (and be), while highlighting cinema's unique ability to modulate duration. Nowhere are the theoretical implications of textual cinema made clearer than in Michael Snow's So Is This, a self-referential film in which individual words appear on screen, one at a time, gradually forming a series of statements which are alternately philosophical, facetious, and false. I will claim that textual films like So Is This help to demonstrate the folly of ontologies of cinema that prescribe necessary conditions. I will also argue for a more Wittgensteinian approach to conceptualizing film, one that recognizes the boundless elasticity of concepts like film and language. However, before analyzing So Is This, it will be useful to situate the work within the broader context of Snow's cinematic oeuvre.

One of the most undertheorized elements in Snow's aesthetic is his fascination with stasis. In some of his films, movement is minimal, as is the case in Dripping Water (1969) (codirected with his wife, Joyce Wieland) in which the only movement portrayed is water dripping into a dish. ${ }^{9}$ In other Snow films, the movement is extremely slow, giving the viewer an impression of stasis. (Snow's protracted films include his widely revered Wavelength, a 45minute zoom from one end of a room to another, and See You Later/Au Revoir, in which an ordinary 30 -second farewell is expanded to 18 minutes.) And Snow is not afraid to push his interest in stasis to its logical conclusion: in several of his films, there is no on-screen movement

\footnotetext{
${ }^{8}$ The most notable scholar in the field of text-based cinema is undoubtedly Scott MacDonald. In addition to the aforementioned Screen Writings, see his "Text as Image in Some Recent North American Avant-Garde Films," Afterimage 13, no. 8 (1986): 9-20.

${ }^{9}$ Dripping Water appears to be a cinematic interpretation of George Brecht's event score Drip Music (Drip Event) (1959), the instructions for which simply read, "A source of dripping water and an empty vessel are arranged so that the water falls into the vessel." See Friedman, Smith, and Sawchyn, 22. Snow's film represents a distinctive "performance" of Brecht's score, however, since the water falling into the vessel and the dripping heard on the sound track are deliberately asynchronous.
} 
at all. One Second in Montreal (1969) consists only of photographs, Side Seat Paintings Slides

Sound Film (1970) offers only paintings, and A Casing Shelved is simply a color slide of a bookshelf accompanied by Snow's voice describing the items on it. Clearly, Snow is intent on challenging conceptions of cinema which see movement as its essence. As he puts it, "The basis of cinema as a technology is stasis; the fundamental unit is the still photograph. Motion is made from the perception of fast stills." 10

Snow's fascination with cinematic stasis is particularly salient in So Is This. This "motion picture" is motionless and pictureless - it consists only of immobile typographical text. ${ }^{11}$ In other words, So Is This serves as a reminder that both imagery and movement are merely contingentnot necessary_components of film. Like so many of the static films thus far considered, what is preeminent here is not movement, but duration. In fact, Snow has claimed that "controlling durations" is the starting point of his cinematic practice, and that So Is This and One Second in Montreal represent his "purest uses of duration."12 As the text itself indicates, "The / decision / has / been / made / to / concentrate / on / the / distinctive / capacity / of / film / to / structure / time."13 While Snow is correct to assert that film has a unique ability "to / structure / time," film's status as "a time form" (to borrow Maya Deren's memorable phrase) ${ }^{14}$ has been challenged by some theorists. Thus, before making an argument about the temporality of textual films (and of cinema writ large), it will be necessary to address these criticisms.

\footnotetext{
${ }^{10}$ Michael Snow, e-mail to author, October 21, 2011.

${ }^{11}$ It is worth noting that not all textual films are static. For example, the text of Richard Serra and Carlotta Fay Schoolman's Television Delivers People (1973) continuously scrolls from the bottom of the screen upwards, in the style of closing credits.

${ }^{12}$ Annette Michelson and Michael Snow, "The Sound of Music: A Conversation with Michael Snow," October 114 (2005): 56.

${ }^{13}$ Slashes do not appear in So Is This. However, the fact that words only appear one at a time is destabilizing for the reader/viewer. I use slashes when quoting from the film to elicit a comparable reading experience, one that is stilted and desultory.

${ }^{14}$ Deren, "Cinematography," 160.
} 
The most prominent argument against film's status as a temporal art form runs like this: "Everything takes place in time. Therefore, film is only temporal in the trivial sense that everything is temporal. After all, even paintings and sculptures must be looked at for a certain duration (even if it is a very brief one) in order to be apprehended." One of the most prominent proponents of this view is Anthony McCall (most famous for his seminal work of expanded cinema Line Describing a Cone [1973]). In McCall's view, “[E]verything that occurs, including the process of looking and thinking, occurs in time and [...] therefore, the distinction [between temporal and atemporal art] is absurd." ${ }^{\prime 15}$ This is a seductive claim, one that is worthy of careful attention. Here is a more extended version of McCall's argument:

Everything that occurs, including the (electrochemical) process of thinking, occurs in time. [...] Art that does not show change within our time-span of attending to it we tend to regard as 'object.' Art that does show change within our time-span of attending to it we regard as 'event.' Art that outlives us we tend to regard as 'eternal.' What is at issue is that we ourselves are the division that cuts across what is essentially a sliding scale of time-bases. A piece of paper on the wall is as much a duration as the projection of a film. Its only difference is in its immediate relationship to our perception. ${ }^{16}$

There is a great deal that McCall gets right here. He is certainly correct, for example, to point out that everything that happens happens in time. He is also right to suggest that there is a certain anthropocentrism subtending our distinctions between temporal and atemporal media: what we call an "object" and what we call an "event" is largely contingent on our own human time-span. (Of course, the obvious rejoinder to this claim would be: Why shouldn't it be? What other timespan should we use as a measuring rod?) I even think McCall is correct to suggest that a piece of

\footnotetext{
15 Anthony McCall, "Line Describing a Cone and Related Films," October 103 (2003): 56.

${ }^{16}$ Anthony McCall, "Two Statements," in The Avant-Garde Film: A Reader of Theory and Criticism, ed. P. Adams Sitney (New York: New York University Press, 1978), 252-253.
} 
paper on a wall may be more like a film than common sense would suggest, insofar as they are both likely to offer visual changes over a period of time-even if the piece of paper undergoes change at a rate that is beyond the realm of immediate human perception. (And is this not precisely the insight underlying Tony Conrad's Yellow Movies (1972-73), in which paper covered in cheap paint is presented as a quasi-cinema-screen, so that the viewer can imagine the white paint slowly turning yellow over the course of several decades ${ }^{17}$ )

In spite of these insights, I think McCall is ultimately mistaken to claim that paper on a wall is "as much a duration as the projection of a film." They may both endure for a period of time (as all things do), but there is a crucial difference: films offer a predetermined and structured duration, while paper does not. A filmmaker can modulate duration, deciding how long a spectator will see a given object or event, but this is not an option for an experimental artist who places pieces of paper on a wall. Obviously, there is no guarantee that a spectator will watch a film in its entirety, from beginning to end (and as I argued in Chapter 2, certain filmmakers, like Warhol, neither expect nor encourage this kind of spectatorship). Still, regardless of what a viewer may choose to do, a film has a fixed temporal structure, a predetermined durational unfolding that distinguishes it from traditional visual art.

Of course, So Is This is a remediation of written text, not visual art, and reading a book is temporally distinct from viewing a film, since the reader has more control over the rate of a work's durational unfolding. ${ }^{18}$ Nevertheless, text remains temporal in a way that traditional

\footnotetext{
${ }^{17}$ In the theorizations of Jonathan Walley, works like Conrad's Yellow Movies would be considered "paracinema," since they "recognize cinematic properties outside the standard film apparatus," and thus find "cinematic qualities or effects in nonfilmic materials." See Jonathan Walley, "The Material of Film and the Idea of Cinema: Contrasting Practices in Sixties and Seventies Avant-Garde Film," October 103 (2003): 15-30. See also Walley's "The Paracinema of Anthony McCall and Tony Conrad," in Avant-Garde Film, ed. Alexander Graf and Dietrich Scheunemann (Amsterdam: Editions Rodopi, 2007), 355-382.

${ }^{18}$ I borrow the term remediation from Jay David Bolter and Richard Grusin, who use it to describe the McLuhanesque appropriation of one medium by another. See Remediation: Understanding New Media (Cambridge: MIT Press, 1999).
} 
visual art is not. Unlike a painting or a sculpture, text (along with film, drama, music, etc.) generally has an inherent trajectory that must be followed for a work to be apprehended. Unlike, say, One Second in Montreal, which temporalizes photography, or Side Seat Paintings Slides Sound Film, which temporalizes painting, So Is This uses the temporal medium of film to remediate another temporal medium: the book. ${ }^{19}$ This raises the obvious question: "Why?"-a query that Snow anticipates: "One / question / which / the / author / expects / is: / 'Why / would / anyone / want / to / do / such / a / thing / as / this?' / followed / by / 'Wouldn't / a / book / be / better?"" This question implicitly hints at its own answer: by cinematizing written text itself (rather than the content of a particular text), Snow impels us to consider the distinctions between the two media. And the viewer gradually comes to the realization that the most salient distinction between the textual film and the written word resides in their varying temporal structures. As Mary Ann Doane notes, "So Is This asserts its difference from a book through its rigorous control of the time of reading. The slowness or the rapidity of the appearance of new words on the screen is a play with filmic temporality and audience anticipation.",20

Indeed, if one sees the film version of So Is This in addition to reading the script, ${ }^{21}$ it is striking just how different the experiences are (even though they both involve reading the same text). For example, the reader of the script can set her own pace: she may choose to skim certain passages while reading others more carefully and deliberately. But this is not an option in So Is This. As Snow points out, "The number of frames per word and spaces between was precisely indicated. It's composed." ${ }^{22}$ Because of this careful structuring of cinematic temporality, a reader

\footnotetext{
19 Throughout this chapter, I will use the term book as a convenient shorthand for referring to all traditionally typographical mediums, including magazines, journals, newspapers, text-based websites, and e-books.

${ }^{20}$ Mary Ann Doane, "The Indexical and the Concept of Medium Specificity," differences: A Journal of Feminist Cultural Studies 18, no. 1 (2007): 137. Italics added.

${ }^{21}$ The text of So Is This can be found in MacDonald, Screen Writings, 140-155.

${ }^{22}$ Snow, e-mail to author, October 21, 2011.
} 
is forced to accept Snow's pacing. At times, this means spending an inordinately long time staring at a single word. For example, at one point in the film, the text reads, "One / of / the / interests / of / this / system / is / that / each / word / can / be / held / on / the / screen / for / a / specific / length / of / time." While most of the words in the film remain on the screen for just a second or two, the word length in this passage remains in place for almost an entire minute (see Figure 2). The eye becomes so tired of viewing the word that it begins to lose its semantic content and simply become an abstract series of shapes and squiggles. By the time the sentence finally completes itself, only alert viewers will remember how it began. On the other hand, certain words appear on only a single frame of the filmstrip, and as a result, inattentive spectators may miss them entirely. This is most evident in the film's assault on the Ontario Board of Censors, which had previously banned Snow's four-and-a-half-hour 'Rameau's Nephew' by Diderot (Thanx to Dennis Young) by Wilma Schoen (1974) for its graphic sexual imagery: "This / is / the / start / of / a / new / paragraph / from / which / any / children / present / should / shield / their / eyes. / Since / this / film / was / tits / originally / composed / ass / The / Ontario / Board / of / Censors / has / started / to / inspect / so-called / Experimental / Films. / e.g. / This. / Its [sic] / difficult / to / cock / understand / why / but / it / seems / as / if / their / purpose / is / to / protect / you / from / this. / To / protect / you / from / people / like / cunt / the / author / discussing / their / sexual / lives / or / fantasies / on / this / screen." ${ }^{23}$ The taboo words here appear on the screen for only a split second, making it easy to miss them altogether. Unlike the word length, which feels weighty and laborious as a result of being on the screen for such an extended period of time, words like cock and cunt, because of their brief duration, seem sharp, caustic, and affectively

\footnotetext{
${ }^{23}$ In fact, So Is This goes so far as to address Mary Brown, the censor who banned 'Rameau's Nephew,' by name: "Hello / Censors, / Hi / Mary. / This / Film / is / as / clean / as / a / whistle. / Ha / Ha / Ha/ Ha / (Hollow / laughter). / This / film / wouldn't / say / shit / if /its / mouth / were / full / of / it. / Gulp." The "Gulp" in this passage simultaneously expresses Snow's fear of censorship (the nervous gulp) and his utter defiance of censorial strictures (the evocation of coprophagia).
} 
jarring-even more so than usual. Through his control of the film's temporal structure, then, Snow is able to modulate the pre-existing connotations of words, slightly altering the "flavor" of each one. (The flavor metaphor, incidentally, is borrowed directly from Snow: "I hope that the spectators can savour the many duration forms that happen in So Is This. There are spicy ones, salty ones, sweet ones, etc. ${ }^{, 24}$ )

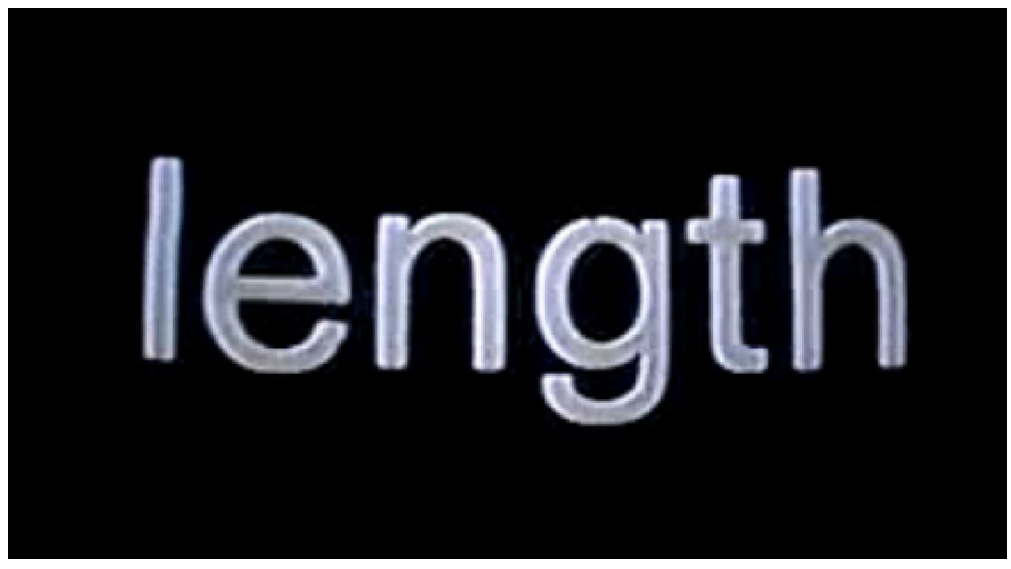

Figure 2: Michael Snow, So Is This (1982)

When struggling to read Snow's taboo words, which appear for only a split-second, one is immediately reminded of another temporal distinction between books and films. In addition to permitting a reader to set his own pace, books allow the reader to return to previous passages in order to "catch" words or ideas that might have been missed the first time — or perhaps to review passages that were particularly compelling or confusing. But the durational unfolding of a film does not permit this. It proceeds at its own pace, indifferent to the demands of the audience. (Of course, the modern media environment complicates such distinctions: films like So Is This are increasingly viewed online, which does permit one to easily scroll back and catch passages that were initially missed.) Snow's strict durational control is what makes a screening of So Is This

\footnotetext{
${ }^{24}$ Snow, e-mail to author, October 21, 2011.
} 
such a compelling experience. Since sentences become subdivided into the individual words that make them up, each word takes on a renewed importance, including words which are normally skimmed over, such as articles, prepositions, and conjunctions. In fact, these words are in larger typeface - and thus more visually dominant - than the more sesquipedalian words that Snow uses (e.g. semiological, Psychoanalytical, Incommunicado). Additionally, the experience becomes more participatory than more conventional modes of reading. In part, this is because the deliberateness (and relative slowness) with which each word appears encourages the audience to play a guessing game, hypothesizing about what direction a sentence will move in and what words will appear next. Scott MacDonald describes this dimension of the film perceptively: "In So Is This, Snow controls time-as all filmmakers do-and we are at his mercy. We cannot know what a sentence means until its over; as a result, Snow's one-word-at-a-time structure forces viewers to construct a meaning, then reconstruct it, as individual words are revealed. Indeed, since the meaning of words is determined by their contexts within sentences, we cannot even be sure how a particular word is to be understood until subsequent words have been revealed.",25

So Is This calls attention to still another key distinction between reading a text and viewing a textual film: reading a book is almost always a solitary activity, while watching a film tends to be communal. Again, this situation has changed a great deal in the past several years, and I must confess that I watch more films alone (via the Web, DVD, etc.) than I do in group settings. Still, one can experience a film with other people in a way that is simply not possible with a book. One can certainly read along with someone else, but the experience is not the same.

\footnotetext{
${ }^{25}$ MacDonald, Screen Writings, 137. In addition to this implicit form of audience participation, there are points in the film when participation is explicitly encouraged - for example, when audience members are incited to sing together in their minds: "Let's / all / raise / our / mental / voices / mutely, / mutually / in / song / (please / don't / move / your / lips). / Ready? / 1 / 2 / 3 / 4: / 'Some / where / o / ver / the / rain / bow / skies / are / blue..."”
} 
I have read parts of a book with a friend reading over my shoulder, for example, but invariably, the experience is temporally asynchronous, if only slightly: one of us will laugh before the other has reached the humorous passage, for example. But given the fixed duration of film, responses become concomitant. As Snow puts it, "Usually the tempo of reading depends on the reader, so it seemed interesting to use film to control the duration of reading because control of duration is a capacity of film, not of a book. ${ }^{, 26}$ And the fact that communality is a concern of Snow's is hinted at in several passages in So Is This: "Warning: / This / film / may / be / especially / unsatisfying / for / those / who / dislike / having / others / read / over / their / shoulders." And later on in the film: "When / was / the / last / time / you / and / your / neighbour / read / together? / This / is / Communal / reading! / it’s [sic] / Group / Lit!",27

As the expression "Group / Lit" implies, So Is This represents a remediation of literary text (broadly defined). One is immediately reminded of Marshall McLuhan's famous claim that the contents of one medium are "always another medium. The content of the press is literary statement, the content of the book is speech, and the content of the movie is the novel." ${ }^{28}$ McLuhan seems to be making the (somewhat myopic) assertion that films remediate novels insofar as they offer extended narratives (ones which occasionally directly adapt novelistic content). This claim clearly has little relevance to avant-garde cinema, which often has closer ties to poetry—or even music or painting - than the novel. Still, what is interesting about textual films is the way that they adapt "literary" content in radically new ways. Rather than attempting

\footnotetext{
${ }^{26}$ Snow, e-mail to author, October 21, 2011.

${ }^{27}$ A rather different form of cinematic "Communal / reading" arises when an audience watches a foreign film with subtitles. Since entire phrases or sentences are usually displayed (as opposed to the word-by-word approach favored by Snow), reading rates can vary slightly, resulting in two kinds of temporal asynchrony: (1) Individual spectators may read at different speeds, leading some to apprehend textual content before others, and (2) spectators may experience a "delay," reading the textual translation of a piece of dialogue before or after it is spoken. (For example, when watching foreign films, I often find myself quickly reading the subtitles with enough time remaining to anticipate how the actor or actress will deliver the lines I have just read.)

${ }^{28}$ McLuhan, Understanding Media, 305.
} 
to translate written text into visual imagery, these films provide written text as visual imagery.

To better appreciate this distinction, consider traditional remediations of the Bible, Western culture's most influential text (or, more accurately, collection of texts). Biblical narratives have been one of the primary sources of cinematic content, from early films about the life of Jesus by Thomas Edison and Louis Lumière to Hollywood blockbusters like Cecil B. DeMille's Samson and Delilah (1949) and The Ten Commandments (1956). But contrast these films to Andy Warhol's proposed cinematic remediation of the Bible. I am not speaking here of his eight-hour Imitation of Christ (1967) (a work which has only a tenuous connection to the Biblical narrative), but of an unrealized project entitled Warhol Bible. Warhol planned on filming each individual page of the Bible, long enough to be read, before displaying the next page. (The film's running length would have been a full 30 days!) It is not clear whether or not Warhol ever seriously planned to bring this project to fruition; it is quite possible that the idea itself fascinated him more than its actualization. In any case, Warhol Bible draws attention to the variety of ways that one medium can be appropriated by another. One need not "translate" the language of text into the language of cinema — one can simply film text directly. The most frequently repeated cliché about filmic adaptation is the claim that "the book was better than the movie." Would it even make sense to compare the two in the case of Warhol Bible? ${ }^{29}$

Warhol's proposition does differ slightly from a film like So Is This. While Snow's words are naked, displayed in isolation from any kind of cinematic imagery, Warhol Bible would still have foregrounded photographic indexicality, in its "capturing" of actual pages from a Bible. In

\footnotetext{
${ }^{29}$ Warhol Bible appears to be a kind of practical joke, although this should not diminish its status as a serious meditation on the distinction between text and cinema. Since most viewers would hear the title and expect some kind of Warholian interpretation of Biblical stories (using actors, sets, dialogue, and so on), the absurdly literal content of the film would subvert these expectations. In fact, the idea for Warhol Bible is strongly reminiscent of the aforementioned Fluxus film 12! Big Names!, in which spectators were lured into the theater by flyers that promised they would see "big names"- - like Warhol and Snow - only to be disappointed when they realized that the event was simply a textual film that displayed the stars' names in typographical text, one at a time.
} 
this sense, Warhol Bible has closer affinities to a textual film like Hollis Frampton's Poetic Justice, in which the pages of a film script are displayed on a table, one at a time, so that, as Allen S. Weiss describes it, "paratext serves as text." 30 This explains why Snow does not mention Frampton in So Is This during the list of filmmakers who "concentrate / on / texts": "Richard / Serra, / Tom / Sherman, / Su / Friedrich, / John / Knight / and / Paul / Haines" -Snow alludes exclusively to "films (and videotapes) that featured only text, that had no pictorial element." ${ }^{31}$ It is the very fact that So Is This has no explicit pictorial element that allows the text itself to become pictorialized. The letters and words of Snow's films are not merely the carriers of semantic information, but also visual experiences in their own right, typographic formations with a host of aesthetic of affective valences.

In some films, the idea of words as an aesthetic (rather than semantic) cinematic element is taken to extreme levels, resulting in text that cannot even be read. One of the earliest examples of this is Joseph Cornell's By Night with Torch and Spear, a collage film in which text plays a prominent role. (The film appears to have been made in the 1940s, although the exact date is uncertain.) Cornell displays footage of camels, caterpillars, and workers in a steel factory, but these images are occasionally broken up by upside-down intertitles that appear and disappear very quickly. Cornell's rigid temporal structure prevents one from reading much of the text, and as a result, it simply becomes a part of the film's atmosphere. Similarly, Paul Sharits' Word Movie (1966), a film comprised entirely of seemingly random words accompanied by flickering

\footnotetext{
${ }^{30}$ Allen S. Weiss, “Poetic Justice': Formations of Subjectivity and Sexual Identity," Cinema Journal 28, no. 1 (1988): 50. Textual films like Poetic Justice are often characterized as "new talkies," experimental films from the 70s and beyond that foreground language. (See, for example, J. Hoberman, "After Avant-Garde Film," in Art After Modernism: Rethinking Representation, ed. Brian Wallis [New York: The New Museum of Contemporary Art, 1984]: 66.) However, I do not find this designation particularly helpful, since what was novel about the original talkies was not language per se, but spoken language and aural synchronicity-elements that are altogether absent from silent textual films like Poetic Justice and So Is This. To his credit, Noël Carroll (who appears to be originator of the term new talkie) categorizes Poetic Justice as a structural film. See Noël Carroll, "Interview with a Woman who...," Millennium Film Journal 7/8/9 (Fall 1980/1981): 37.

${ }^{31}$ Snow, e-mail to author, October 21, 2011.
} 
light, moves at such a frenetic pace (one word per frame) that it is simply impossible to read the vast majority of the words that appear. One can make out individual words from time to time, but for the most part, the information overload results only in a fleeting visual impression of shapes and flashes. $^{32}$

Clearly, By Night with Torch and Spear and Word Movie offer textual experiences that are quite distinct from So Is This - in Snow's film, every word can be read and comprehended, so long as the viewer pays close attention. Still, Snow seeks to excavate more from his words than simply their semantic content. As was mentioned before, words that appear for prolonged durations lose their meaning and begin to become abstract shapes. (Recall Warhol's maxim: "[T]he more you look at the same exact thing, the more the meaning goes away." ${ }^{33}$ ) And since small words like of and is are in very large typeface, the pictorial qualities of each individual letter become foregrounded. This was one of Snow's goals: "The hope was that the changes in scale from word to word will help the spectator to see each word as an individual shape, a pictograph, a picture — but also as a shot. Reading, as we learn it, is not 'seeing,' not 'regarding,' so I wanted to introduce pictorial/design perception as well as 'reading.", 34

But one of the most important questions raised by textual films in general—and So Is This in particular-is "What is a film?" Since Snow breezily jettisons many of the components that have traditionally been thought to be necessary conditions of film (both movement and imagery), what is left, exactly? What are the implications of So Is This (and other static and textual films) for the ontology of cinema?

\footnotetext{
32 Another film that is worth mentioning here is Takahiko Iimura's White Calligraphy (1967), in which characters from The Kojiki, an $8^{\text {th }}$ century Japanese text, are scratched directly into the film stock and displayed in rapid succession. As Iimura points out, it is not possible to read the film's text, even if one is fluent in Japanese: "Certain characters can be read, but not all of them; it's too fast." See MacDonald, “An Interview with Taka Iimura," 26.

${ }^{33}$ Warhol and Hackett, POPism, 64.

${ }^{34}$ Snow, e-mail to author, October 21, 2011.
} 
At the very least, such films should make us wary of any attempt to define cinema through recourse to necessary conditions (i.e. " $x$ is a film if, and only if, it has the following properties"). Many film theorists have found themselves caught in the trap of drawing strict boundary lines around their object of study, only to have those boundaries challenged by some forward-thinking filmmaker or new technology. The result is a series of (more or less) pointless debates about whether $x$ is a true film. Noël Carroll is one of the chief offenders here. In his essay "Defining the Moving Image," he argues that there are five necessary conditions that must be met for something to be accurately categorized as a film. In the interest of time, I will give consideration to only two of them, as this should be sufficient to make my point. $x$ is a film, according to Carroll, "only if $x$ belongs to the class of things from which the impression of movement is technically possible., ${ }^{, 35}$ As I have already argued in Chapter 1, this claim is problematic. Movement is not possible in So Is This-it is a static film. Carroll might respond that So Is This is still projected by an apparatus with the capacity for movement. But what if, after attending a screening of So Is This, I discovered that the particular version that I saw was not displayed via a movie projector, but rather a precisely timed slide projector (or some comparable technology that offered no technical capacity for movement)? Would it then be necessary to revoke the work's cinematic credentials? And Carroll offers another problematic necessary condition of cinema, one that strikes me as exceedingly strange: " $x$ is a moving image only if it is two-dimensional." ${ }^{36}$ In Carroll's view, then, is Francis Ford Coppola's Captain EO (1986) only a film if I watch it without my 3-D glasses on? And if 3-D movies do not "count" as a counterexample to this claim, what would? What about Anthony McCall's Line Describing a Cone, in which the three-dimensional projected light itself becomes the film? And what if future

\footnotetext{
${ }^{35}$ Carroll, "Defining the Moving Image," 130.

${ }^{36}$ Ibid., 130.
} 
technologies enable the creation of "hologram" films, which would literally exist in three dimensions? It is hard to know how Carroll would be able to respond to these questions without falling prey to the no-true-Scotsman fallacy. ${ }^{37}$

This kind of thinking is so widespread that even someone like McCall, who consistently challenges rigid definitions of film with his innovative works of expanded cinema, falls into the trap of prescribing necessary conditions. For example, in 1975, McCall claimed, "Line Describing a Cone deals with one of the irreducible, necessary conditions of film: projected light." 38 This claim has not aged well. Given the ubiquity of films watched on TVs, computer screens, and iPods in the modern era, few would continue to argue that light must be projected in order for a film to exist. (And this is not to mention a film like Walter Ruttmann's Weekend, which features no light at all, but merely an audio track of "found" sounds accompanied by a blank screen.) Of course, it would be anachronistic to expect McCall to foresee future technological developments. But this is precisely the problem with demarcating boundaries around what a film is or can be: since any conception of cinema is necessarily limited by the technological and aesthetic practices that happen to be current at any given time, one can often mistake the contingent for the necessary. Does anyone doubt that 50 years from now, new technologies and innovative filmmakers will have pushed the boundaries of cinema in still new directions, ones which are simply unthinkable today? And this should be seen as a welcome development, not some bothersome challenge to ontological or theoretical dogmas. Concepts are not immutable, discrete entities created by a Deity with strict predetermined functions; they

\footnotetext{
${ }^{37}$ Here is a succinct summation of the fallacy by Antony Flew, who originally conceptualized it: "No Scotsman would do such a thing. But one did. Well, no true Scotsman would." See Antony Flew, A Dictionary of Philosophy, rev. $2^{\text {nd }}$ ed. (New York: St. Martin's Press, 1984), 251. Italics in original. In the context of Carroll's argument, the fallacy might look something like this: "No film is three-dimensional. But Line Describing a Cone is threedimensional. Well, no true film is three-dimensional."

${ }^{38}$ McCall, "Two Statements," 250.
} 
evolve over time and continually adapt to varying intellectual and cultural environments. The concept film is no exception. There is simply no need to speculate about every future development in cinematic praxis before offering a tentative conception of film, so long as one does not paint oneself into a corner by insisting on inflexible boundaries.

But what is the alternative? How can we speak coherently about film without precisely defining our object of study? Ludwig Wittgenstein's famous discussion of games should provide solace to anyone who is troubled by such questions. In one of the most memorable passages of Philosophical Investigations, Wittgenstein points out that while we have little trouble using and understanding a term like game, this does not imply that there are any necessary conditions for something to classified as such:

Consider, for example, the activities that we call "games." I mean board-games, cardgames, ball-games, athletic games, and so on. What is common to them all?-Don't say: "They must have something in common, or they would not be called 'games"”-but look and see whether there is anything common to all.--For if you look at them, you won't see something that is common to all, but similarities, affinities, and a whole series of them at that. [...] I can think of no better expression to characterize these similarities than "family resemblances"; for the various resemblances between members of a familybuild, features, colour of eyes, gait, temperament, and so on and so forth-overlap and criss-cross in the same way.-And I shall say: "games" form a family. ${ }^{39}$

This is precisely the approach one should take in understanding what films are. Films can be incredibly diverse: black and white or color, silent or sound, moving or static, photographic or textual, two-dimensional or three-dimensional, and so on. But as diverse as films can be, they

\footnotetext{
${ }^{39}$ Ludwig Wittgenstein, Philosophical Investigations, Revised $4^{\text {th }}$ ed., eds. P.M.S. Hacker and Joachim Schulte, trans. G.E.M. Anscombe, P.M.S. Hacker, and Joachim Schulte (Oxford: Wiley-Blackwell, 2009), 36. Italics in original.
} 
nevertheless have clear family resemblances that conceptually link them. And we come to understand these resemblances inductively, not deductively. As Wittgenstein puts it, "How would we explain to someone what a game is? I think that we'd describe games to him, and we might add to the description: 'This and similar things are called 'games.",40 And is this not also how we might explain to someone what a film is? There is no need to draw rigid (and arbitrary) boundaries; film, in Wittgensteinian parlance, is "a concept with blurred edges."41

I am not the first film theorist to evoke Wittgenstein in arguing for an amorphous and evolving conception of cinema. In his book The Virtual Life of Film, D.N. Rodowick also astutely asserts that "cinema studies can stake no permanent claims on its disciplinary territories; its borders are in fact continually shifting." 42 He elaborates: "Every medium consists of a variable combination of elements. In this respect, moving image media are related more by a logic of Wittgensteinian family resemblances than by clear and essential differences."43 However, Rodowick does not seem to be fully convinced by his own argument. Consider, for instance, his comments on Stan Brakhage's seminal film Mothlight (1963). To create this innovative work, Brakhage collected the wings of dead moths, blades of grass, dirt, and other miscellany, and taped them directly to the filmstrip. The result is a kind of cinematic alchemythe ordinary objects become utterly transformed by their magnification, luminosity, and spatiotemporal arrangement, and the film's frenetic succession of images creates an experience of rare aesthetic force. Mothlight would seem to be a prime example of a filmmaker "shifting" the borders of cinema, a bold reimagining of what a film can do or be. Yet Rodowick seems to challenge Mothlight's status as a film, claiming that "films of unrecognizable or nearly

\footnotetext{
${ }^{40}$ Ibid., 37. Italics in original.

41 Ibid., 38.

${ }^{42}$ D.N. Rodowick, The Virtual Life of Film (Cambridge: Harvard University Press, 2007), 23.

${ }^{43}$ Ibid., 86.
} 
unrecognizable images such as Peter Gidal's Room Film (1973) remain films, while Stan Brakhage's Mothlight (1963) is rather a motion sculpture animated by the projection apparatus."44 This is a puzzling distinction. Brakhage's original creation could certainly be conceptualized as a kind of sculpture, but why would running this work through a projector fail to produce a film? (Recall that Hollis Frampton once provisionally defined film as "whatever will pass through a projector." ${ }^{45}$ ) To be sure, Mothlight is radically different from a more traditional film, like, say, Casablanca (1942), but is there not a clear family resemblance here? As a careful reader of Wittgenstein might point out, solitaire and basketball offer very different experiences, but they both remain games.

Wittgenstein represents an important influence on textual films in general and Snow's cinema in particular. ${ }^{46}$ Like Wittgenstein, Snow dismantles facile conceptual taxonomies that resort to necessary conditions. By creating films without movement, films without imagery, films without filmstrips, and so on, Snow consistently challenges our preconceived notions of cinema. Consider the aforementioned A Casing Shelved, which presents a single stationary slide of a bookcase accompanied by Snow's recorded voice describing it. As I mentioned in Chapter 1, Carroll has questioned the cinematic credentials of $A$ Casing Shelved: "I would argue that this 'film' is not a film at all; to be a film, properly so called, requires the literal possibility of movement." ${ }^{47}$ When I interviewed Snow about Carroll's contention, I found his response to be impeccably Wittgensteinian. Rather than pedantically obsessing about necessary conditions,

\footnotetext{
${ }^{44}$ Ibid., 59. Italics in original.

${ }^{45}$ Frampton, On the Camera Arts, 137.

${ }^{46}$ Snow has mentioned his interest in Wittgenstein in numerous interviews. For example, see "Information or Illusion: An Interview with Michael Snow," in The Michael Snow Project: The Collected Writings of Michael Snow (Waterloo, Ontario: Wilfrid Laurier University Press, 1994), 85; "The Camera and the Spectator: Michael Snow in Discussion with John Du Cane," in The Michael Snow Project, 88; and "Michael Snow," in Scott MacDonald, A Critical Cinema 2: Interviews with Independent Filmmakers (Berkeley: University of California Press, 1992), 75. For an extended analysis of Wittgenstein's influence on Snow's non-cinematic visual art, see Elizabeth Legge, "Taking it as Red: Michael Snow and Wittgenstein," The Journal of Canadian Art History 18, no. 2 (1997): 68-88.

${ }^{47}$ Carroll, "Philosophizing through the Moving Image," 185.
} 
Snow simply said, "A Casing Shelved is categorically problematic. However, it is a projection on a screen from a $35 \mathrm{~mm}$ transparent source. There is no movement on the screen, but the movements of the eyes of the spectator are directed by the sound — my voice. That there is sound, which is a movement in time, is important in considering the work's cinema status. ${ }^{.48}$ In addition to drawing our attention to the family resemblances between A Casing Shelved and more traditional fare, Snow usefully reminds us of the deeply entrenched bias towards the visual that subtends most theories of cinema. It seems absurd to claim that a work with visual movement but no possibility of sound (e.g. Stan Brakhage's The Riddle of Lumen [1972]) is not a film. Yet somehow it seems more defensible to claim that a work with sound but no possibility of visual movement (like A Casing Shelved) is not a film. Ultimately, either claim rests on an unwarranted assumption that we must draw strict boundaries around the concept of film. It is hard to improve on Wittgenstein's formulation in The Blue Book (one of his studies for Philosophical Investigations): "If $[\ldots]$ you wish to give a definition of wishing, i.e., to draw a sharp boundary, then you are free to draw it as you like; and this boundary will never entirely coincide with the actual usage, as this usage has no sharp boundary. ${ }^{49}$ The same is true of film. Theorists are free to draw prescriptive boundaries, and filmmakers are free to ignore them-in much the same way that traditional grammarians are free to insist that splitting an infinitive results in an ungrammatical sentence, while everyday speakers of English are free to completely disregard this rule. The concept of a film (like the concept of a grammatical sentence) is continually evolving. The word has no fixed definition, nor should we wish to place it in such a conceptual

\footnotetext{
${ }^{48}$ Snow, e-mail to author, October 21, 2011. Italics in original. Snow's conception of sound as a kind of auditory "movement" echoes a remark made by Daniel, the protagonist of Isidore Isou's Treatise on Slobber and Eternity (Traité de bave et d'éternité) (1951): "Who ever said that the cinema, whose meaning is movement, must absolutely be the movement of the photograph and not the movement of the word?" Quoted in Levin, 345. Italics in original.

${ }^{49}$ Ludwig Wittgenstein, "The Blue Book," in Major Works, trans. C.K. Ogden (New York: HarperCollins, 2009), 109.
} 
straightjacket. As Wittgenstein puts it, "We are unable clearly to circumscribe the concepts we use; not because we don't know their real definition, but because there is no real 'definition' to them. To suppose that there must be would be like supposing that whenever children play with a ball they play a game according to strict rules."50

In addition to stretching our predetermined notions of what a film can do, So Is This is equally intent on stretching our notions of what language can do. On both accounts, Snow challenges the facile generalizations that we easily fall prey to (films tell stories, language communicates information, etc.). Wittgenstein's account of the malleability and infinite diversity of language in Philosophical Investigations is especially apposite here: "Think of the tools in a toolbox: there is a hammer, pliers, a saw, a screwdriver, a rule, a glue-pot, glue, nails, and screws. - The functions of words are as diverse as the functions of these objects." ${ }^{, 51}$ A few pages later, Wittgenstein elaborates: "But how many kinds of sentences are there? Say assertion, question, and command? - There are countless kinds; countless different kinds of use of all the things we call 'signs,' 'words,' 'sentences.' And this diversity is not something fixed, given once for all; but new types of language, new language-games, as we may say, come into existence, and others become obsolete and get forgotten." 52 So Is This introduces us to a host of new language games. While the standard uses of sentences all make an appearance — assertion ("This / is / communal / reading!"), question ("Is / there / anybody / reading / this / right / now?") and command ("Just / think / of / this / as / entertainment") —-there are also playful uses of words that represent apparently novel language games. Consider an unusual passage near the end of the film, where Snow announces that he will provide "ten / solo / words" (before going on to provide

\footnotetext{
${ }^{50}$ Ibid., 116. Italics in original.

${ }^{51}$ Wittgenstein, Philosophical Investigations, 10.

${ }^{52}$ Ibid., 15. Italics in original.
} 
twenty-five) $)^{53}$ : “And / Now; / ten / solo / words: / Coffee / Whisper / Psychoanalytical / Sunlight / Sodomy / Chalk / Blast / Mind / Duke / Mohammedan / Braille / Blink / Simulacrum / Hiss / Mask / Annihilation / Lips / Truth / Cuneiform / Choir / Flesh / Liturgy / Cave / Flower / Incommunicado." Putting these words in sequence appears to produce nonsense, an ungrammatical word salad that offers no meaning. Of course, in the words of evolutionary biologist Stephen Jay Gould, "Humans are pattern-seeking animals," 54 so it is difficult to read this sequence of words without searching for some kind of organizing principle (e.g. Is the "Cave" Plato's cave, where there is no "Sunlight," and "Simulacrums" replace "Truth"?) But such a hermeneutic framework risks playing one language game by the rules of another. What is important here is not meaning, but flavor: not only the "spicy," "salty," or "sweet" connotations of each word individually, but also (in the spirit of Eisensteinian montage) the novel connotations that arise as a result of Snow's unusual juxtapositions. As Wittgenstein has noted, nonsensical language can still have a measured and deliberate effect on hearers (or readers), depending on what kind of language game is being played: "When I say that the orders 'Bring me sugar!' and 'Bring me milk!' have a sense, but not the combination 'Milk me sugar,' this does not mean that the utterance of this combination of words has no effect." 55 Similarly, Snow's unusual combinations of words may be senseless, but there is still a clear effect on the audience. Of particular interest is how many of the words in this passage relate to various forms or methods of communication_-"Whisper," "Chalk," "Braille," "Hiss," "Lips," "Cuneiform"even though the passage itself communicates nothing (and ends with a word that evokes a lack of communication: Incommunicado). Both in content and form, this passage reminds the viewer of

\footnotetext{
${ }^{53}$ This is not the only occasion on which the text proves to be untrustworthy. Early in the film, we read, "This / film / will / be / about / two / hours / long," even though actual the running length of So Is This is less than 50 minutes.

${ }^{54}$ Stephen Jay Gould, Bully for Brontosaurus: Reflections in Natural History (New York: W.W. Norton \& Company, 1992), 60.

${ }^{55}$ Wittgenstein, Philosophical Investigations, 146.
} 
the multiplicity of linguistic modalities, the infinite diversity of language games that can be played.

In its recourse to nonsense, So Is This is reminiscent of Duchamp's enigmatic evocations of cauliflower, mosquitoes, incest, and Eskimos in Anémic Cinéma. It is also parallels another textual film released in the same year that So Is This was: Peter Rose's Secondary Currents (1982). Like So Is This, Secondary Currents visually offers nothing more than typographical text, although in this case, the text is accompanied by a soundtrack, one in which a voice is heard speaking a non-existent language. The on-screen text undergoes a kind of linguistic entropy. The film's words are initially fairly straightforward ("I don't remember when the voice began"), but lucid language eventually gives way to incomprehensible jargon ("whose meandering lucubrations / foretold the essential entropy / of euphostolic processes and peregrinations / reinvitriafied by the subcholate stratifications / of an ecstatic generative demuneration"). Eventually, we are left with apparently aleatory combinations of words and punctuation marks: "frisson eldo bas erra ti gon / ship to antel k trio lo montre / pi 1 like s k soke sl abqu ek / dko tj s abi. tu n kto / rt l px ex: s s at l/ t-thel /: kethe ls o / ke lnc i ! u a je t s le / ee tri-sit pn vo tep.” By the end of the film, the screen is littered with random letters and punctuation marks. ${ }^{56}$ Of course, Duchamp's nonsense (grammatically correct yet cryptic wordplay) is distinct from Snow's nonsense (an agrammatical string of words), and both are distinct from Rose's nonsense (random letters and punctuation marks which do not even form recognizable words or morphemes). This

\footnotetext{
${ }^{56}$ For the text of Secondary Currents, see MacDonald, Screen Writings, 162-174. Rose, like Snow, was also influenced by Wittgenstein's philosophy. In fact, after Secondary Currents, Rose released another film about the progression from meaning to nonsense, entitled The Pressures of the Text (1983), which ends with a quotation from Wittgenstein: "Whereof one cannot speak, thereof one must be silent."

I should also briefly note that Rose's early films have a clear precursor in the writings of Samuel Beckett, who was similarly interested in the breakdown of language and meaning. This debt to Beckett is explicitly indicated in Secondary Currents, when one of the sentences reads, "given the existence as uttered forth by" - a direct quotation from the beginning of Lucky's rambling nonsensical soliloquy in Waiting for Godot. See Samuel Beckett, Waiting for Godot: A Tragicomedy in Two Acts (New York: Grove Press, 1982), 45.
} 
diversity supports Wittgenstein's contention that there is no limit to the number of language games we can play — even nonsense is not a single game, but rather, a collection of different games with different rules (or perhaps no rules at all). As Wittgenstein points out, "Even a nonsense poem is not nonsense in the same way as the babble of a baby. ${ }^{, 57}$

While I am unable to catalogue all of the language games that Snow plays throughout So Is This (there are far too many), it will be instructive to give attention to one additional example. Contra Wittgenstein's claim that '[t]he demonstrative 'this' can never be without a bearer," Snow refuses to identify the this of the film's title—or at least, if there is an identity, it seems to continually shift. Consider some of the sentences that appear early in the film: "This / is / the / title / of / this / film." "The / rest / of / this / film / will / look / just / like / this." "This, / as / they / say, / is / the / signifier." There is an inescapable and unresolved ambiguity in these sentences. For example, when the film asserts that "this $[\ldots]$ is / the / signifier," we are left wondering: what is the signifier, exactly? The word this? The language Snow is using? The medium of film itself? Or perhaps all of the above? Snow exploits the same linguistic loophole that was foregrounded by René Magritte when he painted his landmark La trahison des images (The Treachery of Images) (1928-1929), in which a straightforward painting of a pipe is accompanied by text that reads, "Ceci n'est pas une pipe" ("This is not a pipe"). The confusion that the painting frequently engenders (If this is not a pipe, then what is it?) comes from the ambiguity of the word this (ceci) - a viewer might initially interpret this as the representational content of the painting (which clearly is a pipe), but this can also mean the painting itself (which, of course, is most emphatically not a pipe). ${ }^{59}$ In the post-Wittgensteinian universe that Snow inhabits, neither

\footnotetext{
${ }^{57}$ Wittgenstein, Philosophical Investigations, 103.

58 Ibid., 25.

${ }^{59}$ Snow acknowledges his debt to Magritte in So Is This, in a passage written entirely in French: "Ça / fait / penser / l'auteur / au / tableau / bien / connu / de / Magritte: / Ceci / n'est / pas / une / pipe. / C'est / vrai / ici / aussi. /
} 
words nor films have single fixed meanings, functions, or essences - rather, concepts are fluid and in a state of continual flux. Snow puts it this way: "Language lives-grows, bulges, shrinks, learns to talk, loses its hair [...] [T]here is a sense in which the cloudiness at the edges of the compendium of definitions of Art, which is especially noticeable, is also discernible on examination of all definitions." 60

Throughout this chapter, I have claimed that textual films blur the boundaries separating the mediums of literature and film; however, certain media theorists—-such as Noël Carroll— have challenged the very coherence of terms like film medium and the medium of literature. In his essay "Forget the Medium!" Carroll contends that "strictly speaking, there is no single and/or distinctive medium of film from which the film theorist can extrapolate stylistic directives; at best there are film media, some of which perhaps await invention even now."61 Carroll is certainly correct to note that there are a multiplicity of media that can be used to display a film (e.g. celluloid, analog video, digital video, etc.). However, I disagree with Carroll when he claims, "Talk of the (one and only) medium with respect to an artform, then, is generally a misleading simplification or abstraction." ${ }^{62}$ It is certainly a simplification, but I would argue that is generally a useful simplification, not a misleading one. Think of how we use the term art. If I were to visit The Guggenheim and make a generalization about $20^{\text {th }}$ century art, an interlocutor could certainly interject, “Ah, but don't you mean the $20^{\text {th }}$ century arts, since there are numerous artforms from that century, including painting, photography, dance, film, music, etc.?" I might feel compelled to use the plural form simply to pacify this pedant, but in everyday language, it is

L'auteur / amait / beaucoup / le / mot / 'ceci."” ("It / makes / the / author / think / of / the / well / known / painting / by / Magritte: / This / is / not / a / pipe. / It's / true / here / also. / The / author / likes / the / word / "this' / a / lot.") My translation.

${ }^{60}$ Michael Snow, "Trying to Figure It Out," in The Michael Snow Project, 280. Italics in original.

${ }^{61}$ Noël Carroll, "Forget the Medium!," in Engaging the Moving Image (New Haven: Yale University Press, 2003), 7.

${ }^{62}$ Ibid., 7. Italics in original. 
understood that the term art, though technically singular, refers to a multiplicity of artforms. And so it is with the term medium. No one would deny that there is technically more than one medium of film, yet the term film medium can nevertheless serve as a convenient shorthand for denoting this broad array of media forms (conceptually linked via a Wittgensteinian "family resemblance").

Carroll takes issue with references to the medium of literature, as well, albeit for very different reasons: he makes the counterintuitive claim that literature "does not appear to have a medium at all." ${ }^{, 63}$ Anticipating that this assertion will be greeted with skepticism, Carroll elaborates, "Suppose that words do constitute the medium of literature. They could hardly amount to a distinctive artistic medium. For words are shared with all types of speech and writing, on the one hand, and by all sorts of artforms, including theater, opera, song, and even some painting and sculpture, on the other hand." ${ }^{, 64}$ One should immediately notice the rhetorical leap that Carroll makes here- he begins by claiming that literature has no medium at all, before making the less ambitious (and less interesting) claim that words are not limited to literature. But whoever thought they were? I find Murray Smith's rebuttal of Carroll on this point useful, so I will quote him at length:

Can we not say that words play a uniquely central role in the artform of literature, a role they do not characteristically play in any other artform? After all, some works of literature make use of pictorial devices - think of examples of "pattern" or "concrete poetry" in which words are arranged on the page in order to form striking, sometimes depictive patterns. George Herbert's "Easter Wings" is one such poem; Guillaume Apollinarie's Caligrammes form a collection of them. But we would not be tempted to

\footnotetext{
${ }^{63}$ Ibid., 3.

${ }^{64}$ Ibid., 3. Italics in original.
} 
say that Herbert's work is a painting rather than a poem, any more than we would be tempted to say that Michael Snow's So Is This (1982), a film comprised entirely of shots of words, is a poem rather than a film. If the issue of the medium of a work is as incidental or irrelevant as Carroll contends-if it can be eliminated — what would stop us from thinking of Herbert's work as a painting and Snow's work as a poem? Why do we not say these things? Because we recognize that the word (in Herbert's case) and the cinematographic image (in Snow's case) are somehow foundational to the enterprises of each, even if they are being used to unusual ends, in both cases. ${ }^{65}$

As Smith points out, the fact that the medium of language may play a prominent role in several artforms (including textual films like So Is This) is no reason to dismiss its significance as the medium (or at least $a$ medium) of literature. In his counterargument to this claim, Carroll doubles down on his original position, attempting to downplay the role that the medium plays in influencing our categorization of a given artwork. In Carroll's view,

We categorize So Is This as a film because we know the tradition in which Snow is working. It fits into an ongoing conversation about the nature of cinema. If Milton's Paradise Lost were recorded on film — a page being turned every thousand frames or so - and, if that was the only form in which it existed, we would not call it a film, but a poem. The same would be true if Ezra Pound initially "published" his Cantos on film. Our classifications depend far more on history and what we know of the author's intentions than upon that through which medium the work is delivered. ${ }^{66}$

\footnotetext{
${ }^{65}$ Murray Smith, "My Dinner with Noël; or, Can We Forget the Medium?" Film Studies 8 (2006): 142. Italics in original.

${ }^{66}$ Noël Carroll, "Engaging Critics," Film Studies 8 (2006): 162. The infelicitous grammar of this final sentence is quoted directly from Carroll's text.
} 
It is difficult to know how to respond to this peculiar claim. To begin, it seems to rest on a false dichotomy: that a textual film must be either a film or a poem. Why could it not be simultaneously both? In fact, some scholars have written about cine-poetry or the poetry-film as a way of conceptualizing works that that straddle the boundary between these two artforms. ${ }^{67}$ The idea that something - literary or otherwise — might be "recorded on film" but not called a film is perplexing.

Presumably, Carroll is implying the following: if Ezra Pound had released Cantos on film, it would be called a poem, but if he instead decided to publish Cantos as a book, and Andy Warhol later created Warhol Cantos, this would fit "into an ongoing conversation about the nature of cinema" and would now be a film. If this seems like a defensible distinction, imagine the following scenario: I tell my wife that I am going upstairs to see what our son is doing. When I open the door to his bedroom, I find that his DVD player is running, and I see my son eating popcorn while gazing intently at his television screen. On the screen I see only the pages of an opened book with typographical text on it. I return downstairs, and my wife asks me, "What is he doing?" Acceptable answers to this question include "Watching TV," "Watching a film," or even "Watching some really weird film that just shows the pages of a book." But imagine if I responded to my wife's query by saying, "I honestly do not know. I will need to do some research to learn more about the historical circumstances and authorial intent of the object of our son's inquiry before I am in any position to determine what kind of artwork he is engaging with." She would be absolutely justified in worrying about my mental health.

In spite of the criticisms I have been leveling at Carroll, he performs a valuable service when he draws attention to the amorphousness and mutability of terms like medium and film. As

\footnotetext{
${ }^{67}$ See, for example, William C. Wees, "Words and Images in the Poetry-Film," in Words and Moving Images, eds. William C. Wees and Michael Dorland (Montreal: Mediatexte, 1984), 105-113. In this chapter, I favor the term textual film over poetry-film, since poetry is not the only text-based medium that cinema can appropriate.
} 
intermedia hybrids like So Is This (and other textual films) continue to remind us, these terms are constantly being reanalyzed and renegotiated, and it is useful to remember this inherent semantic instability when theorizing about their properties. In fact, interrogating artworks which challenge conventional media boundaries is perhaps the preeminent method of coming to understand a given medium. As David Campany puts it, "[W]e come to know what media are less by looking for their pure centres than their disputed boundaries." "68 Film has no "pure centre," no essence, no rigid boundaries demarcating its territorial domain. But film is in good company here. As Wittgenstein so perceptively notes, “Many words [...] don't have a strict meaning. But this is not a defect. To think it is would be like saying that the light of my reading lamp is no real light at all because it has no sharp boundary."69

\footnotetext{
${ }^{68}$ David Campany, "Posing, Acting, Photography," in Stillness and Time: Photography and the Moving Image, eds. David Green and Joanna Lowry (Manchester: Photoforum/Photoworks, 2006), 98.

${ }^{69}$ Wittgenstein, “The Blue Book," 119. Italics added.
} 


\section{CHAPTER 5}

\section{COLORED BLINDNESS:}

\section{DEREK JARMAN'S BLUE AND THE MONOCHROME FILM}

"[T]here is more than one blue, and more than one meaning of blue." - Barbara Rose ${ }^{1}$

"There is no such thing as an empty space or an empty time. There is always something to see, something to hear." - John Cage ${ }^{2}$

Just a few months before dying of AIDS, Derek Jarman released Blue, one of the most profound meditations on death in the history of cinema. The viewer sees nothing more than a monochromatic blue screen for the duration of the film's seventy-six minutes, while the sound track provides ambient music, poetry, sound effects, and autobiographical musings. In part, the film potently evokes the blindness that gradually overtook Jarman during his struggle with AIDS. Further, it represents a tribute to the French artist Yves Klein, who produced a series of monochromatic paintings in his trademark color, IKB (International Klein Blue). ${ }^{3}$

Blue is a static film, albeit one which is distinct from those discussed so far. The films of Warhol and Fluxus offer motionless objects or individuals, while static textual films like Snow's So Is This provide immobile typographic text. However, Blue offers no image at all-or, if there is an image, it is simply the cobalt-blue cinema screen itself. (This is why Vivian Sobchack

\footnotetext{
${ }^{1}$ Barbara Rose, "The Meanings of Monochrome," in Monochromes: From Malevich to the Present, ed. Valerie Varas (Berkeley: University of California Press, 2004),

${ }^{2}$ Cage, Silence, 8 .

3 Klein manufactured IKB with the assistance of paint chemist Edouard Adam in 1955. For more on Klein's influence on Jarman, see Tony Peake, Derek Jarman (Woodstock, NY: Overlook Press, 2000), 196, 398-400.
} 
maintains that, strictly speaking, Blue is "not image-less," but "figure-less." ) Drained of any visual content or movement, Jarman's film instead offers an ostensible void, an absence, a retreat from representation. In other words, Blue is a monochrome film, a cinematic work which visually presents nothing more than a field of color. In this chapter, I want to consider the implications of remediating monochromatic paintings in cinema, while also exploring the symbolic and affective valences of color itself. While there are numerous monochrome films worthy of close consideration, I will focus primarily on Blue - not only because it is a uniquely poignant and engaging film, but also because it raises important questions about the role of cinematic stasis in the digital age.

The rich history of the monochrome in the realm of painting is well known-it is a tradition that includes seminal works like Kazimir Malevich's Black Square (1915) and Suprematist Composition: White on White (1918), Robert Rauschenberg's White Paintings (1951), and Yves Klein's blue monochromes, such as IKB 191 (1962). ${ }^{5}$ However, this tradition has seen cinematic expression far more often than one might expect. For example, Nam June Paik's Zen for Film consists of a blank white screen and a completely silent sound track. ${ }^{6}$ Robert Huot's Red Stockings (1969) offers three minutes of Kodachrome red, broken up only once by a single frame of a woman's crotch (although the intensity of Huot's red produces flickering green afterimages every time the spectator blinks). Ma (Intervals) (1977), a film by Takahiko Iimura, alternates between black and white screens for its 24-minute duration (the purity of the

\footnotetext{
${ }^{4}$ Vivian Sobchack, "Fleshing Out the Image: Phenomenology, Pedagogy, and Derek Jarman's Blue," in New Takes in Film-Philosophy, eds. Havi Carel and Greg Tuck (New York: Palgrave Macmillan, 2011), 197.

${ }^{5}$ Any history of the monochrome in art must also give credit to the impish Alphonse Allais, a member of the Société des incohérents. Allais produced A Harvest of Tomatoes on the Edge of the Red Sea Harvested by Apoplectic Cardinals (1884), which was simply a small piece of red fabric on a stretcher, as well as Total Eclipse of the Sun in Darkest Africa (1889), a piece of blue fabric. Given his remarkably innovative and prescient work, it is unfortunate that Allais is not as well known as his successors, such as Malevich and Rauschenberg.

${ }^{6}$ Throughout this essay, I classify solid black or solid white screens as monochromatic. While color is often contrasted to black and white in the discursive practices of film and media, I will here favor a broader definition of color which sees black and white as chromatic options on a par with any other that a filmmaker might use.
} 
monochromes is intermittently threatened by a single off-center vertical line). And in Dan McLaughlin's Red/Green (1985), a monochromatic red color field slowly changes to green over the course of about five minutes. ${ }^{7}$

More radical still is Tony Conrad's series of Yellow Movies, such as Yellow Movie 2/1626/73 (1973), which consists only of cheap white paint on paper which is outlined to look like a movie screen. Obviously, these are works that stretch the definition of cinema to its breaking point; however, since the term movie carries with it expectations of duration, one becomes reminded of the temporal dimensions of paint itself (especially cheap paint), the way that it fades over time. (The white paint has yellowed significantly since the work's inception.) Yellow Movie is organic, meditative, and immersive - it is also a practical joke. One of the most common insults leveled at bad films is, "It's like watching paint dry." Here is a film that is not simply like watching paint; one is watching paint. It is little wonder, then, that Conrad calls Yellow Movie "a comedy." ${ }^{\prime 8}$ Monochrome films like these would have perhaps provided the ideal cinematic experience for someone like Theodor Adorno, who once quipped, "I love to go to the movies; what I can't stand are the images."9

What are the aesthetic and theoretical implications of these experiments? Noël Carroll has persuasively argued that "[t]he point of many still films is reflexive — to point to aspects or elements of film that are often neglected (like narration in the case of Ôshima [Band of Ninja] or

\footnotetext{
${ }^{7}$ Even though films like $\mathrm{Ma}$ (Intervals) and Red/Green technically feature more than one color, I would still classify them as monochromatic, since in both cases, only one color dominates the screen at any given moment.

Red/Green was the second version of a monochrome film that McLaughlin created entitled The Only Minimal Conceptual Structuralist Color Field Dissolve Film Done to a Rag Time Tune (1980). McLaughlin claims that one of his primary concerns in these works was blurring the lines between film and painting. Dan McLaughlin, telephone interview with author, April 24, 2011. Both films appear to be based on Fluxus artist George Brecht's event score Two Durations (1961), the instructions for which simply read, "red / green." See Friedman, Smith, and Sawchyn, 23.

${ }^{8}$ Tony Conrad, "Yellow Movie 2/16-26/73," The Museum of Modern Art Multimedia, http://www.moma.org/ explore/multimedia/audios/53/1024. For more on Conrad's yellow movies, see Christopher Müller and Jay Sanders, eds. Tony Conrad: Yellow Movies (New York: Greene Naftali Gallery, 2008).

${ }^{9}$ Quoted in Annette Michelson, “Frampton's Sieve," October 32 (1985): 166.
} 
scripting in the case of Frampton [Poetic Justice]). Subtracting movement from the visual array is a way of leading viewers - or at least certain kinds of viewers-to these reflexive observations." ${ }^{10}$ Along similar lines, by withholding motion, as well as any visual representation, monochrome films like Blue draw attention to color itself. Unlike, say, the 1930s—when black and white was the norm, and films like Rouben Mamoulian's Becky Sharp (1935) delighted audiences with their bold, assertive palettes - color has for decades been the default in cinema, and as such, it easily becomes invisible. But paradoxically, Blue-a film about the loss of vision — enables us to see a color that we had previously been blinded to. Jarman foregrounds the color blue as a color, and thus encourages the viewer to become lost in its affective and associative dimensions.

Before considering the cultural valences of the color blue per se, however, it will be useful to examine the significations of color writ large. In the West, color has often been seen as a marker for difference or alterity. This is why David Batchelor, in his book Chromophobia, notes that Western culture has historically harbored a deep distrust of color, a distrust made manifest in color's association with marginalized Others: "Colour is made out to be the property of some 'foreign' body - usually the feminine, the oriental, the primitive, the infantile, the vulgar, the queer or the pathological." ${ }^{11}$ The link between color and alterity has also been noted by Tom Gunning, who asserts that in film, "color signifies difference itself." 12

Jarman's own homosexuality - as well as his queer politics-designated him an unambiguous cultural Other, particularly in Margaret Thatcher's Britain. The fact that Jarman

\footnotetext{
${ }^{10}$ Carroll, "The Essence of Cinema?" 328.

${ }^{11}$ David Batchelor, Chromophobia (London: Reaktion Books, 2002), 22-23.

12 Tom Gunning, "Colorful Metaphors: The Attraction of Color in Early Silent Film," Fotogenia 1 (2004): 250. Gunning cites the example of color in The Wizard of $\mathrm{Oz}$ (a film that had a strong impact on Jarman when he saw it as a child). In the film, there is a sharp contrast between Kansas, which is a mundane sepia tone, and the otherworldly $\mathrm{Oz}$, which is overflowing with bright, vibrant colors.
} 
linked color to his own queerness is seen in many of his writings. For example, in the introduction to his Wittgenstein (1993) script, he writes, "The forward exploration of Colour is Queer,"13 and in his book Chroma (which features a series of meditations on color), he declares, "Colour seems to have a Queer bent!"14 Blue is nothing if not an embrace of color itself, and for Jarman, this is simultaneously an embrace of his own sexual identity. It is unsurprising, then, that Jarman conceptualizes color as decidedly prelapsarian:

Turfed out of the Garden of Eden for a snack by the unpleasant new God, [Adam and Eve] found themselves in a colourless world. Remember them as you buy a dozen Granny Smiths. There were few colours in the wilderness. At that time God hadn't even sent a rainbow begging for forgiveness. ${ }^{15}$

The "unpleasant new God" that Jarman alludes to is, of course, the same Old Testament God who advocates the stoning of homosexuals - the God whose stringent moral dualism results in a "black and white" universe. For the atheist Jarman, then, color and non-normative sexuality both exist without shame before the invention of God and sin. Jarman's longing for this utopian world is evident throughout his films, which consistently seek to counteract fear of the Other (homophobia, chromophobia, etc.). This stretches from his first feature-length film, Sebastiane (1976), with its explicit depictions of homosexuality, to his final film, Blue, with its privileging of color over line. ${ }^{16}$

\footnotetext{
${ }^{13}$ Quoted in Steven Dillon, Derek Jarman and Lyric Film: The Mirror and the Sea (Austin: University of Texas Press, 2004), 225.

${ }^{14}$ Derek Jarman, Chroma: A Book of Color (Woodstock: The Overlook Press, 1994), 58.

${ }^{15}$ Ibid., 63.

${ }^{16}$ Jarman's fascination with color is further revealed by the fact that he planned on making another monochromatic film after Blue (which was to be called either Demonology or Hell on Earth) which would have featured a red color field. Jarman described it as "a scarlet film in a choking hellfire: smashing glass, madness, a horror film with HIV as a conscious beast rustling around, hysteric laughter, Beelzebub, legions, PCP is summoned, HELL ON EARTH, red generated from sulphur, demonology." See Derek Jarman, Smiling in Slow Motion (Minneapolis: University of Minnesota Press, 2011), 312. Unfortunately, Jarman died before this idea was brought to fruition.
} 
But why does Jarman select blue for his first monochrome film rather than any other color? What does it represent? In a sense, this is a misleading question. As Tracy Biga suggests, Jarman deliberately frustrates any attempts to pin blue down to a single symbolic meaning: "It is variously a color, a person or agent, a mood, a concept and a thing." ${ }^{17}$ Such semiotic slipperiness is central to Jarman's vision. Yves Klein too was wary of attempts to tease a symbolic meaning out of his blue monochromes: 'Novices keep asking me: 'But what does it represent?' I could answer, and I did so in the beginnings [sic], that it simply represents blue, by itself...This is not inaccurate; it is, in my opinion, of the greatest importance." ${ }^{\prime 18}$ In other words, there is a sense in which monochromatic blue, both for Klein and Jarman, can be seen as decidedly asymbolic. What is important is not what the color represents, but its affective power, its ability to induce serenity and contemplation.

While Klein understandably does not want his art to be reduced to a simplistic symbolic meaning, "blue, by itself" can never really exist by itself. That is, even blue's affective dimension is propelled and informed by the various significations that it has been acquiring over the centuries. (As Henri Bergson notes in Matter and Memory, "Perception is never a mere contact of the mind with the object present; it is impregnated with memory-images which complete it as they interpret it." ${ }^{\prime 19}$ ) Consequently, an interrogation of the art of Klein and Jarman necessarily entails an analysis of the symbolic and associative dimensions of the color blue, even though neither Klein's paintings nor Jarman's film should be interpreted as facile symbolic gestures. For example, in viewing Klein's art, one's experience is inevitably colored by blue's

\footnotetext{
${ }^{17}$ Tracy Biga, "The Principle of Non-Narration in the Films of Derek Jarman," in By Angels Driven: The Films of Derek Jarman, ed. Chris Lippard (Westport, CT: Praeger Publishers, 1996), 26.

${ }^{18}$ Yves Klein, Overcoming the Problematics of Art: The Writings of Yves Klein, trans. Klaus Ottmann (New York: Spring Publications, 2007), 138.

${ }^{19}$ Henri Bergson, Matter and Memory, trans. Nancy Margaret Paul and W. Scott Palmer (Lawrence, KS: Digireads, 2010), 73.
} 
association with tranquility-viewing an IKB monochrome is peaceful and contemplative. Jarman's Blue evokes this mood, as well (and this sense of calm is often complemented by the soothing ambient tones on the sound track); however, the film's blue screen simultaneously engenders impatience and frustration. This is partly due to the temporal nature of film, the fact that Jarman (unlike Klein) forces us to look at the color blue for an extended duration. But this sense of frustration is also likely linked to our frequent encounters with blue screens while waiting for a VHS tape or a DVD to begin, an important paratextual element which shapes our affective response to the film. The blue screen marks a period of transition, of waiting for movement to signal that a film has begun. Of course, when viewing Blue, we recognize that this desire to see movement will be denied, but like Vladimir and Estragon, we still somehow anticipate the arrival of something that will never come. Blue becomes a conceptual waiting room, and as the voiceover in the film indicates, "Hell on earth is a waiting room." Jarman's own poor health forced him to "come to terms with sightlessness" (another expression from the film's sound track), and the spectator is forced to come to terms with it as well. ${ }^{20}$

Blue's association with waiting is clearly culturally contingent, but even its status as a peaceful color is not necessarily immanent - as Michel Pastoureau points out, the association of blue with peacefulness is an historical phenomenon which can be traced back to the Middle Ages. ${ }^{21}$ This development is closely related to another association which began around the $12^{\text {th }}$ century: blue as a marker for the numinous. Before this time, blue was the object of considerable prejudice in the West, "with hardly any role in social life, religious practice, or artistic

\footnotetext{
${ }^{20}$ Another paratextual element worth considering here is the color blue's association with chroma key technology. In analogue film, the blue screen is often used as a neutral backdrop over which anything can be superimposed. Thus, Blue represents an embrace of spectatorial projection, in which the audience can imagine whatever content they like on the empty screen.

${ }^{21}$ Michel Pastoureau, Blue: The History of a Color, trans. Markus I. Cruse (Princeton: Princeton University Press, 2001), 180.
} 
creation." ${ }^{, 2}$ However, the $12^{\text {th }}$ century saw the creation of blue stained glass; it was also the time in which blue became the color of the Virgin Mary's robe in art. ${ }^{23}$ Ever since, blue has been closely associated with the sacred, the divine.

This is clearly important in understanding Klein's art. Klein was deeply religious and mystical, and his own belief in Rosicrucianism was a powerful impetus for his blue monochromes. As Jane Alison notes, Klein's paintings were “a genuine bid for transcendence; an art that attempted to be simultaneously radical and spiritual; an avant gardism of the numinous." 24 For Klein, blue was inextricably linked with the infinite, the immaterial. He took his cue from Kandinsky, who saw blue as the "heavenly colour." 25

It could be argued that Jarman is reaching for something similar. Confronting his own mortality, Blue could represent a yearning for transcendence, a vision of a spiritual realm freed from "the pandemonium of image" (an expression used in Blue). This is essentially how Kate Higginson interprets the film. While Jarman obviously rejects the hegemonic (and homophobic) forms of religion that were commonplace in Thatcher's Britain, for Higginson, this is no reason to completely exclude religiosity as a component of his artistic vision. She reads Blue as "Jarman's attempt to see his way to [...] a habitable, even pleasurable, after-life," 26 a “consolatory vision of a queer h(e)aven." 27 The opening lines of Blue are central to Higginson's reading of the film:

You say to the boy open your eyes

\footnotetext{
${ }^{22}$ Ibid., 14.

${ }^{23}$ Ibid., 35, 49.

24 Jane Alison, Colour After Klein: Re-thinking Colour in Modern and Contemporary Art (London: Black Dog Publishing, 2005), 13.

${ }^{25}$ Wassily Kandinsky, Concerning the Spiritual in Art, trans. M.T.H. Sadler (New York: Dover Publications, 1977), 38.

${ }^{26}$ Kate Higginson, “Derek Jarman's 'Ghostly Eye': Prophetic Bliss and Sacrificial Blindness in Blue," Mosaic 41, no. 1 (2008): 92. Italics in original.

${ }^{27}$ Ibid., 78 .
} 
When he opens his eyes and sees the light

You make him cry out. Saying

O Blue come forth

O Blue arise

O Blue ascend

O Blue come in

Higginson first notes the erotic content of these lines: "Assuming 'you' to be Jarman and the 'boy' to be his lover, the 'light' which engenders a 'crying out' is orgasmic, the 'arising,' 'ascending,' and 'coming in' are phallic and penetrative." ${ }^{28}$ But Higginson also suggests that these lines could have a spiritual dimension, in their evocation of a "boy being bedazzled by a divine blue light." 29 For Higginson, this intersection of spirituality and homosexuality, a persistent theme in Jarman's work, constitutes a "queering of the sacred." ${ }^{30}$

While Higginson's reading of Blue is innovative and compelling, she seems too intent on salvaging some kind of religious impulse from the film. There is no reason to suppose that IKB has the same spiritual import in Blue that it had in the hands of Klein. As Donald Judd notes, "Colour will always be interpreted in a new way...infinite change may be its constant nature."31

\footnotetext{
${ }^{28}$ Ibid., 80 .

${ }^{29}$ Ibid., 81 .

${ }^{30}$ Ibid., 83. Higginson provides other examples of this queering of the sacred in Jarman's work, such as Sebastiane, in which a traditional religious story is told while foregrounding graphic depictions of homosexual encounters, and The Garden (1990), in which Jesus' death is juxtaposed with gay desire. Other notable examples which Higginson does not mention can be found in Jarman's film Jubilee (1977). At one point in the film, a Christ-like figure is at the center of an orgy in Westminster Cathedral, a scene which echoes the climax of Luis Buñuel's L'Âge d'Or (The Golden Age) (1930). At the same cathedral, a man dressed as the pope engages in homosexual foreplay. And Jarman's visual art queers the sacred in similar ways. For example, in Flesh Tint, a traditional artistic representation of Jesus is largely masked by what appears to be a used condom.

${ }^{31}$ Quoted in Alison, 10.
} 
And this sentiment is echoed by Jarman himself in Chroma: "Two colours are never the same, even if they're from the same tube. Context changes the way we perceive them." ${ }^{32}$ Even though Jarman alludes to "the blue of Divinity" in Blue's sound track, the contextual significance of the color changes when one remembers that Jarman was an atheist who was deeply suspicious of Church doctrines. As William Gass points out, the color blue is often seen as "the godlike hue,"33 but it can also evoke "the constantly increasing absentness of Heaven $[\ldots]$ the color of everything that's empty." ${ }^{34}$ I would argue that Klein is interested in the former signification, Jarman the latter. Jarman's own skepticism regarding the Divine should color a viewer's response to the film; even though the shade of blue used is essentially the same, its symbolic status has been reversed. Blue no longer connotes heaven, but an empty sky, a vacuum that was filled by God in the pre-Nietzschean universe.

This is Steven Dillon's interpretation of the film. In his book Derek Jarman and Lyric Film: The Mirror and the Sea, Dillon sees in Blue "a deep hopelessness with regard to the possibilities of visualizing another world, ${ }^{35}$ adding that in this new context, blue can be seen as "a visual absence, a nothingness before the abyss of death." 36 This cogent reading helps to explain why one of the questions asked in Blue is, "Will the pearly gates slam shut in the faces of the devout?" The heaven of traditional Christianity is not open for business. In its place is a void, a nothingness. This is why for Jarman, "the way of heaven" can be seen "without looking out of the window." The only spirituality that Jarman is interested in is an inner, subjective one, not one based on the dogmas of any church. This is further hinted at in his film Caravaggio (1986), in which the eponymous protagonist reflects on his own death: "The gods have become diseases.

\footnotetext{
${ }^{32}$ Jarman, Chroma, 42.

${ }^{33}$ William Gass, On Being Blue: A Philosophical Inquiry (Jaffrey, NH: Nonpareil Books, 1976), 69.

${ }^{34}$ Ibid., 3.

${ }^{35}$ Dillon, 11 .

${ }^{36}$ Ibid., 237.
} 
Thought without image. Lost in the pigment." This vision of an imageless color field, uncorrupted by Divine presence, is precisely what Jarman brings to fruition in Blue. By reappropriating IKB, Jarman effectively deconstructs the color's traditional spiritual significance.

Of course, the fact that Jarman uses blue to evoke non-existence is not only a subversion of traditional religious schema; it simultaneously places itself within a related historical tradition in the West: "the bluish hues of death." "37 This connection has been made by Jarman before. For example, in Caravaggio the artist has a revealing interior monologue on his deathbed: "The room turns slowly. I steady myself, staring into the blue void. Dull metallic flies cluster like rotted grapes." The idea of death as a "blue void" here is a clear precursor to Blue. Caravaggio's monologue also echoes Emily Dickinson's famous poem "I heard a Fly buzz—when I died—." In the poem Dickinson imagines seeing a fly just before her death, as she synaesthetically experiences a

Blue - uncertain stumbling Buzz-

Between the light—and me-

And then the Windows failed-and then

I could not see to see-. ${ }^{38}$

In Caravaggio and Blue, Jarman builds on Dickinson's rich symbolism, reiterating blue's association with death, as well as a loss of vision. Further, both Dickinson and Jarman work to de-romanticize death, emphasizing the materiality of the dead body and the absence of an

\footnotetext{
${ }^{37}$ Gass, 11.

${ }^{38}$ Emily Dickinson, "I heard a Fly buzz-when I died-," in The Complete Poems of Emily Dickinson, ed. Thomas H. Johnson (Boston: Little, Brown \& Co., 1960), lines 13-16.
} 
afterlife. ${ }^{39}$ The fly in Dickinson's poem can be read as a symbol of the quotidian, accentuating the eerie ordinariness of death. This is also one of the central insights of Blue. The film eschews traditional Hollywood depictions of death, which are often drenched in bathos and faux profundity. Instead, Blue's sound track emphasizes the ordinary and the mundane, and so a film about dying is filled with the type of minutiae normally reserved for episodes of Seinfeld (e.g. Jarman's observation that a diminutive man in the waiting room looks like Jean Cocteau, his fleeting desire to purchase a new pair of shoes, etc.).

The fly of Dickinson's poem can also be read in a more macabre vein, as an insect preparing to eat the flesh of the deceased. Thus, the poem subverts theorizations of death as a meaningful, spiritual experience, a passing away to another world. Instead, death is merely an opportunity for necrophagia in an indifferent Darwinian universe, a failing of vision followed by the gruesome decomposition of the body. "I heard a Fly buzz—when I died—" is a radically materialist poem, one that confronts the inescapable corporeality of the human body. And an almost identical philosophical stance lies at the heart of Blue. There is certainly an irony here, since for Klein, the monochrome was a means for "attain[ing] the spiritual absolute." idea of a spiritual absolute is undermined in Blue's unflinching emphasis on the ravaged and ill body. This idea becomes especially prominent during a passage in the film in which a voice reads off the interminable list of side effects of the drug Jarman is taking, DHPG:

Low white blood cell count, increased risk of infection, low platelet count which may increase the risk of bleeding, low red blood cell count (anaemia), fever, rush, abnormal liver function, chills, swelling of the body (oedema), infections, malaise, irregular heart

\footnotetext{
${ }^{39}$ Dickinson is often ambivalent when it comes to religion. While many of her poems are devout affirmations of Christian doctrines, I would argue that "I heard a Fly buzz — when I died-" expresses a profound skepticism about the possibility of life after death.

${ }^{40}$ Klein, 164.
} 
beat, high blood pressure (hypertension), low blood pressure (hypotension), abnormal thoughts or dreams, loss of balance (ataxia), come, confusion, dizziness, headache, nervousness, damage to nerves (peristhecia), psychosis, sleepiness (somnolence), shaking, nausea, vomiting, loss of appetite (anorexia), diarrhoea, bleeding from the stomach or intestine (intestinal haemorrhage), abdominal pain, increased number of one type of white blood cell, low blood sugar, shortness of breath, hair loss (alopecia), itching (pruritus), hives, blood in the urine, abnormal kidney functions, increased blood urea, redness (inflammation), pain or irritation (phlebitis).

While this passage from Blue provides the most exhaustive (and exhausting) catalogue of the natural shocks that flesh is heir to, similar monologues that dwell on the physicality of the body are ubiquitous in the film's sound track. Even though Jarman resolutely refuses to give us a visual depiction of the body, the disembodied voice speaks of little else. As Patrizia Lombardo puts it, "With a violent leap, the most bodyless film ever produced projects the human body in its most cruel and unspeakable presence. ${ }^{\prime 41}$

Blue's cathectic attachment to the human body has palpable effects for the spectator, who becomes increasingly aware of the embodied nature of her own perception. Since one cannot see the film's protagonist (or anybody else), the verbal descriptions of bodily ills seem to affect (or perhaps afflict) one's own body. When the voice speaks of "irregular heart beat," my attention is suddenly focused on my own heart beat, which now somehow feels irregular (no doubt a byproduct of the power of suggestion). When the voice speaks of "sleepiness," I am tempted to yawn. And when "shortness of breath" is alluded to, I become increasingly aware of the tempo of my own breathing (not unlike Cage during his famous visit to the anechoic chamber). There is nobody (and no body) on the screen to transfer these sensations to-without on-screen motion to

\footnotetext{
${ }^{41}$ Patrizia Lombardo, “Cruellement Bleu,” Critical Quarterly 36, no. 1 (1994): 133.
} 
command my attention, I instead become the observer of my own miniscule bodily movements, and these subsequently become as much a part of the cinematic experience as the color field or the sound track. Eventually, the film's frequent evocations of death prompt me to imagine all of these movements ceasing - for a brief moment, my body freezes in place, I become breathless, my heart stops. The static film immobilizes me. I do not simply imagine my own death; I experience it. However provisional this experience may be, its affective intensity remains profoundly unsettling.

There is only one other film that rivals Blue in its unblinking insistence on the corporeality of the body facing death: Stan Brakhage's The Act of Seeing with One's Own Eyes (1971), which displays actual autopsies of dead bodies for 32 minutes. Flesh is cut into, brains are removed, bodily fluids are drained. The film is shot with an unsettling objectivity which refuses to assign any kind of meaning to these deaths. Non-existence simply exists. (And Brakhage also evokes Dickinson, though it is likely accidental: in one scene, a fly is seen meandering on the foot of one of the corpses.)

Central to the experience of viewing The Act of Seeing is its complete silence. Somehow, the film would be less disturbing if we could hear the sounds in the morgue: footsteps, breathing, instruments clanging on tables. Instead, we hear what the corpses hear: nothing. In this sense, the film is the inverse of Blue. Brakhage captures non-existence by giving the spectator nothing to hear, while Jarman captures non-existence by giving the spectator nothing to see. It is true that Jarman's blue screen is apprehended visually, and his sound track elicits mental imagery. Nonetheless, the lack of any traditional photographic images on the screen makes clear the film's raison d'être: as the narrator suggests, Blue offers a space in which the viewer can be "released from image," which for Jarman represents "a prison of the soul." Blue and The Act of Seeing are 
both experiments in sensory deprivation. And yet, in spite of their unrelenting visual and auditory voids, both films use the sparse materials available to conjure up the material body and its confrontation with death. ${ }^{42}$

Blue is obviously a static film, and The Act of Seeing could be loosely categorized as such, as well — even though it is not as unrelentingly still as the films I have discussed so far (it includes the movements of the coroners and a great deal of camera movement). Nevertheless, the subject (and paradoxically, the object) of the film is the human cadaver, which is entirely still. Since these are obviously real cadavers, the spectator recognizes that there is no chance that they will become animated. (This clearly is an option in fictional films; consider Dreyer's Ordet [1955], for example, in which the dead body of Inger is resurrected and begins to move again.) Since both Blue and The Act of Seeing interrogate the nature of mortality, it is fitting that they are essentially drained of movement. As Laura Mulvey points out, movement is "the commonly accepted sign of life," which suggests that stasis in cinema is uniquely positioned to suggest just the opposite: "the presence of death.",43

While Blue's voiceover is poignantly evoking the deterioration of Jarman's body, another kind of deterioration takes place: what I have earlier called (in reference to Warhol's stillies) the degradation of signification. In the first part of this chapter, I emphasized the symbolic valences of Jarman's blue and how these informed the viewer's response to the color. But this tells only half of the story. As the film continues, and as the viewer's sense of time becomes distorted, blue itself begins to lose all meaning. The brain becomes weary of processing blue, and as a result, the color as such degenerates_-on a phenomenological level, it no longer seems to even be a color.

\footnotetext{
${ }^{42}$ It should be noted that many of Brakhage's films are completely silent. Nonetheless, the silence in The Act of Seeing is especially resonant, since the auditory void forces the viewer to ponder the deprivation inherent in death.

${ }^{43}$ Mulvey, 22. Mulvey is here referring specifically to the intrusion of the freeze frame in motion pictures; nevertheless, her remark remains pertinent in theorizing other forms of cinematic stasis.
} 
This breakdown begins early on in the film, when the voices begin to allude to other colors (red, magenta, and yellow). The effect of seeing blue while being asked to envision other colors is a bit jarring. It is not unlike the Stroop effect, in which the name of a color (like red) is printed with the ink of a completely different color (like green). The results have been well documented: it is difficult for the spectator to ignore the language and simply recite what color she is seeing, almost as if there is an internal psychological battle between perception and language. ${ }^{44}$ This is the tension that Jarman produces throughout his film. Even though the word blue is spoken frequently in the film's sound track, other words for color dominate as well: the word black is heard ten times, white five times, yellow nine times. Given the constantly changing language in Blue and the unchanging visual field, language begins to win out over perception. Literal sight becomes less and less relevant, and other senses (like the sense of hearing) begin to become more attuned than usual, mirroring Jarman's own experience as someone overcome with blindness. While the static blue originally provoked restlessness, the unrelenting stasis comes to provoke a kind of catatonia.

I have already mentioned several precedents for Jarman's monochromatic screen in the films of Paik, Huot, McLaughlin, and Conrad. However, as Peter Wollen and Roland Wymer have pointed out, Blue's most important precursor is almost certainly Guy Debord's first film, Hurlements en Faveur de Sade, which simply presents alternating black and white voids accompanied by a non-narrative sound track. ${ }^{45}$ Unlike the silent monochromes of Paik's Zen for

\footnotetext{
${ }^{44}$ For a meta-analysis of Stroop effect studies, see Colin M. MacLeod, "Half a Century of Research on the Stroop Effect: An Integrative Review," Psychological Bulletin 109, no. 2 (1991): 163-203.

${ }^{45}$ See Peter Wollen, "Blue," in Colour: The Film Reader, eds. Angela Vacche and Brian Price (New York: Routledge, 2006), 197, and Roland Wymer, Derek Jarman (Manchester: Manchester University Press, 2005), 173174. Given their insistence on counteracting "the society of the spectacle," it should come as no surprise that many Situationist films use blank, figure-less screens as a kind of anti-spectacle: Isidore Isou's Treatise on Slobber and Eternity begins by showing a black screen, accompanied by nonmelodic chanting, for five minutes; François Dufrêne's Drums of the First Judgment (Tambours du jugement premier) (1952) provides only a sound track, with no visual component whatsoever; and the only "image" of Gil Wolman's L'Anticoncept is a static white circle that
} 
Film and Conrad's Yellow Movies, one of the most striking components of Hurlements and Blue is the disembodied voice. Both Debord and Jarman exploit the affective intensity of what Michel Chion has called the acousmatic: sounds which are heard even though their sources cannot be seen. ${ }^{46}$ For Chion, the acousmatic is at its most poignant and haunting when it is a voice, especially one which has not yet been coupled with a face: "[W]hen this voice has not yet been visualized - that is, when we cannot yet connect it to a face-we get a special being, a kind of talking and acting shadow to which we attach the name acousmêtre."47 All of the voices in Hurlements and Blue are radical acousmêtres: rather than being voices which have not yet been connected to faces, they are voices which are never connected to faces-disembodied, incorporeal, even ghostly. It is fitting, then, that both Hurlements and Blue are (to a large extent) films about death. The voices of Blue describe the process of dying in vivid detail, while those of Hurlements allude to "the perfection of suicide," even discussing several actual suicides (those of proto-Surrealist Jacques Vaché, as well as Madeleine Reineri, a twelve-year-old girl who "threw herself into the Isère River." ${ }^{48}$ ) Not only do these films' static monochromatic screens suggest the immobility of the cadaver, but the use of bodiless voices evokes death, as well. As Chion has

occasionally flashes on and off (in a manner that seems to anticipate the flicker films of Peter Kubelka and Tony Conrad). This is not to mention Debord's continued use of empty white and black screen in his later films, such as On the Passage of a Few Persons Through a Rather Brief Unit(y) of Time (Sur le passage de quelques personnes à travers une assez courte unité de temps) (1959) and In girum imus nocte et consumimur igni (We Turn in the Night and Are Consumed by Fire) (1978).

Incidentally, parallels between Debord's monochromatic black and white voids and Klein's blue paintings may be more than incidental. Debord has claimed that Klein's monochromes were inspired by Hurlements: "Yves Klein, whom I knew at the time of Hurlements and who attended the first, very tumultuous showing of this film, was dazzled by a convincing 24 minute-sequence of darkness, and must have derived from that, some years later, his 'monochrome' paintings which - enveloped in a bit of zen mysticism during his famous 'blue period' - made many an expert cry genius. Some still call him that." Debord is careful, however, to avoid taking credit for the discovery of the monochrome: "When it comes to painting, it is not I who could possibly obscure the glory of Yves Klein. That is, rather, what Malévitch had done 40 years before, and which had been temporarily forgotten by these same experts." Guy Debord, Considerations on the Assassination of Gérard Lebovici, trans. Robert Greene (Los Angeles: Tam Tam Books, 2001), 30-31.

${ }^{46}$ Michel Chion, The Voice in Cinema, trans. Claudia Gorbman (New York: Columbia University Press, 1999), 18. Chion credits Pierre Schaeffer with re-discovering this little-known word in the 1950s.

${ }^{47}$ Ibid., 21. Italics in original.

${ }^{48}$ Translations from the French are taken from Ken Knabb, ed. and trans., Guy Debord: Complete Cinematic Works: Scripts, Stills, Documents (Oakland, CA: AK Press, 2003). 
pointed out, in cinema, "the voice of the acousmêtre is frequently the voice of one who is dead"—or at least, one who is "almost-dead." ${ }^{49}$

But in addition to interrogating death, the renunciation of imagery in Blue and Hurlements also becomes a means of evoking blindness—both metaphorically and literally. Not only does Debord's film refuse to give the audience anything to see, the sound track foregrounds this visual void. For example, Debord's own voice is heard saying, "Totally dark, eyes closed to the enormity of the disaster," and another voice later intones, "I don't think we'll ever see each other again. ${ }^{, 50}$ In other words, the recurring darkness of the screen is complemented by language that reinforces visual absence. Suggestions of visual absence are also prominent in Blue; however, in Jarman's hands, they are literalized, since he is frequently describing what it feels like to go blind. Because of the impoverishment of images, the audience of each film becomes more aware of the sound track. Consequently, a viewer of Blue can echo Debord's proclamation in Hurlements: "I lose myself in the hollow archipelagos of language." However, the language that is spoken in Hurlements is often silenced-whenever the screen turns black, all sounds cease. These moments of silence occur momentarily throughout the film's duration, and while they generally only last for a few seconds, or occasionally, a few minutes, the film concludes with a silence that lasts an agonizing 24 minutes, and the effect is unsettling. While Jarman's blue screen and gentle ambient music can momentarily evoke a kind of peacefulness, Debord's black screen — accompanied by an uncompromising silence—is sinister, threatening, affectively jarring. As Janet Harbord has argued, "To throw an audience into darkness is one of the most

\footnotetext{
${ }^{49}$ Chion, 46-47.

${ }^{50}$ Italics added.
} 
powerful, and possibly sadistic, things a film-maker can do"-and here she is discussing the darkness used by Chris Marker in La Jetée, which lasts a mere ten seconds! ${ }^{51}$

Still, in spite of their renunciation of visual movement, most monochromatic films continue to provide some kind of auditory "movement" via the vicissitudes of the sound track. One might wonder, then, what separates works like these from radio broadcasts, or more currently, podcasts? (One is reminded of the voice in Isidore Isou's Treatise on Slobber and Eternity, which asserts, "Take photography away and cinema becomes radio."52) Steven Dillon notes this affinity, saying, "As a movie that is all sound track, Blue might be thought of as a species of radio, where we would read the film into a tradition of radio plays by Samuel Beckett or Harold Pinter., ${ }^{, 53}$ In fact, this comparison to radio becomes especially salient in what appears to be the first monochromatic film—and the first static film-ever made: Walter Ruttmann's Weekend. Ruttmann presents the audience with an audio montage composed of dozens of carefully arranged sounds, including clocks, whistles, dogs, and human voices - a remarkable experiment that anticipates Pierre Schaeffer's musique concrète of the 40s and 50s. While Weekend is sometimes referred to as a piece for radio, it was in fact designed to be projected in a movie theater, accompanied by a static imageless screen. This is why Ruttmann referred to Weekend as "cinema for the ears" 54 and "a blind film.",55

\footnotetext{
${ }^{51}$ Janet Harbord, Chris Marker: La Jetée (London: Afterall Books, 2009), 42. Given its lengthy periods of silence and stasis, Hurlements appears to have several striking affinities with Warhol's furniture films. This may seem like a perverse comparison - after all, it is difficult to think of two experimental filmmakers who have less in common (in terms of both temperament and cinematic content) than Debord and Warhol. Nevertheless, like Sleep and Empire, Hurlements is a film in which (to a large extent) nothing happens, and which thus encourages a more active form of spectatorial engagement. As Thomas Y. Levin astutely notes, "[T] he absence of the film-and similarly the lack of images in Hurlements - is employed as the essential ingredient in a recipe of provocation intended to "radically transform' the cinematic 'situation' from a shrine of passive consumption into an arena of active discussion." See Levin, 347.

${ }^{52}$ The translation is taken from Kino International's DVD release of the film in their two-disc collection AvantGarde 2: Experimental Cinema, 1928-1954 (2007).

${ }_{53}^{53}$ Dillon, 227.

${ }^{54}$ Quoted in Nora M. Alter, "Screening Out Sound: Arnheim and Cinema's Silence," in Arnheim for Film and Media Studies, ed. Scott Higgins (New York: Routledge, 2011), 83.
} 
It seems that such appellations would also be apropos in describing Blue, particularly since (as Roland Wymer points out) Blue was broadcast concomitantly on Channel Four and Radio 3 in 1993: "Listeners who did not have access to a television were invited to apply for a blue postcard which they could stare at during the transmission." ${ }^{, 56}$ Along similar lines, those who purchase Blue on compact disc have the option of staring at the monochromatic blue $\mathrm{CD}$ jacket while listening to the sound track. It is unlikely that many have chosen to take advantage of such options. While such an experience might seem superficially analogous to viewing the film, the affective response produced by Blue comes not merely from staring at the color, but from the frustration of expectations. No one expects movement when looking at a postcard or a $\mathrm{CD}$ jacket, so looking at one for an extended period of time feels absurd, pointless. But movement is more or less ubiquitous on movie screens, so staring at one feels natural, even if a spectator may realize on an intellectual level that the blue screen is going to remain static. ${ }^{57}$

In spite of this intellectual awareness, monochrome films often engender a level of frustration. Whereas most films use the illusion of movement to captivate the audience, keeping them entirely still ("glued to their seats"), the stasis of films like Blue and Hurlements inevitably causes restlessness and fidgeting. Since there is no movement on the screen, the spectators' bodies begin to move to compensate. This is why the experience of just listening to Blue is quite different from seeing it. Listening to Blue is comforting, thoughtful, engaging. One can put on headphones and go about one's day while becoming immersed in the poetry and music that

\footnotetext{
${ }^{55}$ Quoted in Esther Leslie, Hollywood Flatlands: Animation, Critical Theory and the Avant-Garde (London: Verso, 2002), 66. Another monochromatic film that is evocative of Weekend in many ways is Ben Vautier's Monochrome for Yves Klein, Fluxversion I (1963). The event score/script simply reads, "Performer paints a movie screen with nonreflective black paint while a favorite movie is being shown." See Friedman, Smith, and Sawchyn, 104.

${ }^{56}$ Wymer, 173.

${ }^{57}$ During my second viewing of the film, I looked down at one point to scribble some notes. Instinctively, my head jerked up momentarily to look at the screen, just in case I was missing something. I knew nothing had changed, of course, but the expectation of change is so central to most viewing experiences that it can be difficult to overcome this habit.
} 
Jarman provides. But seeing Blue is a much more ambivalent experience. The color itself at first complements the sound track's sense of peacefulness. But the color's refusal to change somehow supplements the soothing sound track with an uneasy, almost maddening quality. Cage's 4'33', is a useful point of reference. We all hear (relative) silence quite frequently and do not even notice it. It is only when we expect to hear sound (when attending a concert, playing a CD, etc.) that silence is striking. Such a subversion of expectations produces an affective shift that causes the body to squirm, sometimes intolerably. This is why the Paris premiere of Hurlements at the Ciné-Club d'Avant-Garde in the Musée de l'Homme elicited a violent reaction from the audience and was terminated after twenty minutes - and why later screenings continued to provoke riots and protests. $^{58}$

What is one to make of the voids that are presented in monochromatic films? Is it sadistic for filmmakers (and masochistic for spectators) to embrace absence, deprivation, nothingness? Does the cinematic void imply a kind of nihilism? I would be hesitant to subscribe to such a view (even though the monochromatic film certainly could be used in such a way). In fact, it is not at all clear why these films should be reductively theorized as nothing more than optical voids. As many philosophers have noted, a void as such is not possible - a void is not the absence of any content, but simply the absence of anticipated content. This is why for Bergson, "the idea of the absolute nought" is "a self-destructive idea, a pseudo-idea, a mere word"; the void is "only a comparison between what is and what could or ought to be, between the full and the full."59

\footnotetext{
${ }^{58}$ For a more thorough account of the reception of Hurlements, see Levin, 343-344. See also Zack Winestine, "Howls for Guy Debord," Film Quarterly 62, no. 4 (2009): 14-15. In addition to outlining the reception that the film received in 1952, Winestine describes his experience seeing a screening of Hurlements at New York's Walter Reade Theater in 2009. Since the audience is uncomfortable with the lengthy silence and black screen that close out the film, many begin to fidget and speak, creating problems with a security guard. Eventually, some in the audience decide to sing a song together: Bruce Springsteen's "Born in the USA." Once again, what is central here is the way that the stasis and silence of the film tend to provoke movement and sound from the audience, in an attempt to compensate.

${ }^{59}$ Bergson, Creative Evolution, 298-299.
} 
Deleuze echoes this sentiment in his second Cinema book, in which he explores the implications of cinematic emptiness. For Deleuze, "An empty space, without characters" can have "a fullness in which there is nothing missing." ${ }^{, 60}$ And the idea of emptiness as a kind of fullness was explored in art well before the experimental monochromes of the $20^{\text {th }}$ century. For example, as Paul Schrader points out, "Emptiness, silence, and stillness are positive elements in Zen art, and represent presence rather than the absence of something." ${ }^{\text {61 }}$ Monochrome paintings and films simply carry on this tradition, reaffirming Rauschenberg's assertion that "A canvas is never empty." 62

In fact, as Barbara Rose has argued, the monochrome painting may initially suggest "simplicity and unity," but this appearance ultimately "masks a potential for multivalence and paradox." ${ }^{, 63}$ Along similar lines, a film like Blue does not use the monochromatic screen to merely posit nihilism and emptiness. Rather, Jarman's blue screen is a site of multiplicity, limitlessness, eternity. As Jim Ellis puts it, Blue “recalls Klein's understanding of the void not as an absence, but rather as an infinity." ${ }^{\prime 64}$ Even when the monochromatic screen presents only whiteness or blackness (as in Weekend, Hurlements, and Zen for Film), colors with strong cultural associations of absence, the effect is not merely one of negation, but of affirmation. These are films which (like the works of Malevich and Rauschenberg) posit absence as a kind of presence. Susan Sontag's formulation in "The Aesthetics of Silence" is apposite here: "[T]here is no such thing as empty space. As long as a human eye is looking, there is always something to see. To look at something which is 'empty' is still to be looking, still to be seeing something —if

\footnotetext{
${ }^{60}$ Deleuze, Cinema 2, 244-245.

${ }^{61}$ Schrader, 27.

62 Quoted in Branden W. Joseph, Random Order: Robert Rauschenberg and the Neo-Avant-Garde Order (Cambridge: MIT Press, 2003), 21.

${ }^{63}$ Rose, 21.

${ }^{64}$ Jim Ellis, Derek Jarman's Angelic Conversations (Minneapolis: University of Minnesota Press, 2009), xxii.
} 
only the ghosts of one's own expectations." ${ }^{, 55}$ In other words, it is not so much that these films give the spectator nothing to see; rather, the spectator is given something new to see: color $a s$ color-a locus of purity, contemplation, and immersion.

In addition to providing a kind of empty fullness, the stasis of Blue also has profound implications for the role of movement in cinema's ontology. ${ }^{66}$ Tom Gunning has suggested that movement may be essential to cinema "[i]nsofar as we are referring to the movement of the apparatus, the film traveling through the projector gate,"67 and Laura Mulvey has similarly claimed that the impression of stasis in film is essentially an "illusion," since it is paradoxically the result of "the continuous flow of the filmstrip and its individual frames." 68 These are worthwhile observations; however, the rise of digital film is quickly making them obsolete. This is an especially important point to remember when discussing Blue, since in its later incarnation, the film does not rely on traditional methods of projection. The color field was initially achieved through the use of a blue film loop; however, this was eventually supplanted by a videogenerated blue screen. (For ease of expression, I will call the celluloid version of the film Blue 1 and the later computer-generated version Blue 2.) When viewing Blue 1, aleatory specks occasionally punctuate the screen and thus remind the spectator of the film's movement through the projector. As Babette Mangolte has pointed out, in traditional cinematic praxis, "[T]ime is

\footnotetext{
${ }^{65}$ Susan Sontag, "The Aesthetics of Silence," in Styles of Radical Will (New York: Picador, 1969), 10.

${ }^{66}$ While Blue is Jarman's only unambiguously static film, stasis nevertheless plays a prominent role in some of his other films. In particular, it could be argued that The Angelic Conversation (1985) represents an interstitial link between traditional motion pictures and the cinema of stasis. The film focuses on two male lovers going through opaque rituals while Judi Dench's voice is heard reading Shakespearean sonnets. Though there is a kind of movement in the film, it all takes place in stroboscopic slow motion. (The film was shot at 6 frames per second and projected at 3.) In other words, the movement is not smooth, but seems to be comprised of a series of "jumps." This defamiliarizing cinematic device lays bare the process that creates the illusion of movement in cinema. While viewing the film, the mind seems to continually shift between processing a series of stills and processing actual "moving" images - even though the ostensible movement is stilted and alienating.

${ }^{67}$ Gunning, "Moving Away from the Index," 49.

${ }^{68}$ Mulvey, 81.
} 
inscribed in the emulsion grain, which constantly trades places and spaces from one frame to the next." ${ }^{69}$ But in Blue 2, there is no emulsion grain, and thus no temporal inscription.

This radically changes the experience of the film. The stasis becomes even purer, since movement is neither directly displayed nor indirectly suggested; in essence, the film has become phenomenologically and ontologically motionless. Mary Ann Doane's words about digital film become especially relevant here: "What is lost in the move to the digital is the imprint of time, the visible degradation of the image. ${ }^{, 70}$ In most of the static films created before Blue, one never really forgets that one is watching a film. In fact, for all its photographic and televisual aspirations, a film like Warhol's Empire nevertheless draws attention to the medium itselfwhen there is little or no on-screen movement, the spectator inevitably becomes more aware of the imperfections of the film stock: its fuzziness, its graininess, the scratches that frequently intrude on the image. (During MoMA's February 19, 2011, screening of Empire, for example, one of the first tweets was "That is one fuzzy mother fuckin building."71) Much the same can be said of the monochrome films released before Blue. For example, the blank screen of Nam June Paik's Zen for Film forces the viewer to become more attuned to the movements taking place on the film stock itself. $^{72}$ And Blue 1 produces a similar effect, as specks, splotches, and momentary discolorations intermittently stain the color field (see Figures 1-2). But in the film's digital

\footnotetext{
${ }^{69}$ Babette Mangolte, "Afterward: A Matter of Time," in Camera Obscura, Camera Lucida: Essays in Honor of Annette Michelson (Amsterdam: Amsterdam UP, 2003), 264.

${ }^{70}$ Doane, "The Indexical and the Concept of Medium Specificity," 144.

${ }^{71}$ Leach, 5.

${ }^{72}$ John Cage, who has called Zen for Film his favorite cinematic work, describes it this way: "It's an hour long and you see the dust on the film and on the camera and on the lens of the projector. That dust actually moves and creates different shapes. The specks of dust become, as you look at the film, extremely comic. They take on character and they take on a kind of plot-whether this speck of dust will meet that speck. And if they do, what happens?" See John Cage, Musicage: Cage Muses on Words, Art, Music (Hanover, NH: Wesleyan University Press, 1996), 135. Incidentally, Cage's enthusiasm for Zen for Film is unsuprising, since it is in many ways a cinematic version of his own 4'33'". In fact, it appears that Cage had been anticipating the release of such a film for several years. In 1956 he remarked, "[T] he most important thing to do in film now is to find a way for it to include invisibility, just as music already enjoys inaudibility (silence)." See John Cage, "On Film," in John Cage: An Anthology, ed. Richard Kostelanetz (New York: Da Capo Press, 1991), 116.
} 
incarnation, Jarman offers a new aesthetic: his computer-generated image suggests neither the movement of on-screen images nor the movement of the film stock itself (see Figure 3). The film's only temporal signposts are now the "movements" of the sound track. In effect, then, Blue 1 foregrounds the process of Jarman's bodily decay through the decay of the filmstrip itself. As Mangolte has suggested, silver-based film evokes "degradation" and "entropy"73 (connotations which are especially pronounced in monochrome films, where there is nothing to look at except the dissolution and disintegration of the film stock). Blue 1 is a corporeal film about the corporeal body. Blue 2, on the other hand, evokes not the process of dying, but death itself. Visually, there is no decay, no entropy, no change—only a perpetual, immutable absence.

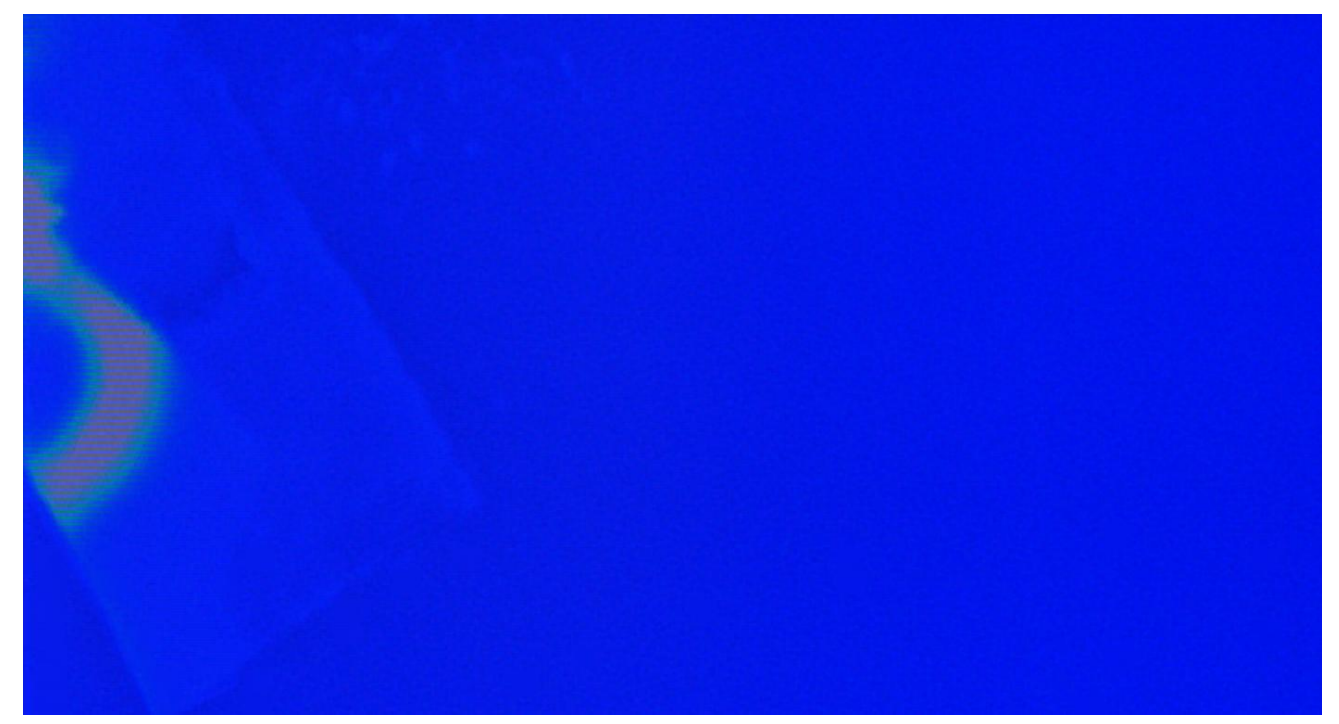

Figure 1: Derek Jarman, Blue 1 (1993)

\footnotetext{
${ }^{73}$ Mangolte, 264.
} 
Figure 2: Derek Jarman, Blue 1 (1993)

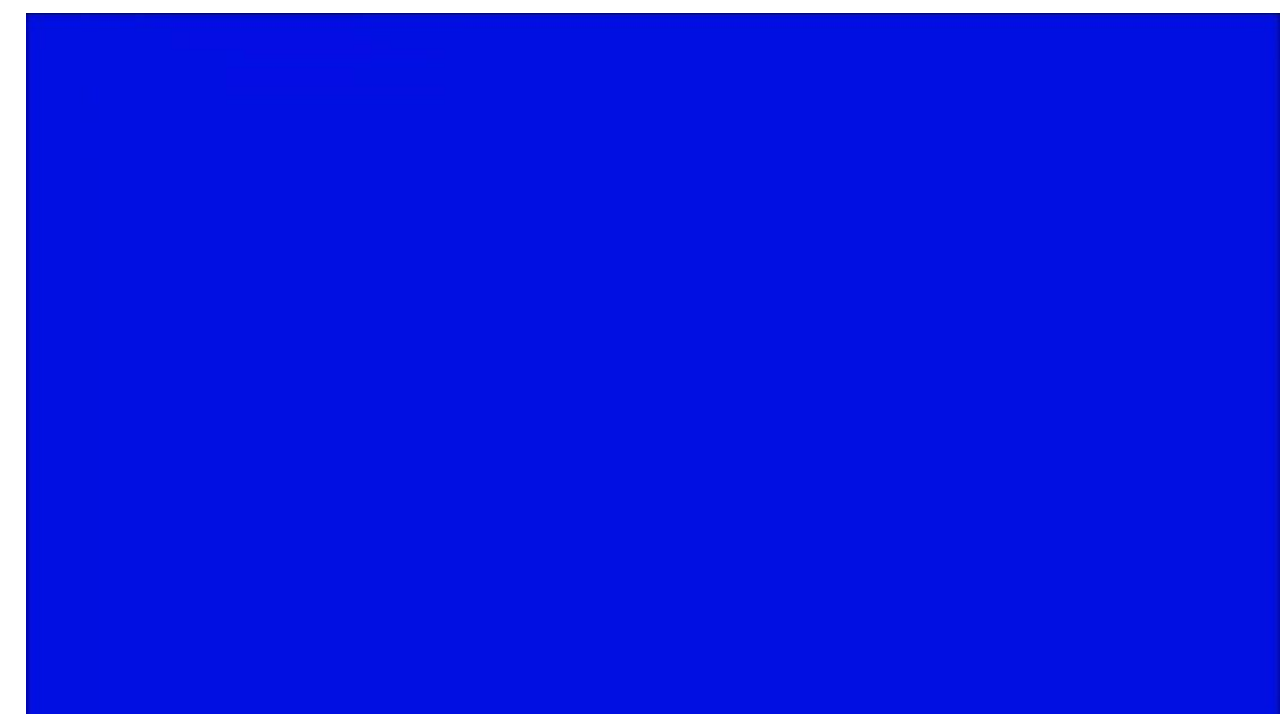

Figure 3: Derek Jarman, Blue 2 (1993)

Notice the way that Blue 2 radically departs from its artistic forebears. The monochromes of Allais, Malevich, Rauschenberg, and Klein are all corporeal objects, and as such, they foreground the materiality and flatness of the artwork itself. ${ }^{74}$ Even most monochrome films-

\footnotetext{
${ }^{74}$ Any discussion of the anti-illusionist flatness of much modernist art is necessarily indebted to the writings of Clement Greenberg. See, for example, his seminal essay "Modernist Painting," in Clement Greenberg: The
} 
such as those of Debord, Paik, Huot, and McLaughlin-foreground the materiality of the filmstrip, since its graininess and splotchiness becomes more salient when our attention is no longer monopolized by moving images. However, Blue 2 would seem to have no materiality to foreground. Norman Bryson's musings on the distinctive nature of PC screens are worth considering here: "[T] he PC screen does not behave like the modernist image [...] It cannot foreground the materiality of the surface (of pigments on canvas) since it has no materiality to speak of, other than the play of shifting light." ${ }^{, 75}$ Much the same can be said of Blue 2 (although in this case, the light is not even shifting). The film becomes a prescient post-Greenbergian meditation on the etherealization that art has undergone in the digital era. Art can no longer draw attention to its own materiality, since it has-to a large extent-become immaterial: films without celluloid; music without records, tapes, or CDs; paintings that exist primarily, not as paint and canvas, but as ones and zeros.

It is difficult to see a screening of the digital version of Jarman's final film—all the DVD versions I have encountered display Blue 1, and all the online versions I have found have fallen victim to lossy compression, resulting in a constant pixilation of the blue screen that is both distracting and aesthetically unsatisfying. However, there are numerous temporalized digital monochromes available online which enable an analogous visual experience. To provide just one example, a series of ten videos on YouTube (created by xsetpointer) offer completely silent monochrome screens of various colors for exactly ten minutes. They are given technical names like monochrome blue - RGB 0,0,255 - \#0000FF (2007) and monochrome green - RGB 0,255,0

Collected Essays and Criticism, Volume 4: Modernism with a Vengeance, 1957-1969, ed. John O'Brian (Chicago: University of Chicago Press, 1993), 85-93.

${ }^{75}$ Quoted in Manovich, 95. 
- \#00FF00 (2007). ${ }^{76}$ Of course, since these videos have no soundtrack, there are now no temporal coordinates - either visual or aural - to ground one's experience (assuming that one does not one move one's mouse to reveal the slowly moving bar at the bottom of the YouTube screen). But if one simply watches one of these videos without interference, it is phenomenologically indistinguishable from looking at an actual picture of a monochrome on one's computer. Like Jarman's computer-generated version of Blue, these temporalized monochromes are paradoxically free of any traces of temporality. ${ }^{77}$

Films and videos that (like Blue) are entirely monochromatic are relatively rare; however, a plethora of works nevertheless make use of the static blank screen. For example, a substantial amount of Ken Jacobs' 33-minute Blonde Cobra (1963) is comprised of a black screen (which is often held for several minutes at a time), accompanied by the acousmêtre of underground film legend Jack Smith telling disturbing stories, singing, and laughing maniacally. (The effect is unsettling — without a visual component, the viewer almost feels as if she is hearing voices in her head.) The black screen was also used extensively by Jean-Luc Godard in his Le gai savoir (The Joy of Learning) (1969) — often (as in Hurlements and Blue) as a way of evoking blindness. (For example, during one "blackout," a voice is heard saying, "Here, the image is missing. The Anglo-Canadian police gouged out the eyes of a cameraman who was filming the landscapes and

\footnotetext{
${ }^{76}$ xsetpointer's works can be found at http://www.youtube.com/user/xsetpointer\#p/u. While each one has thousands of views, there is a range of reasons for engaging with these works. For instance, comments suggest that some have simply used the monochrome screens as a backdrop for playing Snake. (By holding down the left and up arrows after clicking on the YouTube screen, one can play the famous video game superimposed over any video.)

77 A mischievous artist named Nigel Tomm exploited the digitally produced monochrome in a series of DVDs released in 2008, which were sold on sites like Amazon-apparently as a prank. The individual films are simply silent monochrome screens (magenta, turquoise, etc.) that last for over an hour each, and they are given the names of famous works of literature, such as Hamlet, The Brothers Karamazov, Waiting for Godot, etc. (In one case, the title of a classic is perversely altered to Oresteia in the Bambiland Having Ultimate Fisting.) The titles still show up on Amazon, although they are no longer available for purchase, presumably because of a swarm of angry one-star reviews from consumers who expected film versions of the titular literary works. Most reviewers angrily assert that the films are scams, although a handful attempt to see an artistic rationale for the monochrome. For example, one reviewer of Tomm's Oedipus Rex, which features only a monochromatic red screen, writes, "Does this represent what Rex saw (or did not see) after poking his own eyes out?" See http://www.amazon.com/Oedipus-Rex-NigelTomm/dp/B0014A96AA/ref=sr_1_20?ie=UTF8\&qid=1322019067\&sr=8-20.
} 
faces of a free Quebec." ${ }^{, 78}$ ) And a significant portion of Malcolm Le Grice's Threshold (1972) consists of monochromatic black, green, red, and yellow screens (accompanied by long stretches of silence punctuated by brief clips of strange, fragmented sounds). While none of these are static or monochromatic films per se, they all exploit the affective intensity of the empty screen. Much the same could be said of flicker films, like Tony Conrad's The Flicker and Paul Sharits' Ray Gun Virus (1966). While the lability resulting from the continually flashing frames produces an affective experience that is quite distinct from that engendered by monochrome films, both modalities nevertheless use blank figure-less screens of various colors as currency. By remediating the monochrome painting and temporalizing it in diverse ways, all of these films foreground the plenitude of emptiness and the multivalence of the monolithic. They also serve to verify Ivan Chtcheglov's insight (in his analysis of De Chirico's paintings) that “an empty space creates a richly filled time., 79

\footnotetext{
${ }^{78}$ The translation from the French comes from the DVD version of Le gai savoir, released by Koch Lorber Films in 2008. While Godard might appear to be a successor of the Situationists - given his radical politics, cinematic détournements, and use of blank screens-in actuality, the Situationist International saw the "destructive style" of $L e$ gai savoir as "plagiarized," "pointless," and "pretentious." See The Situationist International, "The Practice of Theory: Cinema and Revolution" (trans. Tom McDonough), in McDonough, 187.

${ }^{79}$ Ivan Chtcheglov, "Formulary for a New Urbanism," in Situationist International Anthology: Revised and Expanded Edition, ed. and trans. Ken Knabb (Berkeley: Bureau of Public Secrets, 2006), 5. Italics in original.
} 


\section{CONCLUSION}

\section{STATIC CINEMA IN THE 21ST CENTURY}

"All that was chemical and photographic is disappearing into the electronic and digital." - D.N. Rodowick $^{1}$

"Time $[\ldots]$ is like a wall that keeps crumbling on all sides." - Michel Chion ${ }^{2}$

"No one goes to the movies anymore." This is one of the only lines of dialogue in Tsai Ming-liang's Goodbye, Dragon Inn (2003), a melancholy, visually arresting film about a large dilapidated movie theater in Taipei that is screening its last film (Kung Hu's Dragon Inn [1967]). ${ }^{3}$ The theater is eerily empty, although one feels the weight of the thousands of people who once populated it. (As one man tells another, "This theater is haunted. Ghosts.") There are only a handful of individuals watching the Kung $\mathrm{Hu}$ film at any given moment, and while a few spectators seem genuinely engrossed, most of those present seem more interested in people watching, snacking, or cruising for gay sex. Near the end of Goodbye, Dragon Inn (after the film within the film is over), Tsai provides a prolonged static shot of the empty theater. ${ }^{4}$ The shot is a nostalgic contemplation of how films used to be seen. In the modern era, audiences are increasingly turning to home-viewing options (DVDs, movies on demand, streaming videos, YouTube, etc.) rather than theaters, and this significantly alters the cinematic experience. As I stared at Tsai's empty seats, I reflected wistfully on my own experiences of going to the theater

\footnotetext{
${ }^{1}$ Rodowick, 27.

2 "Interview with Michel Chion," Fluid-Radio, June 17, 2011, http://www.fluid-radio.co.uk/2011/06/michel-chion/.

${ }^{3}$ Translations are taken from the DVD version of Goodbye, Dragon Inn, released by Wellspring Media in 2005.

${ }^{4}$ Tsai's static shots of the theatrical space are reminiscent of Sharon Lockhart's Teatro Amazonas (1999), which offers a single shot of a theater audience for its entire half-hour running time.
} 
when I was younger, and how long it has been (about a year) since I attended a film screening at a movie theater. (I was watching Goodbye, Dragon Inn where I watch most films now-on my computer monitor. The contrast made the film even more poignant for me.)

It may seem strange to conclude a dissertation on static avant-garde cinema with an evocation of Tsai's magnum opus. Goodbye, Dragon Inn is not an experimental film, but an art film. And in spite of its frequent stillness (with the exception of one shot, Tsai's camera never moves), it is not a static film per se, but a work of slow cinema. ${ }^{5}$ Nevertheless, I believe a brief discussion of Goodbye, Dragon Inn provides a fitting coda for this project. Not only does it foreground the continued centrality of stasis for many filmmakers in the modern era, even outside of the avant-garde, but it also draws attention to the decline of the movie theater, and thus forces us to ponder the fate of the cinema of stasis (and cinema more broadly) in the "postcinematic" era. ${ }^{6}$

The "death" of cinema was perhaps inevitable, given the rise of VHS and DVD technology—not to mention Pay-per-view, TiVo, Netflix streaming videos, and other similar technologies that enable home viewing. While it is easy to lament the way that such technological developments have displaced the ambience-perhaps even the aura-of the traditional movie theater, it should also be remembered that they offer unprecedented opportunities: at no time in history has it been easier to access any film that one is interested in seeing. One's cinematic "diet" is no longer strictly determined by whatever the nearest cineplex happens to be screening at any given moment. For most of my life, I had very little access to art

\footnotetext{
${ }^{5}$ The term slow cinema is generally used to refer to modern feature-length films which carry on the legacy of arthouse auteurs like Antonioni and Akerman by offering very little action, narrative development, and movement.

${ }^{6}$ I borrow the term post-cinematic from Steven Shaviro, Post-Cinematic Affect (Winchester: Zero Books, 2010). Of course, the term should not be taken too literally, since, as Wheeler Winston Dixon points out, "Film 'as we know it' has always been dying and is always being reborn." See his "Twenty-five Reasons Why It's All Over," in The End of Cinema as We Know It: American Film in the Nineties, ed. Jon Lewis (New York: New York University Press, 2001), 366 .
} 
films. (There were no arthouse cinemas in my area, and many video rental shops carried only commercial films.) And while I was occasionally able to find well known masterpieces like Bergman's The Seventh Seal (1957) or Antonioni's Blow-Up (1966), I had essentially no access at all to avant-garde cinema. Now I watch several experimental films per week. Some are obtained via DVD; most are only available through websites like UbuWeb, YouTube, and Dailymotion. Indeed, many of the films I have discussed in this dissertation-such as So Is This - are rarely screened and unavailable on DVD, and as a result, they would be practically impossible to see if they had not been made available online.

In addition to its convenience and accessibility, "screening" films on one's computer has significant ramifications for the temporal dimensions of film. Of particular note here is the moving "time bar" that generally appears at the bottom of the screen. Perhaps someone seeing So Is This in a theater would take Snow at his word when the on-screen language indicates that the film is "about / two / hours / long." But all I need to do is briefly shake my mouse and reveal the time bar to verify that the film is actually 48 minutes and 33 seconds in length. The bar provides a visual cue that allows me to gauge how far a film has progressed (and how much time remains) at any given moment. It also allows unprecedented control of the filmic experience. While pausing, rewinding, and fast-forwarding have long been features of VHS tapes and DVDs, never before has spectatorial control been so salient and pronounced. After my first viewing of Disappearing Music for Face, for example, I was able to quickly jump from the film's beginning to its end and back again to determine precisely how much Ono's lips had moved. After watching Snow's Wavelength on Google Video, I could take Snow's 45-minute zoom and "scroll" through it in just a few seconds, to get a better sense of the space that Snow's camera had traversed. And while watching Warhol's uneventful Eat on YouTube, I decided to play a 
game of Snake superimposed over the image of Robert Indiana slowly masticating. (I suspect Warhol would have approved.)

The ontology of film, too, has been profoundly altered by the rise of the digital. Onscreen movement and stasis are no longer reliant on the movement of film stock, but on the transfer of information. In spite of this fundamental shift, some theorists continue to see movement as essential to the ontology of film, even in its digital incarnation. In D.N. Rodowick's theorization, "The film projector produces movement by animating still images. But as presented on electronic displays, the image is movement or subject to continual change because the screened image is being constantly reconstituted, scanned, or refreshed." ${ }^{, 7}$ Rodowick is certainly correct to point out that the technological basis of digital cinema demands that the images undergo constant permutations; however, I fail to see why this implies that "the image is movement." It seems that Rodowick is problematically conflating movement and change. The digital image may be labile, but it is not movement itself - it simply engenders the perception of movement (or stasis) in a way quite distinct from the film projector. A similar confusion subtends Rodowick's claim that 'even a 'photograph' displayed on an electronic screen is not a still image. It may appear so, but its ontological structure is of a constantly shifting or selfrefreshing display." ${ }^{\prime}$ Again, Rodowick seems to use the word still synonymously with unchanging. A photograph displayed in a digital static film does undergo continual change, but in a sense, it remains still—both ontologically and phenomenologically. That is, it neither relies on movement for its existence (as does the celluloid film, which must constantly move through the projector), nor does it produce the phenomenal perception of movement.

\footnotetext{
${ }^{7}$ Rodowick, 137. Italics in original.

${ }^{8}$ Ibid., 138.
} 
Jon Jost's digital film Muri Romani (Roman Walls) (1999-2000) provides a useful way of thinking through this distinction. The film begins with a static shot of a patch of decaying wall in Rome, scrawled with white graffiti that reads, "IL SOGNO E FINITO L'ILLUSIONE CONTINUO" ("The dream is over, the illusion continues") (see Figure 1). There is a slow dissolve to a similar patch of wall, which gradually gives way to still another wall, and so on. By the end of the 80-minute film, a full 280 static shots of walls have been displayed (all of them shot with a DV camera). Jost has claimed, "Editing decisions were based on the aesthetic commonality between images so that one does not 'see' a dissolve, but rather the image seems only to change in time." ${ }^{\prime 10}$ The result of this approach is that it is generally very difficult for a viewer to know, at any given moment, if she is looking at a single wall, or if there are elements of the previous shot or the upcoming shot which are pervading the image. (All of this is complemented by the quotidian sounds of Rome's streets, such as sirens, bells, and barely audible conversations.) The screen remains devoid of movement, even though it is constantly changing — and (contra Rodowick) the same could be said of the digital process that produces it. $^{11}$

\footnotetext{
${ }^{9}$ Translation by Jon Jost, e-mail to author, November 16, 2011.

${ }^{10}$ Jon Jost, "Muri Romani," http://www.jon-jost.com/work/muri.html. A similar process was used to create Jost's strikingly beautiful static landscape film Canyon (1970), comprised of several shots of the Grand Canyon.

${ }^{11}$ Jost has indicated his intention to make a much lengthier version of Muri Romani, one that would use 1,000 stills and last over eight hours. Ibid.
} 


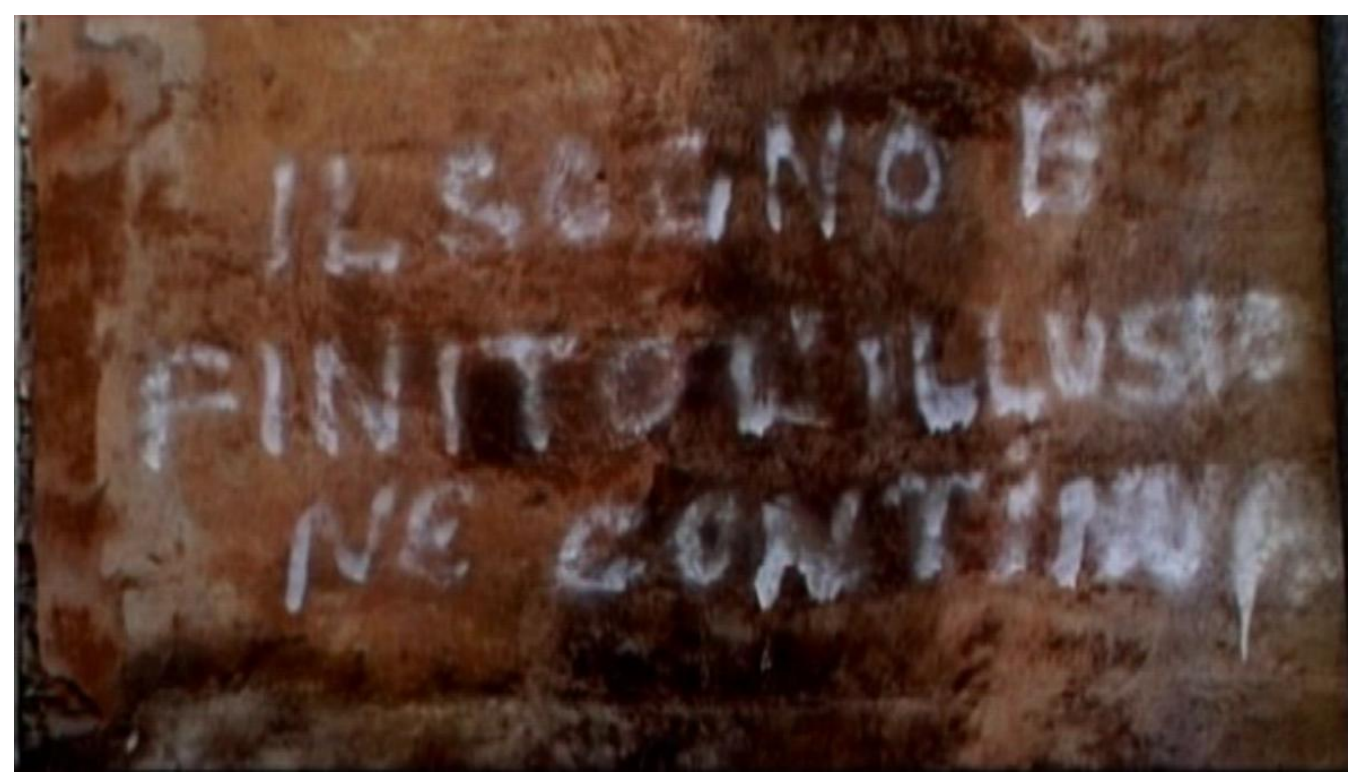

Figure 1: Jon Jost, Muri Romani (Roman Walls) (1999-2000)

One of the ironies of Muri Romani is the fact that, while the walls are decaying, the film stock is not. No matter how many times the work is screened, its digital ontology ensures that each viewing will be identical — the film will not undergo the entropic degradation that Rome's walls have clearly been the victim of. Absent are the discolorations and splotches that invariably intrude on the celluloid image (not to mention the specks of dust that so enthralled John Cage during his viewing of Zen for Film). The film has become visually "perfect." This is not a value judgment. In fact, for many filmmakers and theorists, this perfection is precisely the problem with digital film. For example, Babette Mangolte finds digital cinema to be "too perfect," even suggesting that "this perfection distracts from its credibility." 12 However, as Nicholas Rombes has pointed out, this perfection has also prompted many digital filmmakers "to reassert imperfection, flaws, an aura of human mistakes to counterbalance the logic of perfection that pervades the digital." ${ }^{\prime 13}$ And this is the paradox at the core of Muri Romani. As the graffiti in the

\footnotetext{
${ }^{12}$ Mangolte, 273.

${ }^{13}$ Nicholas Rombes, Cinema in the Digital Age (London: Wallflower Press, 2009), 2. Italics in original. A useful example of this reassertion of imperfection is provided by Lev Manovich. He notes how the synthesis of reality and
} 
opening shot implies, the film is interested in exploring both termination and continuation. The dream of cinematic indexicality is over, but the illusions that this indexicality produced continue to assert their presence in digital form. The walls themselves are decrepit and decaying-they will eventually be torn down or replaced. But their representations in Muri Romani will live on; they will not decay, no matter how many times the film is screened or copied. ${ }^{14}$

I certainly sympathize with cinephiles like Mangolte who prefer the pulsations and imperfections of celluloid to the sanitized crispness of digital film - in much the way that I sympathize with audiophiles who eschew iPods and CD players in favor of vinyl records, in spite of (or perhaps because of) their "imperfect" scratches and pops. But there is also something tantalizing about digital cinema-its liberation from photographic indexicality creates a multiplicity of new aesthetic possibilities, and its "purity" of image is often absorbing, even sublime. Additionally, as a film like Muri Romani makes clear, digital film can make substantive and compelling contributions to the cinema of stasis. Film can now be stripped not only of the movement of the camera and elements within the mise-en-scène, but even of the suggestion of movement provided by the emulsion of the film grain. For the first time, it is possible for a static film to be perceptually indistinguishable from a photograph. Mangolte suggests that such advances have come at a price: namely, she claims that, without the emulsion grain, without the shutter, without the rhythmic pulsations of the film stock, digital film is "unable to establish and construct an experiential sense of time passing." ${ }^{15}$ But I would argue that digital film simply constructs an alternate experience of time passing, one which is free of the temporal signposts

computer-generated images in Steven Spielberg's Jurassic Park (1993) was only successful because the film's CGI elements were consciously "degraded": "their perfection had to be diluted to match the imperfection of the film's graininess." See Manovich, 202.

${ }^{14}$ This is at least true in principle, although in practice, as Manovich usefully points out, the transmission of digital media often involves lossy compression, which can result in "loss of data, degradation, and noise." See Manovich, 54-55.

${ }^{15}$ Mangolte, 263. 
that cineastes have become so accustomed to. After all, it is not as if time no longer seems to pass when viewing a digital film-even one as static as Muri Romani. Rather, the movements that permit the experience of temporal flow are no longer those of the traditional cinematographic apparatus, but those of consciousness itself. Barthesian duration continues to unfold, Bergson's snowball continues to roll —and this is why a cinematic spectator always experiences the passing of time.

However, it should be emphasized that cinema—even when it is static—can offer a vast array of temporal experiences. When watching a furniture film, time is malleable and dispersed — the work's temporal coordinates are molded and partitioned by the spectator. In protracted films, time seems to grind to a halt, only to proceed at a radically decelerated rate, one that offers perceptual access to microtime. In textual films, temporality is generally rigidly structured, resulting in disparate cadences that can be swift and disorienting or lethargic and alienating. And in monochrome films, temporal signposts become the province of the sound track or the moving emulsion grain (when these elements are present) - or else, such signposts disappear altogether, leaving only naked duration in their wake. As the existence of these diverse modalities of static cinema makes clear, movement's place in the ontology and phenomenology of film has been grossly over-stated. Movement—whether actual or potential—is not a necessary condition of cinema, but a contingent one. In the words of Raymond Bellour, "[I]t isn't movement that defines most profoundly the cinema [...] it is time."

\footnotetext{
${ }^{16}$ Raymond Bellour, "The Pensive Spectator" (trans. Lynne Kirby), in Campany, The Cinematic, 122.
} 


\section{APPENDIX 1: THE CINEMA OF STASIS}

1 in 10. Dir. Takahiko Iimura. Japan, date unknown.

1 to 60 Seconds. Dir. Takahiko Iimura. Japan, 1973.

5 Year Drive-By. Dir. Douglas Gordon. UK, 1995.

8h01-8h11. Dir. Gottfried Schlemmer. Austria, 1968.

9 Minutes. Dir. James Riddle. USA, 1966.

10 Feet. Dir. George Maciunas. USA, 1966.

12! Big Names! Dir. George Maciunas. USA, 1975.

13 Lakes. Dir. James Benning. USA, 2004.

24 Hour Psycho. Dir. Douglas Gordon. UK, 1993.

1000 Frames. Dir. George Maciunas. USA, 1966.

2068 Schatzi. Dir. Kurt Kren. Austria, 1968.

3175 Asyl. Dir. Kurt Kren. Austria, 1975.

5262 Washington Boulevard. Dir. Mark Lewis. Canada, 2008.

Academic Still Life (Cézanne). Dir. Malcolm Le Grice. UK, 1977.

Angel. Dir. Joseph Cornell. USA, 1957.

Anima. Dir. Bill Viola. USA, 2000.

The Anticoncept (L'Anticoncept). Dir. Gil Wolman. France, 1951.

Argument. Dirs. Anthony McCall and Andrew Tyndall. USA, 1978.

Band of Ninja (Ninja bugei-cho). Dir. Nagisa Ôshima. Japan, 1967.

The Blind Spot (La tache aveugle). Dir. James Coleman. France, 1978-1990.

Blow Job. Dir. Andy Warhol. USA, 1964.

Blue. Dir. Derek Jarman. UK, 1993. 
Boom. Dir. David Claerbout. Belgium, 1996.

Breach. Dir. Sam Taylor-Wood. UK, 2001.

Canyon. Dir. Jon Jost. USA, 1970.

Carrots and Peas. Dir. Hollis Frampton. USA, 1969.

A Casing Shelved. Dir. Michael Snow. Canada, 1970.

Centers. Dir. Vito Acconci. USA, 1971.

Le corbeau et le renard (The Fox and the Crow). Dir. Marcel Broodthaers. Belgium, 1967.

Dead Movie (aka Projection Piece). Dir. Takahiko Iimura. Japan, 1968.

Deux Devises \& Onomatopoeia. Dir. Stan Douglas. Canada, 1983-1986.

Disappearing Music for Face. Dirs. George Maciunas \& Mieko Shiomi. USA, 1966.

Dolorosa. Dir. Bill Viola. USA, 2000.

Dripping Water. Dirs. Michael Snow \& Joyce Weiland. Canada, 1969.

Eat. Dir. Andy Warhol. USA, 1963.

Empire. Dir. Andy Warhol. USA, 1964.

End After Nine. Dir. George Maciunas. USA, 1966.

Entrance to Exit. Dir. George Brecht. USA, 1965.

Eureka. Dir. Ernie Gehr. USA, 1974.

Eye Blink. Dir. Yoko Ono. USA, 1966.

Film in Which There Appear Edge Lettering, Sprocket Holes, Dirt Particles, Etc. Dir. George Landow. USA, 1966.

Film No. 5 (Smile). Dirs. John Lennon and Yoko Ono. UK, 1968.

Five: Dedicated to Ozu. Dir. Abbas Kiarostami. Iran, 2003.

Five O'Clock in the Morning. Dir. Pieter Vanderbeck. USA, 1966. 
Fog Line. Dir. Larry Gottheim. Canada, 1970.

Gellért. Dir. Tacita Dean. UK, 1998.

Haircut. Dir. Andy Warhol. USA, 1964.

Hermes Bird. Dir. James Broughton. USA, 1979.

Heterodyne. Dir. Hollis Frampton. USA, 1967.

Hôtel Monterey. Dir. Chantal Akerman. USA, 1972.

Howls for Sade (Hurlements en faveur de Sade). Dir. Guy Debord. France, 1952.

If I Had Four Dromedaries. Dir. Chris Marker. France, 1966.

I See Nothing, I Hear Nothing, I Say Nothing (Je ne vois rien, je n'entends rien, je ne dis rien). Dir. Ben Vautier. USA, 1966.

Island. Dir. Fiona Tan. Sweden, 2008.

La Jetée (The Jetty). Dir. Chris Marker. France, 1962.

Kindergarten Antonio Sant'Elia, 1932. Dir. David Claerbout. Belgium, 1998.

Kiss. Dir. Andy Warhol. USA, 1963.

Knackered. Dir. Sam Taylor-Wood. UK, 1996.

The Last Century. Dir. Sam Taylor-Wood. UK, 2005.

A Lecture. Dir. Hollis Frampton. USA, 1968.

Lemon (For Robert Huot). Dir. Hollis Frampton. USA, 1969.

Letters, Notes. Dir. Stephanie Barber. USA, 2000.

Letter to Jane: An Investigation About a Still. Dirs. Jean-Luc Godard and Jean-Pierre Gorin France, 1972.

Line Describing a Cone. Dir. Anthony McCall. USA, 1973.

A Little Death. Dir. Sam Taylor-Wood. UK, 2002. 
A Little Phantasy on a Nineteenth-Century Painting. Dir. Norman McLaren. Canada, 1946.

Long Film for Ambient Light. Dir. Anthony McCall. USA, 1975.

Ma (Intervals). Dir. Takahiko Iimura. Japan, 1972.

The Man We Want to Hang. Dir. Kenneth Anger. USA, 1995-2002.

Muri Romani. Dir. Jon Jost. USA, 1999-2000.

New York Near Sleep For Saski. Dir. Peter Hutton. USA, 1972.

Notions of Silence (1-5). Dir. Johnnie Lawson. Ireland, 2010.

On a Most Beautiful Meadow. Dir. Peter von Guten. Switzerland, 1968.

One (Match). Dir. Yoko Ono. USA, 1966.

One Frame Duration. Dir. Takahiko Iimura. Japan, 1977.

One Second in Montreal. Dir. Michael Snow. Canada, 1969.

Parallel. Dir. Takahiko Iimura. Japan, 1974.

Pietà. Dir. Sam Taylor-Wood. UK, 2001.

Plague Summer. Dir. Chester Kessler. USA, 1951.

Poetic Justice. Dir. Hollis Frampton. USA, 1972.

Production Stills. Dir. Morgan Fisher. USA, 1970.

Projection Instructions. Dir. Morgan Fisher. USA, 1976.

Queensway: Pan and Zoom. Dir. Mark Lewis. Canada, 2005.

The Quiet Shore. Dir. David Claerbout. Belgium, 2011.

Red/Green. Dir. Dan McLaughlin. USA, 1985.

Red Stockings. Dir. Robert Huot. USA, 1969.

Reflecting Sunset. Dir. David Claerbout. Belgium, 2003.

Screen Tests. Dir. Andy Warhol. USA, 1964-1966. 
Secondary Currents. Dir. Peter Rose. USA, 1982.

See You Later/Au Revoir. Dir. Michael Snow. Canada, 1990.

Serene Velocity. Dir. Ernie Gehr. USA, 1970.

Side Seat Paintings Slides Sound Film. Dir. Michael Snow. Canada, 1970.

Sixty-Minute Silence. Dir. Gillian Wearing. UK, 1996.

Skagafjördur. Dir. Peter Hutton. USA, 2002-2004.

Sleep. Dir. Andy Warhol. USA, 1963.

Smoking. Dir. Joe Jones. USA, 1970.

Soft Rain. Dir. Ken Jacobs. USA, 1968.

So Is This. Dir. Michael Snow. Canada, 1982.

Song 12. Dir. Stan Brakhage. USA, 1965.

Song 27: My Mountain. Dir. Stan Brakhage. USA, 1968.

Sound Distance of a Good Man. Dir. Robert Longo. USA, 1978.

Still Life. Dir. Bruce Baillie. USA, 1966.

Still Life. Dir. Sam Taylor-Wood. UK, 2001.

Study for a Portrait (Violetta). Dir. David Claerbout. Belgium, 2001.

Sunset. Dir. Andy Warhol. USA, 1967.

Tambours du jugement premier (Drums of the First Judgment). François Dufrêne. France, 1952.

Teatro Amazonas. Dir. Sharon Lockhart. USA, 1999.

the ten mark. Dir. Joe Sheehan. UK, 2010.

Ten Skies. Dir. James Benning. USA, 2004.

Tree Movie. Dir. Jackson Mac Low. USA, 1961. 
A Voyage on the North Sea (Un voyage en mer du nord). Dir. Marcel Broodthaers. Belgium, 1973-1974.

Warhol Bible. Dir. Andy Warhol. USA, unfinished.

Wavelength. Dir. Michael Snow. Canada/USA, 1967.

Weekend (Wochenende). Dir. Walter Ruttmann. Germany, 1930.

Zen for Film. Dir. Nam June Paik. USA, 1962-1964. 


\section{APPENDIX 2: FILMS RELEVANT TO UNDERSTANDING THE CINEMA OF STASIS}

1165 Bild Helga Philipp. Dir. Kurt Kren. Austria, 1965.

3778 Tree Again. Dir. Kurt Kren. Austria, 1978.

3879 Sentimental Punk. Dir. Kurt Kren. Austria, 1979.

The Act of Seeing with One's Own Eyes. Dir. Stan Brakhage. USA, 1971.

Adebar. Dir. Peter Kubelka. Austria, 1957.

The Angelic Conversation. Dir. Derek Jarman. UK, 1985.

Apotheosis. Dirs. John Lennon and Yoko Ono. UK, 1970.

Arnulf Rainer. Dir. Peter Kubelka. Austria, 1958-1960.

Around Five. Dir. Abbas Kiarostami. Iran, 2005.

Bad Burns. Dir. Paul Sharits. USA, 1982.

Ballet Mécanique. Dirs. Fernand Léger and Dudley Murphy. France, 1924.

Blink. Dir. John Cavanaugh. USA, 1966.

Blonde Cobra. Dir. Ken Jacobs. USA, 1963.

Bleu Shut. Dir. Robert Nelson. USA, 1971.

La Chambre. Dir. Chantal Akerman. USA, 1972.

Chinese Series. Dir. Stan Brakhage. USA, 2003.

Closed Vision. Dir. Marc’O. USA/France, 1954.

Critical Mass. Dir. Hollis Frampton. USA, 1971.

Critique of Separation (Critique de la séparation). Dir. Guy Debord. France, 1961.

Cross Cut: A Blue Movie. Dir. Robert Huot. USA, 1969.

The Dante Quartet. Dir. Stan Brakhage. USA, 1987. 
Doppelprojection I-IV. Dirs. Birgit and Wilhelm Hein. Germany, 1971-1972.

Film about a Woman who... Dir. Yvonne Rainer. USA, 1974.

Filmmakers. Dir. Takahiko Iimura. Japan, 1966-1970.

Film No. 4 (Bottoms). Dir. Yoko Ono. USA, 1966.

The Flicker. Dir. Tony Conrad. USA, 1965.

Le gai savoir (The Joy of Knowledge). Dir. Jean-Luc Godard. France, 1969.

Gently Down the Stream. Dir. Su Friedrich. USA, 1981.

Gloria! Dir. Hollis Frampton. USA, 1979.

God is Dog Spelled Backwards. Dir. Dan McLaughlin. USA, 1967.

The Great Society. Dir. Fred Mogubgub. USA, $1967 ?$

The Greeting. Dir. Bill Viola. USA, 1995.

Guy Debord: His Art and His Time (Guy Debord, son art, son temps). Dirs. Guy Debord and Brigitte Cornand. France, 1994.

Là-haut sur ces montagnes. Dir. Norman McLaren. Canada, 1945.

Henry Geldzahler. Dir. Andy Warhol. USA, 1964.

The Human Face is a Monument. Dir. Stan Vanderbeek. USA, 1965.

In the Penal Colony. Dir. Dan McLaughlin. USA, 2003.

Into Great Silence. Dir. Philip Gröning. Germany, 2005.

Jeanne Dielman, 23 quai du Commerce, 1080 Bruxelles. Dir. Chantal Akerman. France, 1975.

Je tu il elle. Dir. Chantal Akerman. France, 1974.

Lunch Break. Dir. Sharon Lockhart. USA, 2009.

Manhatta. Dirs. Charles Sheeler and Paul Strand. USA, 1921.

Man with a Movie Camera. Dir. Dziga Vertov. Soviet Union, 1929. 
(nostalgia). Dir. Hollis Frampton. USA, 1971.

A Movie. Dir. Bruce Conner. USA, 1958.

Object Lesson. Dir. Christopher Baughman Young. USA, 1941.

On the Passage of a Few Persons Through a Rather Brief Unity of Time (Sur le passage de quelques personnes à travers une assez courte unité de temps). Dir. Guy Debord. France, 1959.

Paul Swan. Dir. Andy Warhol. USA, 1965.

Palindrome. Dir. Hollis Frampton. USA, 1969.

Phi Phenomenon. Dir. Morgan Fisher. USA, 1968.

Piece Mandala/End War. Dir. Paul Sharits. USA, 1966.

Poemfield No. 2. Dir. Stan Vanderbeek. USA, 1966.

Police Car. Dir. John Cale. USA, 1966.

Pond Scum, One Line. Dir. Mark Lewis. Canada, 2010.

La Poulette Grise (The Grey Chicken). Dir. Norman McLaren. Canada, 1947.

The Pressures of the Text. Dir. Peter Rose. USA, 1983.

Ray Gun Virus. Dir. Paul Sharits. USA, 1966.

... Reel Five. Dir. Stan Brakhage. USA, 1999.

Refutation of All the Judgements, Pro or Con, Thus Far Rendered on the Film The Society of the Spectacle (Réfutation de tous les judgements, tant élogieux qu'hostiles, qui ont été jusqu’ici portés sur le film La Société du spectacle). Dir. Guy Debord. France, 1975. Remembrance of Things to Come (Le souvenir d'un avenir). Dirs. Yannick Bellon and Chris Marker. France, 2001.

Sears Catalogue 1-3. Dir. Paul Sharits. USA, 1965. 
See Saw Seams. Dir. Stan Vanderbeek. USA, 1966.

Shutter. Dir. Takahiko Iimura. Japan, 1971.

Sirius Remembered. Dir. Stan Brakhage. USA, 1959.

Snowblind. Dir. Hollis Frampton. USA, 1968.

Society of the Spectacle (La Société du spectacle). Dir. Guy Debord. France, 1973.

Still. Dir. Ernie Gehr. USA, 1971.

Television Delivers People. Dirs. Richard Serra \& Carlotta Schoolman. USA, 1973.

Third Beach 1. Dir. Mark Lewis. Canada, 2010.

$T, O, U, C, H, I, N, G$. Dir. Paul Sharits. USA, 1968.

Treatise on Venom and Eternity (Traité de Bave et d'Éternité). Dir. Isidore Isou. France, 1951.

Unrolling Event. Dir. Paul Sharits. USA, 1965.

Views from Home. Dir. Guy Sherwin. UK, 2005.

We Turn in the Night, Consumed by Fire (In girum imus nocte et consumimur igni). Dir. Guy Debord. France, 1978.

White Calligraphy. Dir. Takahiko Iimura. Japan, 1967.

Word Movie. Dir. Paul Sharits. USA, 1966.

Wrist Trick. Dir. Paul Sharits. USA, 1965. 


\section{ABSTRACT \\ MOTION(LESS) PICTURES: THE CINEMA OF STASIS \\ by}

\section{JUSTIN REMESELNIK}

\section{August 2012}

Advisor: Dr. Kirsten Thompson

Major: English (Film and Media Studies)

Degree: Doctor of Philosophy

Since cinema's inception, there has been much disagreement among film theorists about the role of movement in cinema's ontology. For example, while Rudolf Arnheim has argued that motion is a sine qua non of cinema, Roland Barthes has insisted that motion is not as central to cinema's ontology as duration, an experiential "unfolding." In this dissertation, I arguefollowing Barthes - that movement is merely a contingent, not a necessary, condition of cinema. I further suggest that the very enterprise of prescribing necessary conditions of cinema is myopic, reductive, and reactionary.

In supporting these claims, I interrogate the cinema of stasis, a modality of avant-garde films which feature little or no movement. By foregrounding stillness, these films often blur the lines between cinema and other art forms, including photography, painting, and literature. Giving especially close attention to films by Andy Warhol, Fluxus, Michael Snow, and Derek Jarman, I explore the aesthetic and affective valences of cinematic stasis, while drawing attention to the numerous ways that static films broaden our conception of what films can be and do. 


\begin{abstract}
AUTOBIOGRAPHICAL STATEMENT
Justin Remeselnik received a BA in English from Oakland University and an MA in English from Wayne State University. In addition to presenting papers at The Space Between conference and the Film-Philosophy conference, he has published articles in The Journal of Religion and Popular Culture, Film-Philosophy, and the British Journal of Aesthetics. He has also contributed a chapter to Faith and Spirituality in Masters of World Cinema, Volume II (Cambridge Scholars Press, 2011). His research interests include avant-garde cinema, religion and film, and philosophy and film. He is currently an Instructor of English at Baker College of Port Huron.
\end{abstract}

